\title{
Metal-organic Framework-based Materials: Synthesis, Stability and Applications in Food Safety and Preservation
}

\author{
Wenqian Nong, ${ }^{1}$ Xiaoyue Liu, ${ }^{2}$ Qin Wang, ${ }^{3}$ Jun $\mathrm{Wu}^{1,}{ }^{*}$ and Yongguang Guan ${ }^{2,}$ *
}

\begin{abstract}
Investigation on food safety and preservation is essential to provide high quality and safe food for human beings, including accurate determination and efficient removal of inorganic heavy metal ions and organic contaminants, as well as regulation of food postharvest ripening and intelligent sterilization. In the last two decades, metal-organic frameworks (MOFs), as functionalized porous materials, have aroused interests of researchers because of their advantages of high porosity, large specific surface area, flexible structure properties, and abundant binding sites for guest molecules. MOFs have shown great potentials in practical applications in food and related fields. In this overview, we summarized the MOF crystallization mechanisms, synthesis routes and methods, stability, as well as the applications in food contamination including removal of heavy metal ions, dyes, and antibiotics, and food preservation including regulation of fruit and vegetable ripening, removal of moisture and oxygen, and high-efficiency sterilization. Finally, two perspectives focusing on the development of MOFs for innovative food research, i.e., food-grade MOFs and MOF composites are suggested based on our understanding.
\end{abstract}

Keywords: Metal-organic frameworks; Composites; Synthesis; Food safety; Food preservation.

Received: 5 April 2020; Accepted: 30 April 2020.

Article type: Review article.

\section{Introduction}

Food safety and preservation are important with broad applications in food industry for improving food safety and extending food shelf-life. ${ }^{[1-5]}$ Nanotechnologies have promoted the development of food safety and quality. For example, antibacterial essential oil emulsions and films were employed for food sterilization, ${ }^{[6-11]}$ high-efficiency preservatives and growth regulators were synthesized through nano-assembly to govern food shelf-life and ripening, ${ }^{[12,13]}$ also, sensitive nanosensors were developed to determine harmful and safety uncertain ingredients in food. ${ }^{[14,15]}$ Porous materials have gradually aroused the interest of scientists because of their unique structure and property, and showed great potential in food applications. For example, employing three-dimensional (3D)-printing to develop porous starch-based clove oil encapsulation has been applied in food sterilization. ${ }^{[16]}$ Porous

${ }^{1}$ Department of Chemistry, Zhejiang University, Hangzhou, Zhejiang 310027, China

${ }^{2}$ Department of Food Science and Technology, Shanghai Jiao Tong University, Shanghai 200240, China

${ }^{3}$ Department of Nutrition and Food Science, University of Maryland, College Park, MD 20742, USA

*E-mail: yguan@sjtu.edu.cn (Y. Guan) superabsorbent food packaging produced from cellulosebased aerogels were developed originated from the A. donax biomass with the ability to enrich and release antioxidants, suggesting a significant reduction of the color loss and lipid oxidation in red meat preservation. ${ }^{[17]}$

Metal-organic frameworks (MOFs) are a series of hybrid micro- or nano- crystalline porous coordination polymers synthesized through coordinate bonding between inorganic metal ion clusters and organic ligands. Following the initial concept and pioneering works of MOFs, ${ }^{[18,19]}$ a worldwide emerging research in this field rose gradually with the simple self-assembly of metal ions and lig and molecules to synthesize the first generation of MOFs that were always not stable after removing the guest molecules. Subsequently, the second generation of MOFs was synthesized with permanent porosity and rigid architectures employing rigid secondary building units (SBUs). ${ }^{[20]}$ Recently, a large number of switchable MOFs with flexible properties governed by external stimuli such as light, pressure, red ox, temperature, and wettability were constructed, ${ }^{[21]}$ and considered as the third generation of MOFs. ${ }^{[22,23]}$ The advantages of MOFs can be summed up as large pore aperture, ${ }^{[24-26]}$ high porosity, ${ }^{[27,28]}$ large specific surface area, ${ }^{[24,29,30]}$ flexible surface 
(a)

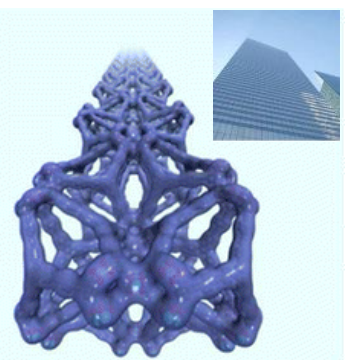

(b)

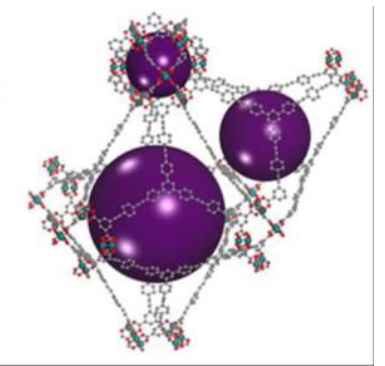

Fig. 1 (a) The simulated NU-110 framework structure like a high-rise building (on the top right) with the BET specific surface area of 7140 $\mathrm{m}^{2} / \mathrm{g}$ from the NU-110E. (b) The single-crystal X-ray structure of NU110 cages. $\mathrm{C}$ atoms are shown in gray; $\mathrm{O}$ atoms are shown in red; $\mathrm{Cu}$ atoms are shown in teal. Purple spheres are included to guide the eye in distinguishing between the three cages. $\mathrm{H}$ atoms and disordered solvent molecules are omitted for clarity. ${ }^{[30]}$ Adapted and reprinted with permission from reference of 30, copyright 2012 American Chemical Society.

structure, ${ }^{[31,32]}$ and abundant binding sites (open metal sites and ligands) for guest molecules. ${ }^{[33]}$ These endow MOFs as promising candidates for successful applications in various fields, such as gas separation, ${ }^{[34-43]}$ energy storage, ${ }^{[23,37]}$ chemical catalysis, ${ }^{[3,44,45]}$ drug delivery, ${ }^{[27,46-51]}$ and sensor development. ${ }^{[52-54]}$ Based on our knowledge, the largest pore aperture of MOF is $9.8 \times 8.5 \mathrm{~nm}$, belonging to one of the isoreticular MOF (IRMOF) structures termed IRMOF-74-XI with Orth hexagonal pores and ring of 282atoms through conventional synthesis and coordinative linking $\mathrm{Zn}^{2+} / \mathrm{Mg}^{2+}$ and polymerized 2,5-dioxidoterephthalate or derivatives. ${ }^{[2]} \mathrm{A}$ recent study utilized a template mineralization method and super macro-porous zeolitic imidazo late frameworks (ZIFs, ZIF-8) with pore aperture of $470 \mathrm{~nm}$ were fabricated. ${ }^{[25]}$ The largest Brunauer-Emmett-Teller (BET) specific surface area of MOFs ever found is $7140 \mathrm{~m}^{2} / \mathrm{g}$ from the NU-110E (Fig. 1), which is close to the limit of solid materials. ${ }^{\left[{ }^{[0]}\right.}$ Featuring with highly tunable pore sizes (usually $0-3 \mathrm{~nm}$, up to $9.8 \times 8.5 \mathrm{~nm}$ ) and large specific surface area, MOFs can cover the full pore size gap of both microporous and mesoporous materials. ${ }^{[55]}$

Moreover, flexible structure properties give MOFs rich functionalities. Water-triggered "breathing behavior" of MIL$53(\mathrm{Cr})$ was firstly reported by Serre et al. with pore size transformation from $19.69 \times 7.85 \AA$ of hydration to $16.83 \times$ $13.04 \AA$ of dehydration (Fig. 2a), attributing to a significant change of bond angles of ligand-metal-ligand with and without guest molecules of water. ${ }^{[5]}$ Further investigation from the molecular mechanism of the "breathing behavior" of MIL-53(Cr) and MIL-53(Fe) in the presence of water molecule suggested that the flexible aperture changes were primarily owing to the hydrogen bonding interactions between the oxygen atoms of water molecules and the hydrogen atoms of the $\mu_{2}-\mathrm{OH}$ groups of MIL-53, and also

(a)

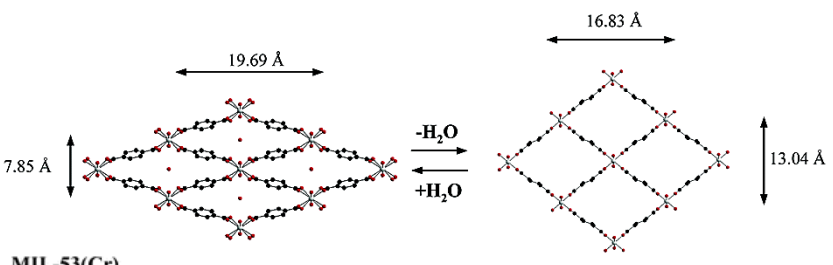

(b)
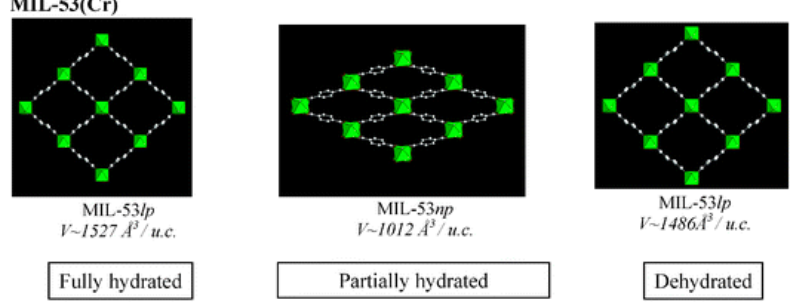

Partially hydrated

Dehydrated
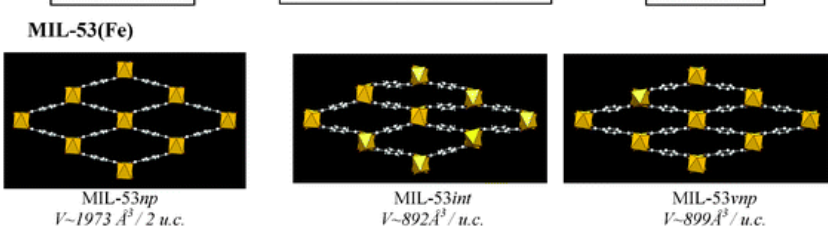

Fig. 2 (a) Pore size transformation with flexible "breathing behavior" properties of MIL-53(Cr) in the presence of water. ${ }^{[56]}$ (b) Crystal structures of the MIL-53(Cr) (lp and $n p$ versions) and MIL-53(Fe) (np, int and vnp versions) upon water desorption. ${ }^{[57]}$ Adapted and reprinted with permission from references of 56, 57, copyright 2002 American Chemical Society and 2010 Royal Society of Chemistry.

hydrogen bonds between the protons of water and the oxygen atoms of the carboxy late groups of the organic ligand (Fig. 2b). ${ }^{[57,58]}$ Pressure-triggered "breathing behavior" with openclosed pore of ZIF-4 was found by using the mercury intrusion-extrusion curve measurement, revealing that the ZIF-4(Zn) underwent the open-closed phase transition at a hydrostatic mechanical pressure of $28 \mathrm{MPa}$ to contract about $20 \%$ in volume, while $\mathrm{ZIF}-4(\mathrm{Co})$ required about $50 \mathrm{MPa}$ to trigger the same volume shrinking. Interestingly, ZIF-4(Co) fully returned to the complete open phase after decompression, whereas $\mathrm{ZIF}-4(\mathrm{Zn})$ remained in the closed phase after pressure release and required subsequent heating to switch back to the open phase (Fig. 3). ${ }^{[32]} \mathrm{Tu}$ and co-workers investigated the open-closed flexibility of surface aperture of ZIFs (i.e., ZIF-7, 8, 9, 67, 90, and ZIF-65-Zn) through covalently coating ZIFs onto quartz crystal microbalance (QCM) substrates to accurately determine guest molecule adsorption. ${ }^{[59]}$ Authors concluded that the open gate of ZIFs to absorb benzene rather than cyclohexane was driven by $\pi$-interactions, whilst, hydrophobic organic ligands of ZIFs (i.e., ZIF-7, 8, 9, and 67) closed the gate for water molecule capture. That is, the openclosed gate mechanism of surface aperture of ZIFs in this work was likely due to the steric potency or hindrance by ligands based on the chemical structure of guest molecules, rather than the change of the bond angles of ligand-metal-ligandlike the "breathing" mechanism of MIL-53. ${ }^{[56]}$ These flexible characteristics provide MOFs a potential application in food industry with a tendency to develop food safe MOFs and MOF composites. 
(a)
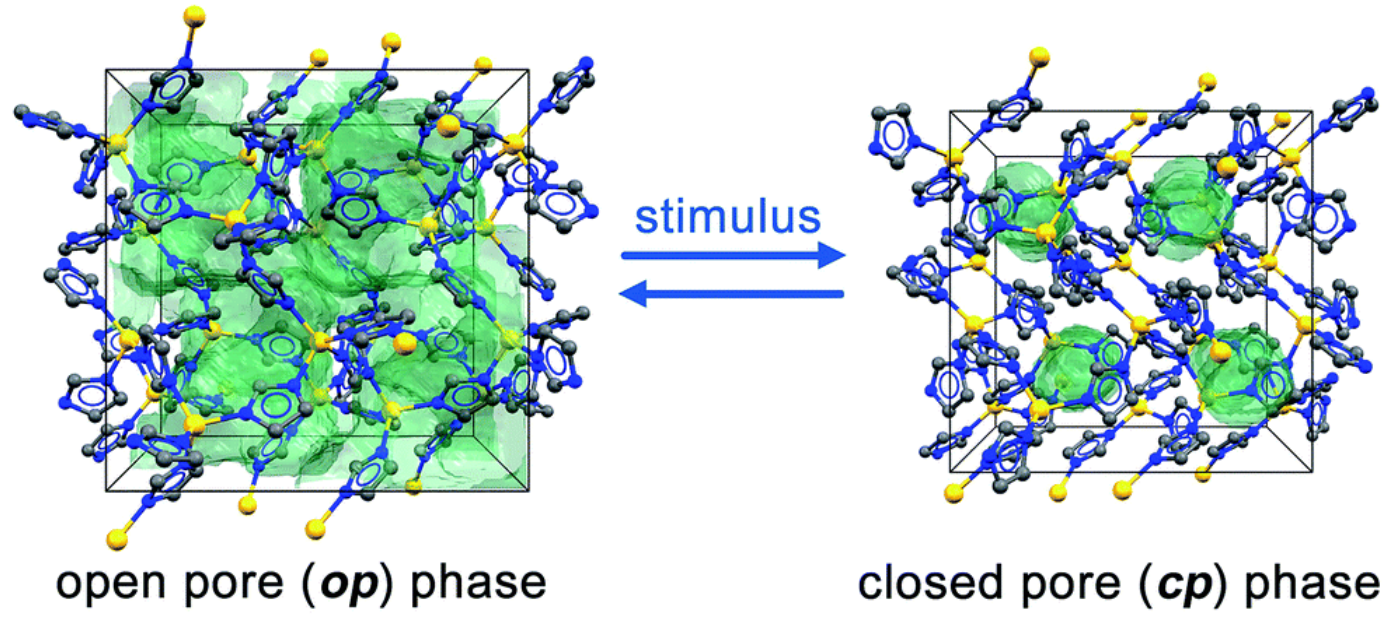

closed pore (cp) phase
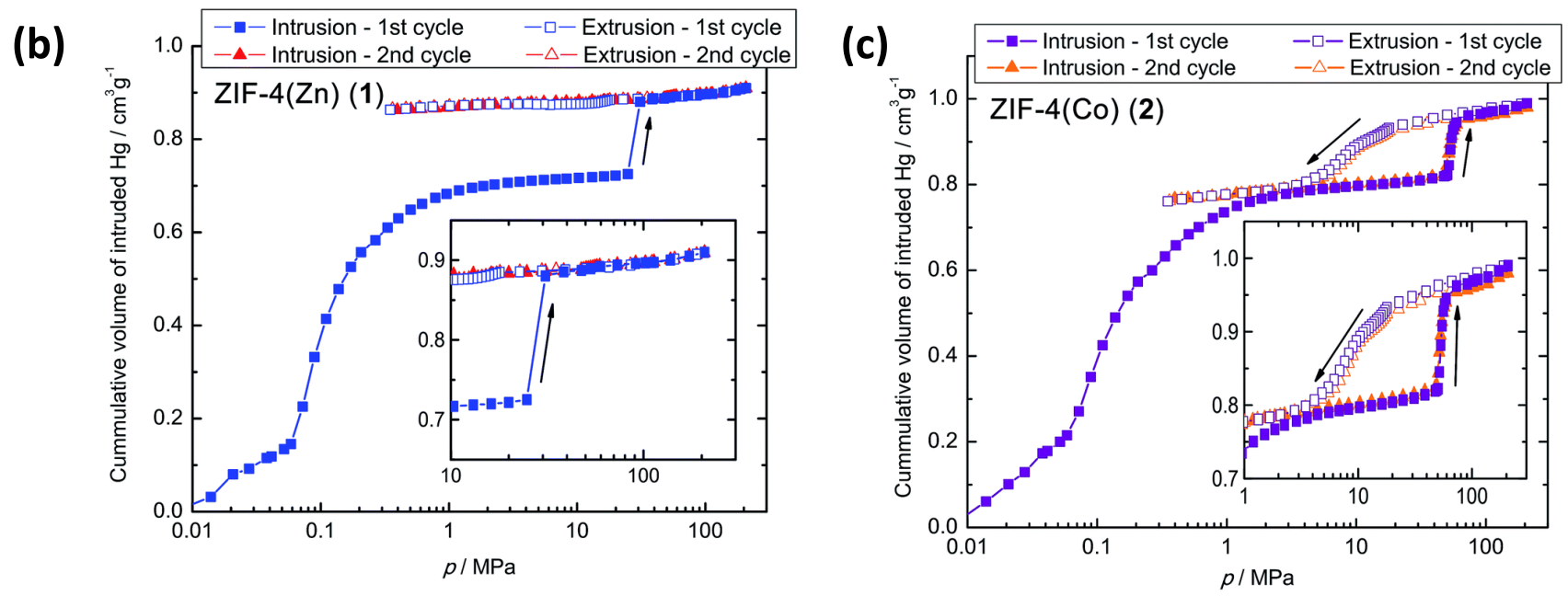

Fig. 3 (a) View on a unit cell of themimetic crystal structure of desolvated ZIF-4(Zn) along the crystallographic $c$ axis. At room temperature, the ZIF-4 exhibits an open pore $(o p)$ phase with continuous porosity. At temperatures below $140 \mathrm{~K}$, the material features a closed pore $(c p)$ phase with very small and inaccessible pores. $\mathrm{C}, \mathrm{N}$ and $\mathrm{Zn}$ atoms are shown in grey, blue and yellow, respectively. The void surface is shown in green. Both structures are drawn to the same scale. Mercury intrusion-extrusion curves recorded at room temperature for ZIF-4(Zn) (b) and ZIF-4(Co) (c), respectively. The insets reveal a closer look on the data in the region of the $o p$ - $c p$ phase transition, which is irreversible for ZIF- $4(\mathrm{Zn})$ but reversible for ZIF-4(Co). Lines represent a guide to the eye only. Data have been corrected by a blank measurement. Although data were measured from $0.001 \mathrm{MPa}$, the range of 0.01 to $210 \mathrm{MPa}$ is shown for clarity. ${ }^{[32]}$ Adapted and reprinted with permission from reference of 32 , copyright 2018 Royal Society of Chemistry.

In this review, we summarized recent studies and our knowledges on MOFs and their composites to understand their potential applications in food safety and preservation. Subtopics, including: (i) MOF synthesis and stability, (ii) applications of MOF-based materials in food safety and preservation, and (iii) perspectives of MOFs in this field, are carefully discussed and reviewed to give researchers a better understanding of MOF application in food safety and preservation related fields.

\section{Synthesis of MOFs}

\subsection{MOF crystallization}

The MOFs are crystals with structures belonging to one of the seven space groups, i.e., triclinic, monoclinic, orthorhombic, tetragonal, trigonal, hexagonal, and cubic (Fig. 4). For example, MOF-5 belongs to cubic space group ${ }^{[60]}$ and ZIF-78 belongs to hexagonal space group. ${ }^{[1]}$ Different crystal structures endowed MOFs with different properties and functions. A comprehensive overview of MOF crystallization has been reported by Van Vleet and co-workers, ${ }^{[62]}$ in which the classical and nonclassical crystal nucleation theories were discussed. That is (i) the homogeneous nucleation or traditional classic nucleation theory (CNT) predicts nucleation to be an activated process, whose kinetics are partly determined by "critical nucleus size". (ii) The heterogeneous nucleation can be seen as a nucleation process onto foreign substrates, and (iii) the secondary nucleation is a nucleating process onto pre-existed nucleus or crystals of the final products. Aerts and co- workers also discussed the models of zeolitenucleation, which were grouped into three primary mechanisms as the MONOMER, SBU, and NANOSLAB (Fig. 5). ${ }^{[63]}$ Among them, the SBU is generally employed to 


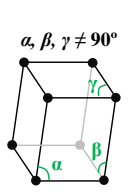

Triclinic

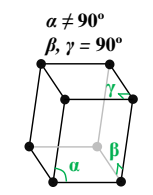

Monoclinic

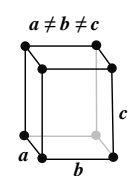

Orthorhombic

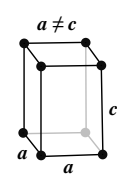

Tetragonal

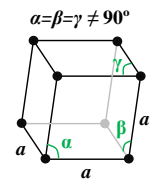

Trigonal

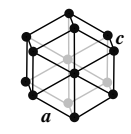

Hexagonal

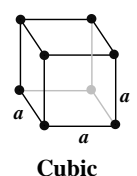

Cubic
Fig. 4 The space groups of crystals of triclinic, monoclinic, orthorhombic, tetragonal, trigonal, hexagonal, and cubic.

explain most of the MOF nucleation, which is primarily through the aggregation of soluble SBUs to build crystal nucleus and also defined as the nucleation building unit (NBU) model. ${ }^{[62]}$

As stated by Van Vleet and co-workers, ${ }^{[62]}$ the crystal growth is thermodynamically favored under supersaturation and yields morphologies to minimize the total Gibbs surface free energy under equilibrium conditions. The Ostwald ripening always occurs to further minimize unfavorable
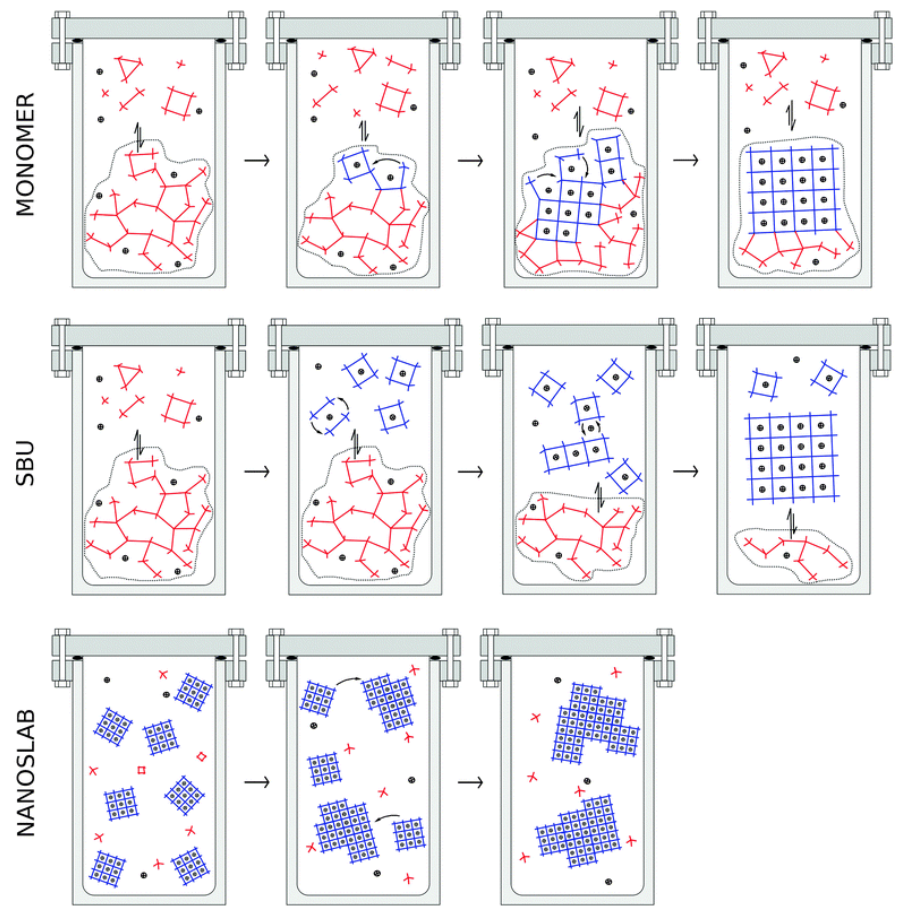

Fig. 5 Mechanisms for zeolite crystallization classified according to growth unit. Black dots represent template cations. Growth from monomers (top row); from SBUs (middle row); and by oriented aggregation of nanoparticles (bottom row). ${ }^{[63]}$ Adapted and reprinted with permission from reference of 63, copyright 2018 Royal Society of Chemistry. a)
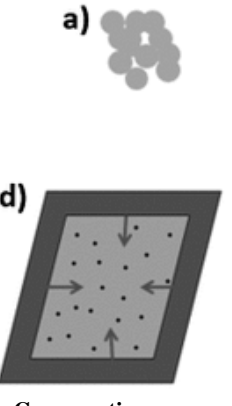

Cross-section b)

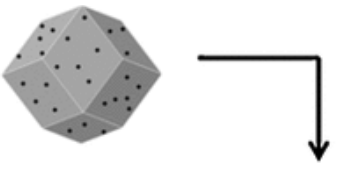

c)
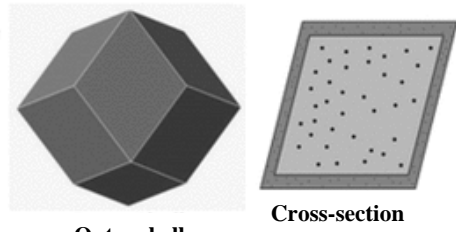

Fig. 6 Schematic of proposed rhombic dodecahedral ZIF crystal growing mechanism. (a) Disordered precursor materials form spherical aggregates. (b) Aggregates aggregate together to form porous pseudorhombic dodecahedral particles. (c) Surface recrystallization occurs to forming a single-crystal outer shell encasing a porous core. (d) Finally, the crystallization extends from the surface to the core until true single crystals are formed. ${ }^{[68]}$ Adapted and reprinted with permission from reference of 68 , copyright 2015 John Wiley and Sons.

surface energies by dissolving smaller particles to accumulate onto larger particle surfaces. ${ }^{[64]}$ Typical Ostwald ripening inducing gradual disappearance of smaller crystals and evolvement of larger crystal morphologies of ZIF-8 with improved crystallinity was demonstrated by using scanning electron microscope (SEM) ${ }^{[65]}$ and transmission electron microscope(TEM) ${ }^{[66]} \mathrm{An}$ interesting finding reported by Chen et al. suggested a reversed zeolite crystal growth mechanism through oriented aggregation of nano crystallites and surface recrystallization rather than following the classic crystal growth principle. ${ }^{[67]}$ Based on the aforementioned mechanism, Self et al. revealed the reversed crystal growth process of rhombic dodecahedral ZIF(Zn). ${ }^{[68]}$ That is, precursor materials joined together to form disordered aggregates at an initial stage to undergo surface recrystallization and generated less porous core-shell crystals, in which disordered cores were encased in a layer of denser. Along with the crystal growth, the shell became less and less porous until it was a layer of true single crystal with a subsequent crystallization extended from the surface to the core (Fig. 6). ${ }^{[68]}$

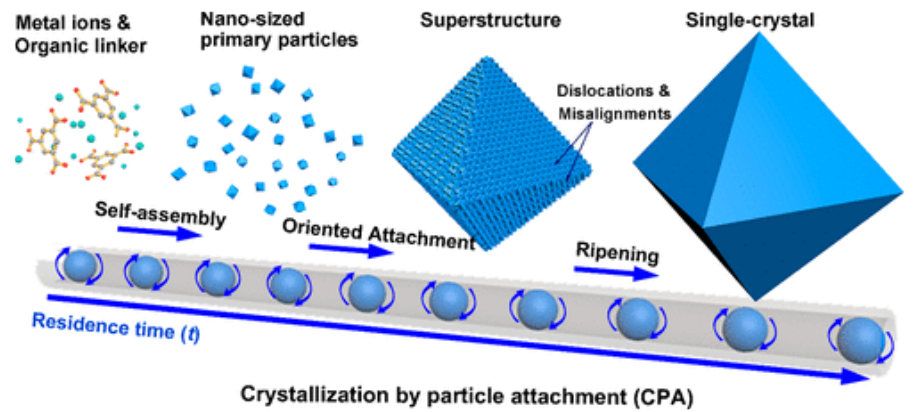

Fig. 7 Schematic of the crystallization pathway through particle attachment process for HKUST-1 under microdroplet flow conditions. ${ }^{[69]}$ Adapted and reprinted with permission from reference of 69, copyright 2019 American Chemical Society. 
Recently, Wang and co-workers found an intermediate state of MOF crystallization from HKUST-1 through particle attachment employing a micro-droplet flow reaction, which was elucidated to involve three steps: (i) the generation of nano-sized primary particles, (ii) the following assembly of the primary particles into a superstructure, and (iii) the ripening of superstructure into a crystal (Fig. 7). ${ }^{[69]}$ All these fundamental pathways of nucleation and crystal growth can support the crystallization process of most MOFs, and are significantly affected by reaction temperature, temperature change rate, solvents, pressure, initial reactants, etc.

\subsection{Common basic ligands}

Table 1. Summary of representative ligands based on coordinating functionalized groups with metal ion clusters of porous MOFs.

\begin{tabular}{|c|c|c|c|}
\hline MOF & Ligands & Metal ions & Ref. \\
\hline & Carboxylate & & \\
\hline BUT-12 & $\begin{array}{l}\text { CTTA, 5'-(4-carboxyphenyl)-2',4',6'-trimethyl-[1,1':3', } \\
\text { 1"-terphenyl]-4,4"-dicarboxylate }\end{array}$ & $\mathrm{Zr}^{4+}$ & 83 \\
\hline CAU-4 & BTB, 1,3,5-benzenetrisbenzoate & $\mathrm{Al}^{3+}$ & 84 \\
\hline CPO-8 & 5-aminoisophthalate & $\mathrm{Zn}^{2+}$ & 85 \\
\hline $\mathrm{CPO}-27$ & 2,5-dihydroxyterephthalate & $\begin{array}{l}\mathrm{Ni}^{2+}, \mathrm{Co}^{2+}, \mathrm{Mg}^{2+}, \\
\mathrm{Fe}^{2+}, \mathrm{Cu}^{2+}, \mathrm{Zn}^{2+}\end{array}$ & $86-90$ \\
\hline DUT-67, -68, -69 & TDC, 2,5-thiophenedicarboxylate & $\mathrm{Zr}^{4+}, \mathrm{Hf}^{4+}$ & 91 \\
\hline $\begin{array}{l}\text { HKUST-1 (MOF- } \\
199)\end{array}$ & BTC, benzene-1,3,5-tricarboxylate & $\mathrm{Cu}^{2+}$ & 92 \\
\hline IRMOF-2 & 1,4-BDC-Br, 1,4-terephthalate-Br & $\mathrm{Zn}^{2+}$ & 93 \\
\hline IRMOF-3 & 1,4-BDC-NH $2,1,4$-terephthalate- $\mathrm{NH}_{2}$ & $\mathrm{Zn}^{2+}$ & 93 \\
\hline IRMOF-4 & 1,4-BDC-OC $3 \mathrm{H}_{7}, 1,4$-terephthalate- $\mathrm{OC}_{3} \mathrm{H}_{7}$ & $\mathrm{Zn}^{2+}$ & 93 \\
\hline IRMOF-5 & 1,4-BDC-OC $5 \mathrm{H}_{11}, 1,4$-terephthalate- $\mathrm{OC}_{5} \mathrm{H}_{11}$ & $\mathrm{Zn}^{2+}$ & 93 \\
\hline IRMOF-6 & 1,4-BDC- $\mathrm{C}_{2} \mathrm{H}_{4}, 1,4$-terephthalate- $\mathrm{C}_{2} \mathrm{H}_{4}$ & $\mathrm{Zn}^{2+}$ & 93 \\
\hline IRMOF-7 & 1,4-BDC- $\mathrm{C}_{4} \mathrm{H}_{4}, 1,4$-terephthalate- $\mathrm{C}_{4} \mathrm{H}_{4}$ & $\mathrm{Zn}^{2+}$ & 93 \\
\hline IRMOF-8 & NDC, 2,6-naphthalenedicarboxylate & $\mathrm{Zn}^{2+}$ & 93 \\
\hline IRMOF-11 & HPDC, 2,7-tetrahydropyrenedicarboxylate & $\mathrm{Zn}^{2+}$ & 93 \\
\hline IRMOF-13 & PDC, 2,7-pyrenedicarboxylate & $\mathrm{Zn}^{2+}$ & 93 \\
\hline IRMOF-74-I to -XI & DOT-I to -XI, dioxidoterephthalate & $\mathrm{Mg}^{2+}, \mathrm{Zn}^{2+}$ & 24 \\
\hline MIL-47 & 1,4-BDC, 1,4-terephthalate & $\mathrm{V}^{4+}$ & $94-96$ \\
\hline MIL-53 & 1,4-BDC, 1,4-terephthalate & $\mathrm{Al}^{3+}, \mathrm{Cr}^{3+}, \mathrm{Fe}^{3+}$ & $56,95-97$ \\
\hline MIL-88B & 1,4-BDC, 1,4-terephthalate & $\mathrm{Cr}^{3+}$ & 98 \\
\hline MIL-88, -89 & fumarate & Transition ions & 99 \\
\hline MIL-100(Cr)/(Fe) & BTC, benzene-1,3,5-tricarboxylate & $\mathrm{Cr}^{3+}, \mathrm{Fe}^{3+}$ & $100-102$ \\
\hline MIL-100(Al)/(V) & BTC, benzene-1,3,5-tricarboxylate & $\mathrm{Al}^{3+}, \mathrm{V}^{3+}$ & 100 \\
\hline MIL-101 & 1,4-BDC, 1,4-terephthalate & $\mathrm{Al}^{3+}, \mathrm{Cr}^{3+}, \mathrm{Fe}^{3+}$ & $\begin{array}{l}96, \quad 103, \\
104\end{array}$ \\
\hline MIL-101-NH 2 & 1,4-BDC, 1,4-terephthalate- $\mathrm{NH}_{2}$ & $\mathrm{Cr}^{3+}$ & 105 \\
\hline MIL-101-NO ${ }_{2}$ & 1,4-BDC, 1,4-terephthalate- $\mathrm{NO}_{2}$ & $\mathrm{Cr}^{3+}$ & 105 \\
\hline MIL-121 & BTEC, 1,2,4,5-benzenetetracarboxylate & $\mathrm{Al}^{3+}$ & 106 \\
\hline
\end{tabular}

Generally, the MOFs are built through strong coordinate bonds between metallic centers (nodes) and organic ligands by a self-assembly process. ${ }^{[70]}$ The incorporation of metallic centers into MOFs is significant to improve the stability of framework structure, ${ }^{[71]}$ and the organic ligands are always primary to generate porosity with different apertures and pore structures. ${ }^{[72]}$ In brief, the commonly used organic ligands have polydentate structures for coordinating with metal ion clusters, and are mainly classified to be carboxylate, ${ }^{[73,74]}$ imidazolate, ${ }^{[75]}$ triazole, ${ }^{[76]}$ tetrazolate, ${ }^{[73,77]}$ tetrazine, ${ }^{[78]}$ hydrazine, ${ }^{[79]}$ phosphonate, ${ }^{[73]}$ hydroxy, ${ }^{[80,81]}$ and amino group, ${ }^{[82]}$ and are summarized in Table 1. 
Continued

\begin{tabular}{|c|c|c|c|}
\hline MOF & Ligands & Metal ions & Ref. \\
\hline MIL-125 & 1,4-BDC, 1,4-terephthalate & $\mathrm{Ti}^{4+}$ & 107 \\
\hline MOF-2 & 1,4-BDC, 1,4-terephthalate & $\mathrm{Zn}^{2+}$ & 108 \\
\hline MOF-5 (IRMOF-1) & 1,4-BDC, 1,4-terephthalate & $\mathrm{Zn}^{2+}$ & 42,109 \\
\hline MOF-69A & BPDC, 4,4'-biphenyldicarboxylate & $\mathrm{Zn}^{2+}$ & 20 \\
\hline MOF-69C & 1,4-BDC, 1,4-benzenedicarboxylate & $\mathrm{Zn}^{2+}$ & 20 \\
\hline MOF-70 & 1,4-BDC, 1,4-benzenedicarboxylate & $\mathrm{Pb}^{2+}$ & 20 \\
\hline MOF-71 & 1,4-BDC, 1,4-benzenedicarboxylate & $\mathrm{Co}^{2+}$ & 20 \\
\hline MOF-72 & 1,3-BDC, 1,3-benzenedicarboxylate & $\mathrm{Cd}^{2+}$ & 20 \\
\hline MOF-73 & 1,4-BDC, 1,4-benzenedicarboxylate & $\mathrm{Mn}^{2+}$ & 20 \\
\hline MOF-74 & DHBDC, 2,5-dihydroxybenzenedicarboxylate & $\mathrm{Zn}^{2+}$ & 20 \\
\hline MOF-75 & TDC, 2,5-thiophenedicarboxylate & $\mathrm{Tb}^{3+}$ & 20 \\
\hline MOF-76 & BTC, 1,3,5-benzenetricarboxylate & $\mathrm{Tb}^{2+}$ & 20 \\
\hline MOF-77 & ATC, 1,3,5,7-adamantanetetracarboxylate & $\mathrm{Zn}^{2+}$ & 20 \\
\hline MOF-78 & HPDC, 2,7-tetrahydropyrenedicarboxylate & $\mathrm{Co}^{2+}$ & 20 \\
\hline MOF-79 & HPDC, 2,7-tetrahydropyrenedicarboxylate & $\mathrm{Cd}^{2+}$ & 20 \\
\hline MOF-80 & PDC, 2,7-pyrenedicarboxylate & $\mathrm{Tb}^{3+}$ & 20 \\
\hline MOF-177 & BTB, 1,3,5-benzenetribenzoate & $\mathrm{Zn}^{2+}$ & 110 \\
\hline MOF-505 & BPTC, 3,3',5,5'-biphenyltetracarboxylate & $\mathrm{Cu}^{2+}$ & 111 \\
\hline MOF-808 & BTC, benzene-1,3,5-tricarboxylate & $\mathrm{Zr}^{4+}$ & 112 \\
\hline NOTT-300 & BPTC, 3,3',5,5'-biphenyltetracarboxylate & $\mathrm{Al}^{3+}$ & 113 \\
\hline NU-110 (PCN-610) & $\begin{array}{l}\text { 1,3,5-tris[((1,3-carboxylate-5-(4- } \\
\text { (ethynyl)phenyl))ethynyl)phenyl]-benzene) }\end{array}$ & $\mathrm{Cu}^{2+}$ & 30 \\
\hline \multicolumn{4}{|l|}{ PCN-6 (catenated) } \\
\hline $\begin{array}{l}\text { PCN-6' } \\
\text { (noncatenated) }\end{array}$ & TATB, 4,4',4"-s-triazine-2,4,6-triyl-tribenzoate & $\mathrm{Cu}^{2+}$ & 114 \\
\hline PCN-222 & Fe-TCPP, Fe-tetrakis(4-carboxyphenyl)porphyrin & $\mathrm{Zr}^{4+}$ & 115 \\
\hline POST-1 & $\begin{array}{l}\text { (4R,5R)- (and (4S,5S)-) 2,2-Dimethyl-5-[(4-pyridinyl } \\
\text { amino)carbonyl]-1,3-dioxolane-4-carboxylate }\end{array}$ & $\mathrm{Zn}^{2+}$ & 44 \\
\hline UiO-66 & 1,4-BDC, 1,4-benzenedicarboxylate & $\mathrm{Zr}^{4+}$ & 116,117 \\
\hline UMCM-1 & $\begin{array}{l}\text { BDC (benzenedicarboxylate) and BTB (1,3,5- } \\
\text { benzenetri-benzoate), } 4: 3 \text { (molar ratio) }\end{array}$ & $\mathrm{Zn}^{2+}$ & 118 \\
\hline UMCM-150 & biphenyl-3,4',5-tricarboxylate & $\mathrm{Cu}^{2+}$ & 119 \\
\hline UMCM-312 & 3,3',5,5'-tetrakis(4-carboxyphenyl)-1,1'-biphenyl & $\mathrm{Zr}^{4+}$ & 120 \\
\hline UMCM-313 & 2,5,8,11-tetrakis(4-carboxyphenyl)perylene & $\mathrm{Zr}^{4+}$ & 120 \\
\hline UTSA-15 & 2-hydroxy-benzenedicarboxylate & $\mathrm{Cu}^{2+}$ & 121 \\
\hline UTSA-16 & citrate & $\mathrm{K}^{+} / \mathrm{Co}^{2+}$ & 122,123 \\
\hline UTSA-25 & 2-hydroxy-benzenedicarboxylate & $\mathrm{Zn}^{2+}$ & 124 \\
\hline UTSA-28 & BTN, 6,6',6"-benzene-1,3,5-triyl2,2',2"-trinaphthalate & $\mathrm{Cu}^{2+}, \mathrm{Zn}^{2+}, \mathrm{Mn}^{2+}$ & 125 \\
\hline UTSA-33 & $\begin{array}{l}\text { 1,2,4,5-tetra(5-isophthalate)benzene and N,N'- } \\
\text { dimethy-lacetamide }\end{array}$ & $\mathrm{Zn}^{2+}$ & 126 \\
\hline UTSA-36 & $\begin{array}{l}\text { PBA, 4-(4-pyridyl) benzoate and 1,4-BDC, 1,4- } \\
\text { benzene-dicarboxylate }\end{array}$ & $\mathrm{Zn}^{2+}$ & 127 \\
\hline UTSA-50 & PDC, 3,5-pyridine-dicarboxylate & $\mathrm{Cu}^{2+}$ & 128 \\
\hline
\end{tabular}


Continued

\begin{tabular}{|c|c|c|c|}
\hline MOF & Ligands & Metal ions & Ref. \\
\hline UTSA-72 & 3,3',3",3'"-(pyrene-1,3,6,8-tetrayl)tetrabenzoate & $\mathrm{Zn} 2+$ & 129 \\
\hline UTSA-74 & DOBDC, 2,5-dioxido-1,4-benzenedicarboxylate & $\mathrm{Zn}^{2+}$ & 130 \\
\hline UTSA-76 & 5, 5'-(pyrimidine-2, 5-diyl)diisophthalate & $\mathrm{Cu}^{2+}$ & 131 \\
\hline UTSA-80 & 1,3-diethylcarboxylate-4-ethynylbenzene & $\mathrm{Cu}^{2+}$ & 132 \\
\hline UTSA-86 & $\begin{array}{l}\text { ETTC, 4',4"',4"'"',4"'"'"-(ethane-1,1,2,2-tetrayl)tetrakis } \\
\text { (1,1'-biphenyl-4-carboxylate }\end{array}$ & $\mathrm{Cd}^{2+}$ & 133 \\
\hline \multirow[t]{2}{*}{ TSA-90 } & $\begin{array}{l}\text { 2',5'-dimethoxy-[1,1':4',1"-terpheny1]-3,3",5,5"- } \\
\text { tetracarboxylate }\end{array}$ & $\mathrm{Cu}^{2+}$ & 134 \\
\hline & $\begin{array}{l}\text { Imidazolate/Triazole/Tetrazolate/Tetrazine/Azopyr } \\
\text { idine/Hydrazine }\end{array}$ & & \\
\hline Fe-BTT & BTT, 1,3,5-benzenetristetrazolate & $\mathrm{Fe}^{2+}$ & 77 \\
\hline MAF-7 & MTZ, 3-methyl1,2,4-triazole & $\mathrm{Zn}^{2+}$ & 76 \\
\hline UTSA-120 & 3,6-di(4-pyridyl)-1,2,4,5-tetrazine and $\mathrm{SiF}_{6}$ & $\mathrm{Cu}^{2+}$ & 78 \\
\hline UTSA-200 & 4,4'-azopyridine and $\mathrm{SiF}_{6}$ & $\mathrm{Cu}^{2+}$ & 135 \\
\hline UTSA-220 & $\begin{array}{l}\text { (1E,2E)-1,2-bis(pyridin-4-ylmethylene)hydrazine and } \\
\mathrm{SiF}_{6}\end{array}$ & $\mathrm{Cu}^{2+}$ & 79 \\
\hline ZIF-7 & bIM, benzimidazole & $\mathrm{Zn}^{2+}$ & 136 \\
\hline ZIF-9 & bIM, benzimidazole & $\mathrm{Co}^{2+}$ & 137 \\
\hline ZIF-8 & mIM, 2-methyimidazole & $\mathrm{Zn}^{2+}$ & 138,139 \\
\hline ZIF-65 & nIM, 2-nitroimidazole & $\mathrm{Co}^{2+}$ & 75 \\
\hline ZIF-67 & mIM, 2-methyimidazole & $\mathrm{Co}^{2+}$ & 75 \\
\hline \multirow[t]{2}{*}{ ZIF-90 } & ICA, imidazolate-2-carboxyaldehyde & $\mathrm{Zn}^{2+}$ & 76 \\
\hline & Phosphonate & & \\
\hline $\mathrm{La}_{2}\left(\mathrm{LH}_{2}\right)_{2}\left(\mathrm{LH}_{4}\right) \mathrm{Cl}_{2}$ & $\mathrm{~L}=\mathrm{N}, \mathrm{N}^{\prime}$-piperazine-bis(methylenephosphonates) & $\mathrm{La}^{3+}$ & 140 \\
\hline $\mathrm{La}_{2}\left(\mathrm{LH}_{2}\right)_{2}\left(\mathrm{LH}_{3}\right) \mathrm{Cl}$ & $\mathrm{L}=\mathrm{N}, \mathrm{N}^{\prime}$-piperazine-bis(methylenephosphonates) & $\mathrm{La}^{3+}$ & 140 \\
\hline $\begin{array}{l}\mathrm{Ln}\left(\mathrm{H}_{5} \mathrm{~L}^{\prime}\right) \\
\mathrm{Ln}=\mathrm{La}, \mathrm{Nd}, \mathrm{Gd}, \mathrm{Dy}\end{array}$ & $\begin{array}{l}\mathrm{L}^{\prime}=1,4 \text {-phenylenebis(methylidyne)-tetrakis(phospho- } \\
\text { nate) }\end{array}$ & $\begin{array}{l}\mathrm{La}^{3+}, \mathrm{Nd}^{3+}, \mathrm{Gd}^{3+}, \\
\mathrm{Dy}^{3+}\end{array}$ & 141 \\
\hline $\begin{array}{l}\mathrm{Ln}_{2}\left(\mathrm{H}_{2} \mathrm{~L}^{\prime}\right) \\
\mathrm{Ln}=\mathrm{La}, \mathrm{Nd}, \mathrm{Gd}, \mathrm{Dy}\end{array}$ & $\begin{array}{l}\mathrm{L}^{\prime}=1,4 \text {-phenylenebis(methylidyne)-tetrakis(phospho- } \\
\text { nate) }\end{array}$ & $\begin{array}{l}\mathrm{La}^{3+}, \mathrm{Nd}^{3+}, \mathrm{Gd}^{3+} \\
\mathrm{Dy}^{3+}\end{array}$ & 141 \\
\hline $\begin{array}{l}\mathrm{NaLn}\left(\mathrm{H}_{4} \mathrm{~L}^{\prime}\right) \\
\mathrm{Ln}=\mathrm{La}, \mathrm{Nd}, \mathrm{Gd}, \mathrm{Dy}\end{array}$ & $\begin{array}{l}\mathrm{L}^{\prime}=1,4 \text {-phenylenebis(methylidyne)-tetrakis(phospho- } \\
\text { nate) }\end{array}$ & $\begin{array}{l}\mathrm{La}^{3+}, \quad \mathrm{Nd}^{3+}, \mathrm{Gd}^{3+}, \\
\mathrm{Dy}^{3+}\end{array}$ & 141 \\
\hline & Edible materials & & \\
\hline$\alpha-\mathrm{CD}-\mathrm{MOF}$ & $\alpha$-CD, $\alpha$-cyclodextrin & $\mathrm{K}^{+}$ & 80 \\
\hline$\beta-\mathrm{CD}-\mathrm{MOF}$ & $\beta$-CD, $\beta$-cyclodextrin & $\mathrm{K}^{+}$ & 80 \\
\hline $\begin{array}{l}\gamma \text {-CD-MOF } \quad(\mathrm{CD}- \\
\mathrm{MOF}-1)\end{array}$ & $\gamma-\mathrm{CD}, \gamma$-cyclodextrin & $\mathrm{K}^{+}$ & 80,81 \\
\hline MOF-1201 & L-lactate & $\mathrm{Ca}^{2+}$ & 74 \\
\hline MOF-1203 & L-lactate & $\mathrm{Ca}^{2+}$ & 74 \\
\hline Ni-MOFs & aspartate & $\mathrm{Ni}^{2+}$ & 82 \\
\hline $\mathrm{Zn}(\mathrm{GlyThr})_{2}$ & glycine-thronine dipeptide & $\mathrm{Zn}^{2+}$ & 142 \\
\hline $\mathrm{Zn}(\text { GlyAla })_{2}$ & glycine-alanine dipeptide & $\mathrm{Zn}^{2+}$ & 143 \\
\hline
\end{tabular}




\subsection{High throughput (HT) screening of MOFs}

The HT method was originally from the synthesis and screening of drugs with high-efficiency targeting ability, and had been successfully applied to accomplish the novel MOF development. The HT method provided an overall MOF screening strategy with advantages of automation, parallelization, and miniaturization. ${ }^{[73]}$ A successful application of HT method in solvothermal synthesis of ZIFs was first reported in $1998 .^{[144]}$ The synthesis process of MOFs by HT method is always carried out in 96-well plates with automated crystal characteristic analysis by X-Ray Diffraction (XRD) and pattern comparison with simulated patterns of the known crystals. The optical microscopy is automatically employed to observe the morphology of products and even to pre-screen single crystals. ${ }^{[75]}$ Parameters such as reaction temperature and time, ligands, metal ion, molar ratio of starting materials, overall concentration, $\mathrm{pH}$, and solvent are considered and established in MOF synthesis by the HT method. ${ }^{[145-149]}$ The conventional MOFs, such as classical $\mathrm{Fe}^{3+}$ and $\mathrm{Al}^{3+}$ based MOFs with amino group $\left(\mathrm{NH}_{2}\right)$ compounds of MIL-53-NH 2, MIL-88- $\mathrm{NH}_{2}$, and MIL-101- $\mathrm{NH}_{2}$ with ligands of $\mathrm{H}_{2} \mathrm{BDC}-\mathrm{NH}_{2}$, and also MIL-101(Cr), MIL-118, -120, -121, CAU-4, HKUST-1, and Fe-BTT have been developed by the HT method and reported by Stock and Biswas. ${ }^{[73]}$ Recently, a novel work using HT method for screening the macroscale heteroepitaxial alignment MOFs from thousands of structures was presented based on surface chemical compatibility, lattice matching with substrate and interfacial bonding, which could be completed in a few days on a desktop workstation. ${ }^{[150]}$ This estimated HT screening process shown in Fig. 8 provided a simple and efficient measure of the interfacial energy that considered both bond and defect formation at the interface, and accurately predicted aligned heteroepitaxial growth, which had been applied in developing Cu-MOFs on a copper hydroxide surface.

\subsection{Synthesis routes}

The conventional synthesis strategies of MOFs, in general, can be classified as solvothermal and non-solvothermal methods defined by Rabenau, ${ }^{[151]}$ and reported by Stock and Biswas. ${ }^{[73]}$ That is, the synthesis of MOFs taking place in a closed vessel under autogenous pressure above the boiling point of the solvent is defined as the solvothermal method, whilst below or at the boiling point under ambient pressure is defined as the non-solvothermal method. The conventional solvothermal method includes (i) hydrothermal method, ${ }^{[152,153]}$ and (ii) organic solvothermal method. ${ }^{[154]}$ The non-solvothermal method can be further classified as (i) solvent evaporation, (ii) diffusion, (iii) electrochemical synthesis, ${ }^{[155]}$ (iv) microwaveassisted synthesis, (v) ultrasound-assisted synthesis, and (vi) mechanochemical synthesis.

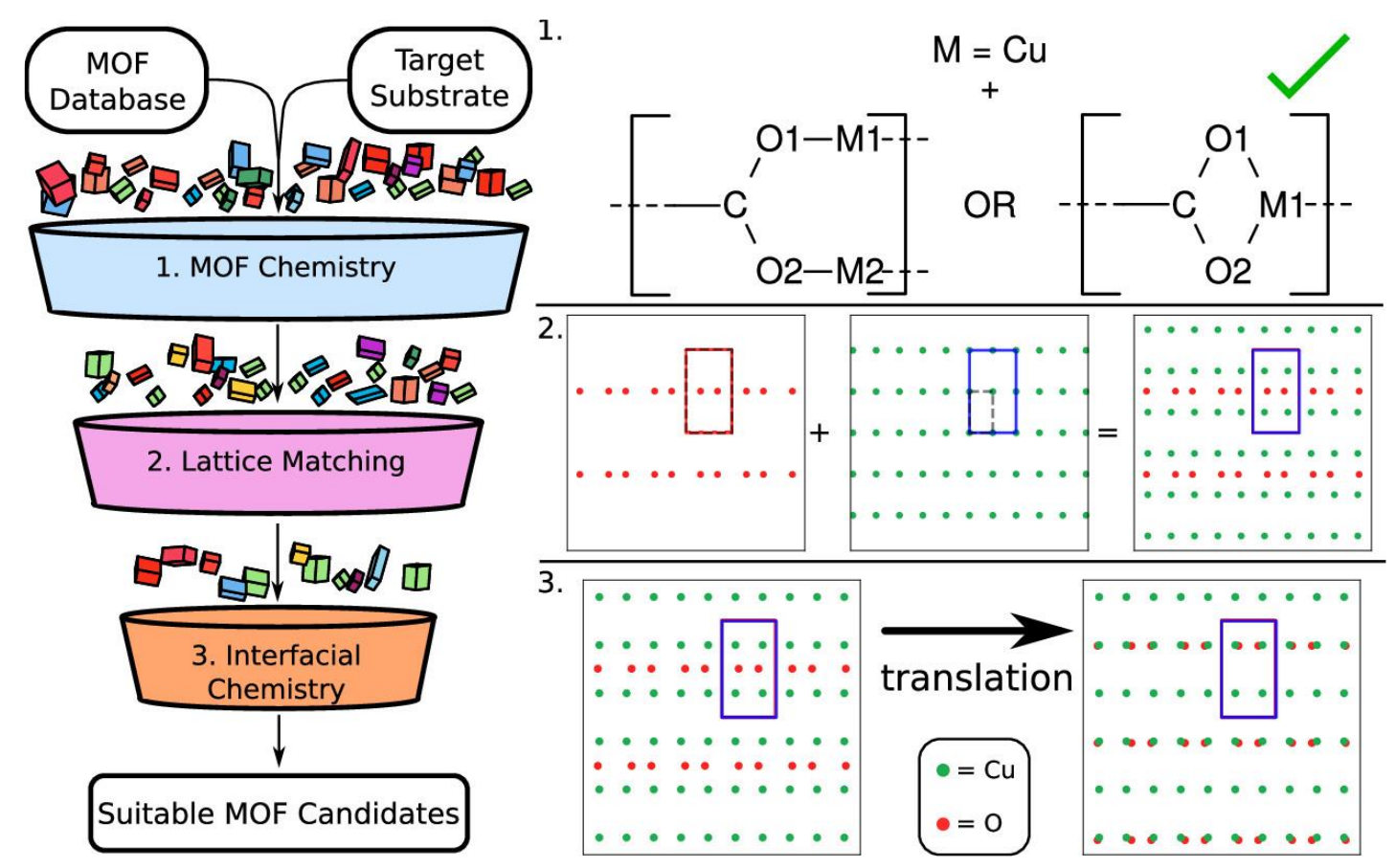

Fig. 8 Flowchart of the screening process, in which a database of MOF crystal structures and a target substrate crystal structure act as inputs. The MOF database is filtered toward a smaller list of candidate structures for aligned heteroepitaxial growth. Each step is illustrated schematically on the right. Step 1 filters the database for MOFs that contain a carboxylate functionality bound to copper atoms and do not contain any metal other than copper. Step 2 checks if matching supercells (e.g., those outlined in solid lines, with dashed lines showing the corresponding unit cells; in this example, the red supercell is the same size and shape as the unit cell) exist for a given MOF-substrate pair. Step 3 checks all possible supercells for interfacial bonding, allowing for translations along the supercell vectors. ${ }^{[150]}$ Adapted and reprinted with permission from reference of 150 , copyright 2018 American Chemical Society. 
The MOF synthesis needs continuous input of energy that can be introduced through heating (solvothermal or nonsolvothermal synthesis), electric potential (electrochemical synthesis), electromagnetic radiation (microwave-assisted synthesis), ball-milled sample (mechanochemical synthesis), ultrasound (so nonchemical synthesis), etc. These introduced energies promote MOF synthesis and further affect the properties such as size, structure, surface, and morphology. ${ }^{[73,156]}$ In addition, reaction parameters including molar ratio of initial ion to ligand, $\mathrm{pH}$, solvent, temperature, time, and pressure are crucial for the MOF synthesis with desired structures, characteristics, and functions, and therefore need extra attention in experimental processes. Representative MOF synthesis methods are discussed below.

\subsubsection{Solvothermal method}

The solvothermal method is a recurrent method for the MOF synthesis via self-assembly of metal ions and organic ligands from soluble precursors in a closed reactor under autogenous pressure in solvents e.g., dimethyl formamide, ethanol, methanol, and water. The major advantage of solvothermal method is comparatively higher yield of products. However, the crystallinity, morphology, structure, size, and yield of synthesized MOFs are sensitively affected mainly by the cooling speed rate at the end of reaction. Fundamental investigation of solvothermal induced MIL-53(Al) synthesis was revealed by using in-situ Raman Spectro's copy, Fourier transform infrared spectroscopy, and turbidity measurements, suggesting that $\mathrm{Al}^{3+}$ and $\mathrm{BDC}$ were firstly synthesized into $\mathrm{Al}-$ $\mathrm{BDC}$ monomers through ionic bridge bonds and coordination bonds. Subsequently, Al-BDC monomers were selfaggregated to form low crystalline MOF colloid structures, which quickly rearranged into ordered, crystalline prenucleation building units (PNBUs) with simultaneous decomposition of N,N-dimethylformamide (DMF) to formic acid and dimethylamine, and further crystal growth. ${ }^{[157]}$ Recently, a novel mixed-solvothermal method was applied to develop MIL-101(Cr) crystals with a significantly higher yield of $83.3 \%$ using a mixture of DMF and water as solvent at $140{ }^{\circ} \mathrm{C}$ compared to conventional solvothermal method in water, suggesting an increased capacity of water uptake, which was caused by a larger BET specific surface area of 2453.1 $\mathrm{m}^{2} / \mathrm{g}$ and smaller crystal particle size of $200 \mathrm{~nm} .{ }^{[158]}$

\subsubsection{Solvent evaporation method}

The solvent evaporation method is an ancient synthesis technique belonging to non-solvothermal method, which occurs at a particular temperature without an external energy supply but could be a time-consuming process. Utilizing the solvent evaporation method to synthesize MOFs is on the principle that products are oversaturated in solvents. Thus, this technique must meet conditions of (i) MOFs grow in saturated solutions, and (ii) the solubility increases when temperature and products can be supersaturated out in cooling temperature. Employing this low-temperature route, Hoskins and Robson successfully synthesized the colorless crystals of $\mathrm{Cu}\left[\mathrm{C}\left(\mathrm{C}_{6} \mathrm{H}_{4} \cdot \mathrm{CN}\right)_{4}\right] \mathrm{BF} 4, x \mathrm{C}_{6} \mathrm{H}_{5} \mathrm{NO}_{2}$ in $1989 .{ }^{[18]}$ Murinzi et al. also utilized the solvent evaporation method to synthesize a Co-MOF with 2, 6-pyridinedicarboxylate as ligand. ${ }^{[159]}$

\subsubsection{Electrochemical method}

The electrochemical synthesis mechanism can be reported as the reactant gains and loses electrons. ${ }^{[160]}$ In MOF synthesis by electrochemical method, the metal ions are continuously introduced to the reaction medium through anodic dissolution for sufficient reaction with molecular ligands. Enhanced ion strength in reaction medium via preventing electrostatic attractions can inhibit the metal ion deposition on the cathode. ${ }^{[73]}$ The major advantages of electrochemical method for MOF synthesis are producing highly purified MOFs, mild reaction condition, shorter reaction time, and potential scaleup to industrial level. Jabarian et al. reported an electrochemical rapid-synthesis method of HKUST-1 at room temperature for performing an electrocatalyst of oxygen reduction reaction. ${ }^{[161]}$ Recent study exhibited a work utilizing electrochemical method to synthesize a nickel benzene-1,3,5tricarboxylate (BTC)MOF (Ni(BTC)-MOF) on $\mathrm{Ni}$ bubbles with an improved catalytic activity for hydrogen evolution reaction. ${ }^{[162]}$

\subsubsection{Microwave-assisted method}

The microwave-assisted synthesis of MOFs is attributed to the mobile electric charges in reaction system directly interacted by electromagnetic wave irradiation. The mobile electric charges further generate electric current in solid or homogeneous orientation arrangement of polar molecules in solution. Suffering continuous electric current surge, the energy is accumulated with increased temperature because of resistance of solid medium and collision between the molecules in solution. ${ }^{[73]}$ The advantages of microwaveassisted method for MOF synthesis are summarized as less period of reaction time, ${ }^{[163-165]}$ high yield, ${ }^{[163]}$ high reaction efficiency, ${ }^{[73]}$ and flexible control of morphology and size. ${ }^{[166]}$ Smaller sized MOF particles with nanoscale and polymorphs are always obtained by the microwave-assisted method, which is likely due to the accelerated nucleation and crystal growth caused by direct heating from microwave. ${ }^{[73]}$ Microwaveassisted synthesis of $\mathrm{UiO}-66(\mathrm{Zr})$ in a continuous-flow microwave system was completed for only $10 \mathrm{~min}$ with the yield of $\sim 90 \%$, which took typically $24 \mathrm{~h}$ for completion in the solvothermal method with a very low synthetic ratio. ${ }^{[163]}$ Zhang et al. found that microwave-assisted method can synthesize various morphologies of ZIF-8 with spherical, fibrous, hollow butterfly, and ring shapes driven by the change of surface energy with the stimuli of $\mathrm{Ni}$ ions. ${ }^{[166]}$ These synthesized ZIF-8 crystals showed different catalytic activities in the Knoevenagel reaction.

\subsubsection{Ultrasound-assisted method}

The ultrasound induced chemical reaction happens commonly at frequency of $20 \mathrm{kHz}$ to $10 \mathrm{MHz}$ with wavelength of $300 \mu \mathrm{m}$ or even longer, which is dramatically larger than conventional molecules or PNBUs, and therefore cannot generate direct interaction. However, cyclic alternating ultrasound generates reduplicative compression and rarefaction in solutions, 
resulting in the formation and growth of cavities (i.e. bubbles) and ultrasound-produced mechanical energy accumulation. These bubbles become unstable after reaching their critical size with subsequently instantaneous collapse. The overall process of bubble formation, growth, and collapse is called cavitation with heating and cooling at rate of higher than $10^{10}$ $\mathrm{K} / \mathrm{s}$, temperature of $\sim 5000 \mathrm{~K}$, and pressures of $\sim 1000 \mathrm{bar}^{\left[{ }^{[73]}\right.}$ Therefore, the ultrasound-assisted method can provide sudden changes in temperature and pressure and introduce energy into MOF synthesis system to form different morphologies and unique properties. Increased utilization of ultrasound-assisted MOF synthesis is presented because of the advantages such as short reaction time, high efficiency, mild reaction temperature and pressure, and reproducibility. Recent study on ultrasoundassisted HKUST-1 synthesis found that ultrasound amplitude and solvent choice primarily affected the MOF dimension, while amplitude-change pole size and reactor size primarily affected the size distribution, as well as ultrasound time mainly affected the yield. ${ }^{[167]}$ Tunsrichon et al. employed ultrasoundassisted method to synthesize a novel $\mathrm{Zn}^{2+}$ coordination aggregate with 5-(3-pyridyl)-1,3,4-oxadiazole-2-thiol in an aqueous medium at room temperature within only $30 \mathrm{~min}$, and utilized as a luminescence sensor for the detection of nitroaromatic compounds. ${ }^{[168]}$ Briefly, microwave- and ultrasound- assisted MOF syntheses have shown great potential primarily caused by their quick synthesis rate, high yield, and controlled size and shape of the resulting particles. 2.4.6. Mechanochemical method

As an old reaction strategy, mechanochemical method was applied in chemical synthesis through the breakage of intramolecular bonds for initiating chemical reactions driven by mechanical forces, ${ }^{[169]}$ but firstly employed in MOF syntheses until 2006. ${ }^{[73,170]}$ Advantages of mechanochemical reaction are solvent-free condition, ${ }^{[170]}$ reduced reaction time,,$^{[171]}$ and potential scale-up to industrial level..$^{[172,173]}$ One of the mechanochemical method, i.e., ball milling was successfully applied in MOF synthesis, ${ }^{[174-176]}$ where metal oxides were usually employed as an initial reactant instead of metal ion salts, e.g., zinc oxide was utilized to produce zinc nitrate. ${ }^{[177,178]}$ An early research performed a liquid-assisted grinding via the ball milling method to synthesize homo- and hetero- rare-earth MOFs from trivalent metal carbonates and benzene-1,3,5-tricarboxylic acid in small amount of DMF or water within only 20 min. ${ }^{[179]}$ Recently, conventional metals (Co, Ni, and $\mathrm{Zn}$ )-BDC MOFs with square lattice structures were synthesized by the ball-milling method at room temperature in solvent-free conditions with high yield and short reaction time. ${ }^{[176]}$

In brief, although all methods discussed above have been well demonstrated to be effective in MOF synthesis, a suitable strategy to select correct route according to the development of specific MOFs is necessary in practical experiments.

\section{Stability of MOFs}

Recently, many more researches have focused on the practical applications of MOFs, where the stability is the most crucial factor especially in a food matrix, ${ }^{[180]}$ which can be improved by modifying the coordinate bond property, ${ }^{[181]}$ ligand configuration, ${ }^{[180]}$ and metal node characteristic. ${ }^{[182]}$ The stability of MOFs is generalized to be thermal, ${ }^{[139,183]}$ chemical, ${ }^{[139,180]}$ hydrolytic, ${ }^{[139,182,184]}$ and mechanical stabilities, ${ }^{[185]}$ and has been well discussed by Howarth and coworkers, ${ }^{[181]}$ and also by Burch and co-workers. ${ }^{[58]}$ The thermal stability of MOFs is generally related to the strength of coordinate bonds and the number of linkers. Using high valence metal ions such as $\mathrm{Ln}^{3+}, \mathrm{Al}^{3+}, \mathrm{Zr}^{4+}$, and $\mathrm{Ti}^{3+}$ coordinating carboxyl-terminated ligands is an effective strategy to improve thermal stability via increasing the metalligand bond strength. ${ }^{[181]} \mathrm{The} \mathrm{Ti}^{3+}$ and 2-aminoterephthalate synthesized MIL-125(Ti)- $\mathrm{NH}_{2}$ showed outstanding thermal stability at $300{ }^{\circ} \mathrm{C}$, and could be employed for photocatalysis of carbon dioxide $\left(\mathrm{CO}_{2}\right)$ to produce bicarbonate radical negative ions under visible-light irradiation. ${ }^{[186]}$ Modification on ligand configuration via changing flexible arms of coreshared tetra carboxylate ligands to rigid naphthoate-based ligands was used to enhance the chemical stability of the $\mathrm{Zr}$ (IV)-MOFs (Fig. 9), and was also demonstrated to improve the chemical stability of BUT-73 and BUT-63 with the rigid naphthoate-based ligands toward commonly used chemical solvents compared to BUT-72 and BUT-74 with the flexible phenyl acrylate-based ones. ${ }^{[180]}$ Coordinative reduction of metal ion chemical valences of HKUST-1 via inner sphere "single" electron transfer from hydroquinone $\left(\mathrm{H}_{2} \mathrm{Q}\right)$ to $\mathrm{Cu}^{2+}$ through its coordination bonds to form $\mathrm{Cu}^{+}$was achieved based on the principle of modifying metal node characteristic (Fig. 10). ${ }^{[182]}$ This coordinative reduction strategy has been demonstrated to enhance the HKUST-1 moisture stability with the structure retention even after exposure to humid air for two years. The outstanding moisture stability of ZIF-8 has been demonstrated even if after heating at $100{ }^{\circ} \mathrm{C}$ in $8 \mathrm{~mol} / \mathrm{L}$ sodium hydroxide $(\mathrm{NaOH})$ solution, which was attributed to the hydrophobic apertures inhibiting water permeation into internal frameworks. ${ }^{[181]}$ A primary factor decreasing the mechanical stability of MOFs is their porosity attribute. ${ }^{[181]}$ Filling guest molecules into empty pores of MOFs was demonstrated to be a successful strategy to improve the mechanical stability of MOFs principally through enhancing intermolecular holding forces between guest molecules and MOF ligands (Fig. 11). ${ }^{[187]}$ Recently, Moussavi et al. reported a strategy using zinc and imidazolate derivatives (including imidazolate, 2-methylimidazolate, dichloroimi-dazolate, and 2-nitroimidazolate) to build robust MOFs (also denoted as chemical caryatids by the authors). The imidazolate derivative ligands can either enhance the mechanical stability through forming a secondary network based on physical attractions 


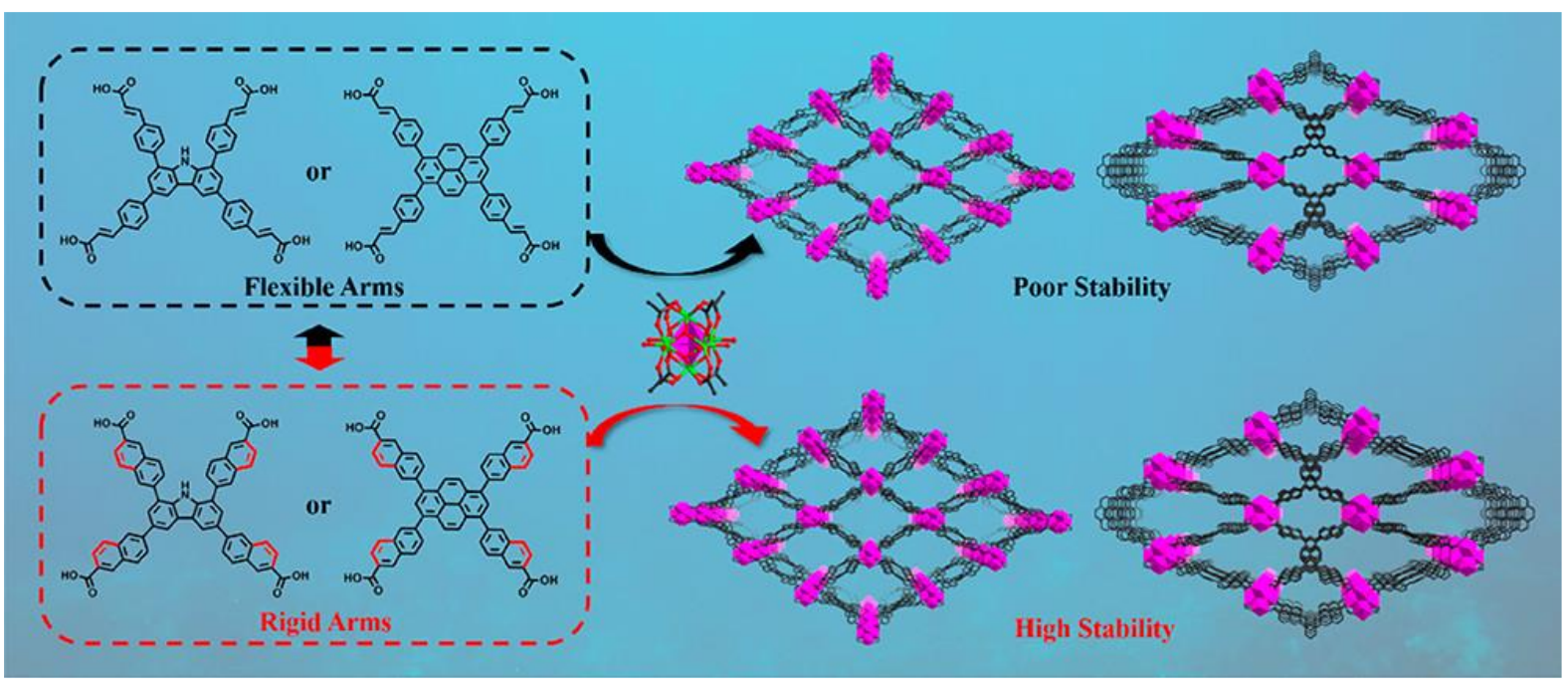

Fig. 9 Chemical structures of core-shared tetracarboxylate ligands of 3,3',3",3"'-(pyrene-1,3,6,8-tetrayltetrakis(benzene-4,1- diyl))tetraacrylate $\left(\right.$ PTSA $\left.^{4-}\right)$ with the pyrene core and 3,3',3",3"'-((9H-carbazole-1,3,6,8-tetrayl)tetrakis(benzene-4,1-diyl)) -tetraacrylate (CTSA $\left.{ }^{4-}\right)$ with the carbazole core for the synthesis of Zr6 cluster MOFs of BUT-72 and BUT-74with poor stability. Transforming PTSA ${ }^{4-}$ and CTSA ${ }^{4-}$ to 6,6',6",6"'-(pyrene1,3,6,8-tetrayl)tetrakis(2-naphthoate) (PTNA ${ }^{4-}$ ) and 6,6',6",6"'-(9H-carbazole-1,3,6,8-tetrayl)tetrakis-(2-naphthoate) (CTNA ${ }^{4-}$ ) for the synthesis of BUT-73 and BUT-63 significantly improves their chemical stability. ${ }^{[180]}$ Adapted and reprinted with permission from reference of 180 , copyright 2019 American Chemical Society.

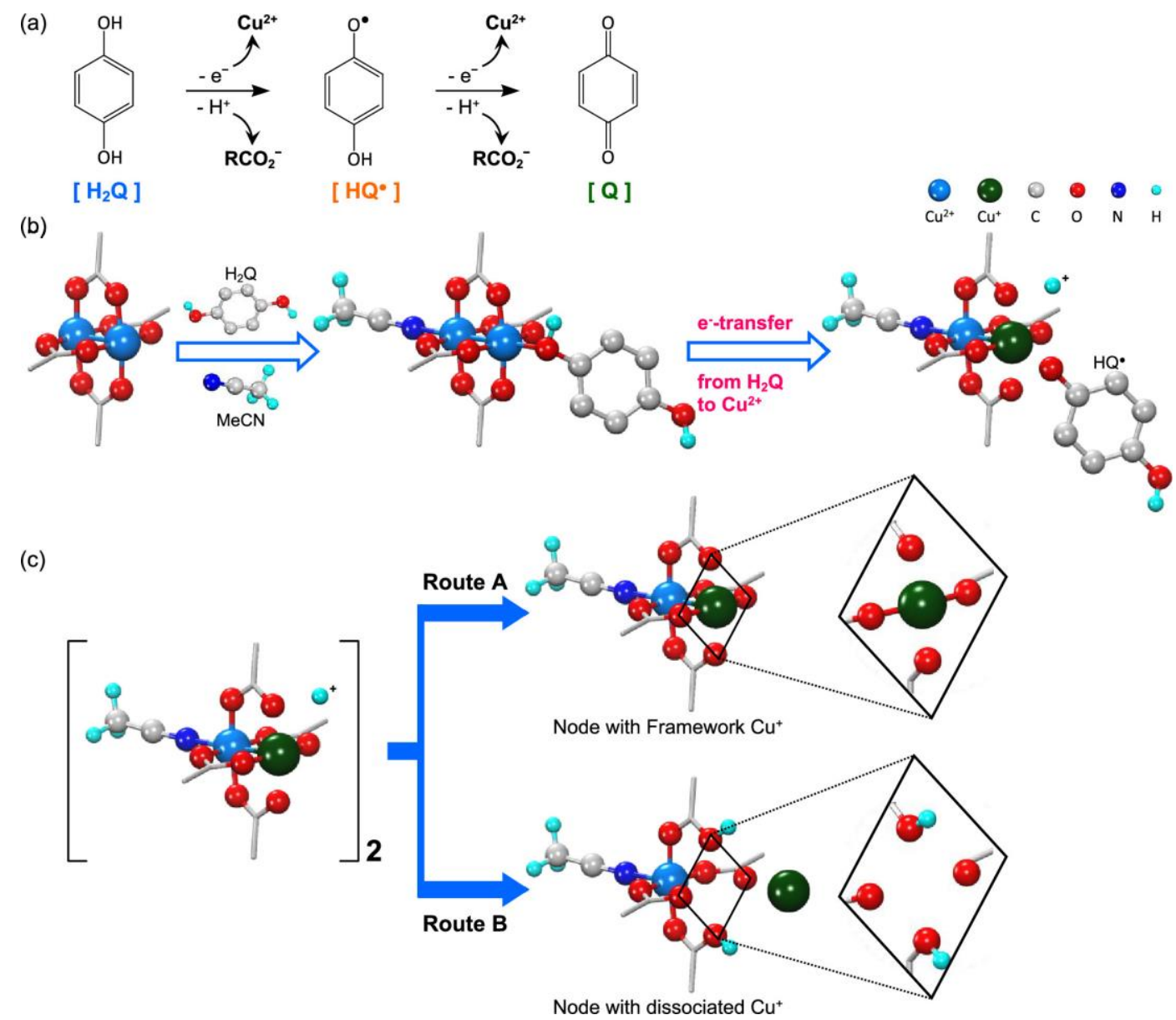

Fig. 10 (a) Illustration of a mechanism for the proton-coupled electron donation reaction of $\mathrm{H}_{2} \mathrm{Q}$ to $\mathrm{Cu}^{2+}$. (b) Schematic of $\mathrm{H}_{2} \mathrm{Q}-$ coupled coordinative reduction of $\mathrm{Cu}^{2+}$ in the paddlewheel node of HKUST-1. H atoms bound to $\mathrm{C}$ atoms in the benzene moieties are omitted for clarity. (c) Schematic of two possible routes by which $\mathrm{Cu}^{+}$-associated nodes can turn to a node with framework $\mathrm{Cu}^{+}$or a $\mathrm{Cu}^{+}$-released node. ${ }^{[182]} \mathrm{Adapted}$ and reprinted with permission from reference of 182, copyright 2019 American Chemical Society. 
or soften and increase the flexibility for MOF structures by destabilizing the bonded network of a MOF. ${ }^{[185]}$ The UiO-66 composed of cationic $\mathrm{Zr}_{6} \mathrm{O}_{4}(\mathrm{OH})_{4}$ nodes and 1,4benzenedicarboxylate ligands was first synthesized by Cavka and co-workers in 2008 , and was thermal (up to $450{ }^{\circ} \mathrm{C}$ ), mechanical, and moisture stability, ${ }^{[117,188]}$ which was mainly attributed to the robust coordination bonds between $\mathrm{Zr}^{4+}$ cultures and carboxylate- based ligands. All these stability investigations on MOFs can be supported by the fundamental hard/soft acid/base (HSAB) principle. That is, the hard Lewis acid and hard Lewis base formed bond and the soft Lewis acid and soft Lewis base formed bond are stronger than those formed between hard Lewis acid and soft Lewis base or soft Lewis acid and hard Lewis base. ${ }^{[188]}$ The mechanism of the instability of coordination bond is as follows. In acidic environment, protons and metal ions compete coordinating $\begin{array}{lllllllllll} & \mathrm{i} & \mathrm{t} & \mathrm{h} & \mathrm{O} & \mathrm{r} & \mathrm{g} & \mathrm{a} & \mathrm{n} & \mathrm{i} & \mathrm{c}\end{array}$ (a)

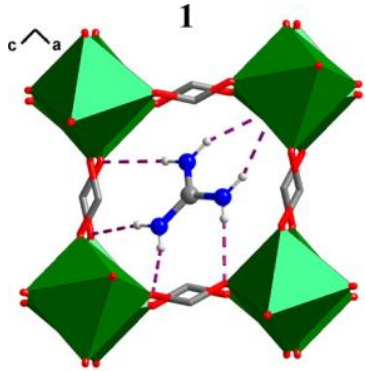

(b)

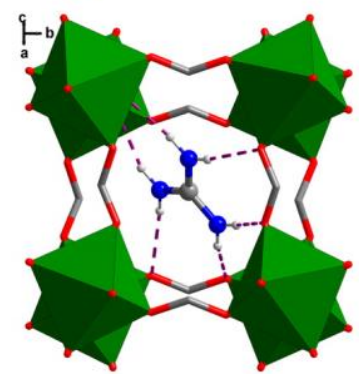

(c)

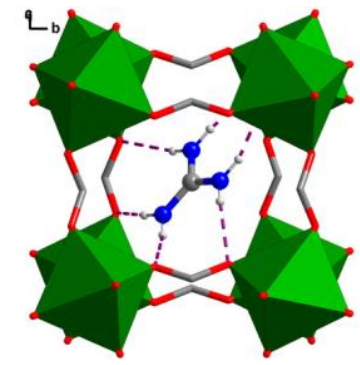

(d)

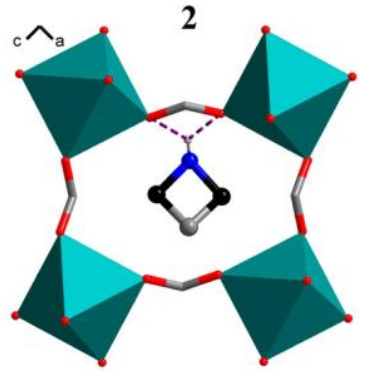

(e)

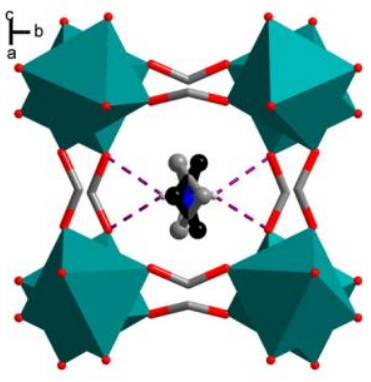

(f)

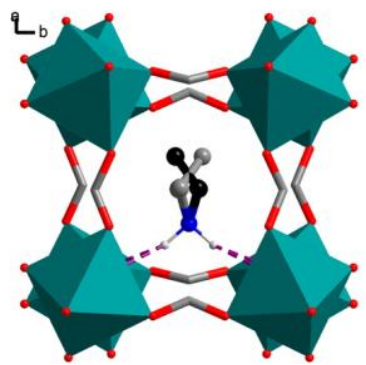

Fig. 11 Framework structures of $(\mathrm{a}-\mathrm{c})\left[\mathrm{C}\left(\mathrm{NH}_{2}\right)_{3}\right]\left[\mathrm{Mn}(\mathrm{HCOO})_{3}\right](1)$ and (d-f) $\left[(\mathrm{CH} 2)_{3} \mathrm{NH}_{2}\right]\left[\mathrm{Mn}(\mathrm{HCOO})_{3}\right]$ (2) showing the pseudocubic perovskite unit cell: (a, d) (010); (b, e) (101); (c, f) (101). Color scheme: $\mathrm{Mn}$ atoms in green or teal; $\mathrm{O}$ atoms in red; $\mathrm{C}$ atoms in gray or black; $\mathrm{N}$ atoms in blue. $\mathrm{N}-\mathrm{H} \cdots \mathrm{O}$ bonds are represented as dashed purple lines. $\mathrm{H}$ atoms of format ligands in 1 and 2 and $-\mathrm{CH}_{2}$ - groups of the azetidium in framework 2 have been omitted for clarity. Note: the azetidium in 2 is equally disordered at two positions, as illustrated in gray and black colors. ${ }^{[187]}$ Adapted and reprinted with permission from reference of 187 , copyright 2014 American Chemical Society. ligands. Meanwhile, hydroxide and organic ligands compete coordinating to metal ions in alkaline environment. The competitive binding in both acidic and alkaline environments leads to the MOFs to be kinetically labile. ${ }^{[189]}$ As a part of many contributions, these theoretical and practical investigations will provide valuable strategies on improving stability of MOFs.

\section{Applications in food safety}

\subsection{Removal of organic dyes}

Organic dyes are a class of pollutants always determined in industrial and agricultural contaminated water. These dyes can be utilized by microorganism, result in the growth of pathogens and are considered to be toxic or even carcinogenic. Removing organic dyes from contaminated water is significant to improve the quality of the drinking water. In general, organic dyes have negative charges because of the deprotonation of special functionalized groups like sulfonic acid and carboxyl groups. The robust nitrogen heterocyclic MOFs, such as imidazole, pyrazine, pyridazine, and pyrazolo frame works that are positively charged attributing to the protonation of $-\mathrm{NH}_{2}$ at ligand portion, provide binding sites between organic dyes and ligands of MOFs through electrostatic attractions. Additionally, these MOFs with conjugated groups, such as imidazole and benzene at ligand portion, are capable of absorbing organic dyes having conjugated groups like phenols through $\pi$-type interactions. Also, the ligand of MOFs containing a lone electron pair is likely to conjugate with hydrogen donors and therefore provides hydrogen bonding sites. At last, the unsaturated metal ion centers provide active coordination sites, e.g., a metal ion at the highest valence from the third or fourth period elements can coordinately conjugate 6 ligands in theory. In brief, based on such feasible intermolecular forces, MOFs reveal a highly effective capacity on organic dyes adsorption.

Successful cases of employing MOFs to absorb and remove organic dyes from water have been reported. In an early research, the MOF-235, a Fe ${ }^{3+}$ terephthalate $\left[\left[\mathrm{Fe}_{3} \mathrm{O}(1,4-\right.\right.$ $\left.\left.\mathrm{BDC})_{3}(\mathrm{DMF})_{3}\right]\left[\mathrm{FeCl}_{4}\right] \cdot(\mathrm{DMF})_{3}\right],{ }^{[190]}$ was successfully utilized to absorb anionic methyl orange (MO) and cationic methylene blue (MB) via electrostatic interaction between MOF-235 and dyes, and a possible $\pi$ - $\pi$ interaction between benzene rings of MOF-235 ligand and dyes of MO and MB. ${ }^{[191]}$ A magnetic HKUST-1 (i.e. $\mathrm{Cu}_{3}(\mathrm{BTC})_{2}$ ) was also found to remove MB with an high-efficiency collection capacity, attributing to the electrostatic interaction, $\pi-\pi$ stacking interaction, and/or hydrophobic interaction. ${ }^{[192]}$ Recent investigation suggested that the ZIF-67 ( $\mathrm{Co}(\mathrm{Hmim})_{2}$, Hmim is 2-methylimidazole) can efficiently absorb and remove 21 organic dyes including MO (anionic), MB (cationic), orange II (OG-II, anionic), acriflavine (AF, cationic), sudan III (SD-III, neutral), etc., especially fuchsin acid (FA, anionic) and cotton blue (CB, anionic) with an absorption capacity of $800 \mathrm{mg} / \mathrm{g}$ 
(a)

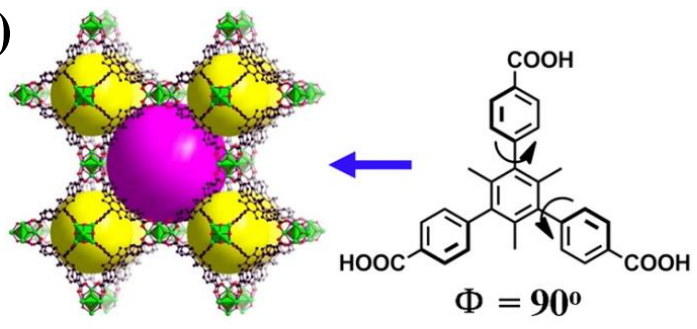

BUT-12

(c)

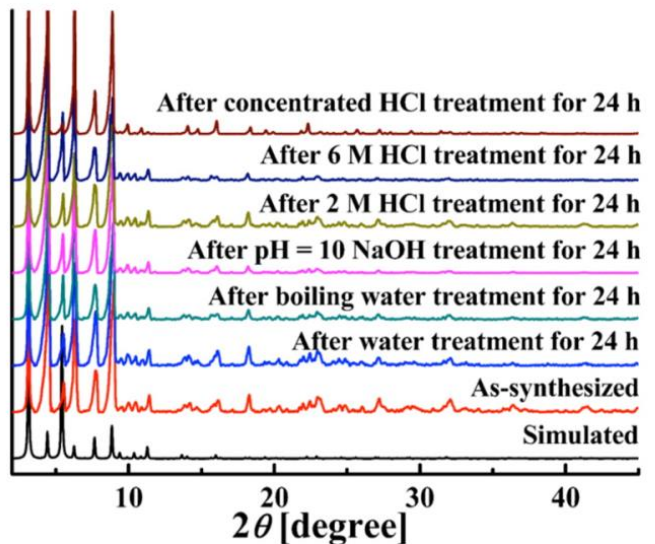

(e)

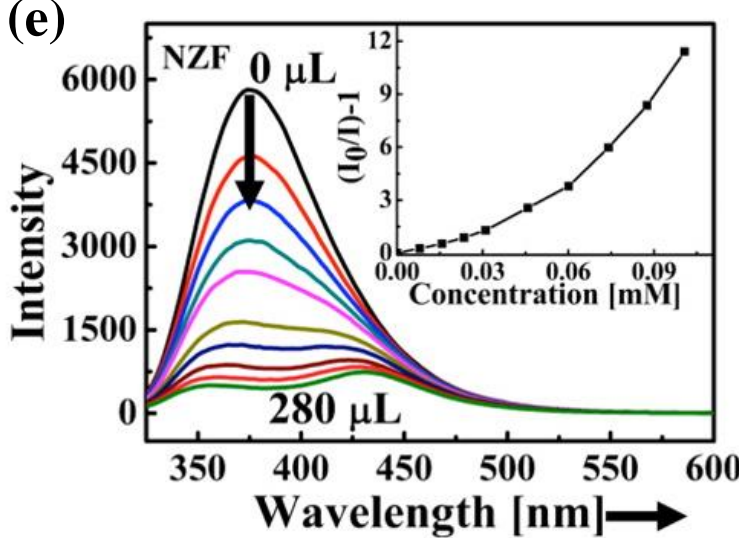

(g)

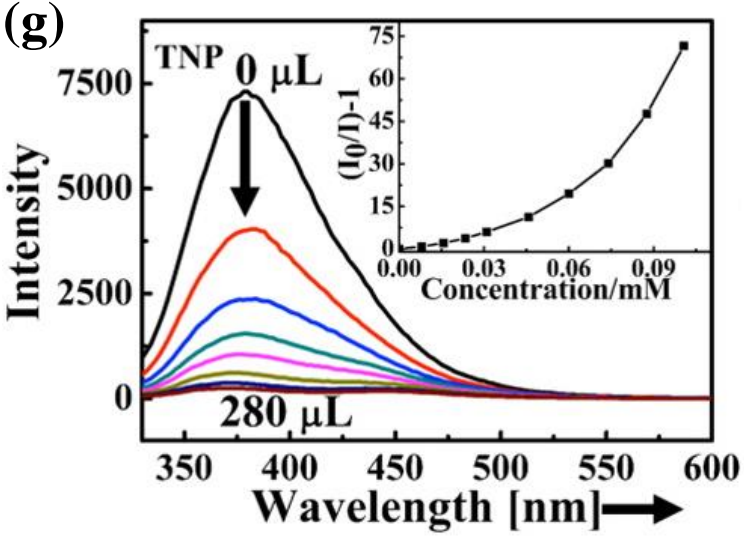

(b)

$\mathrm{H}_{3}$ TTNA

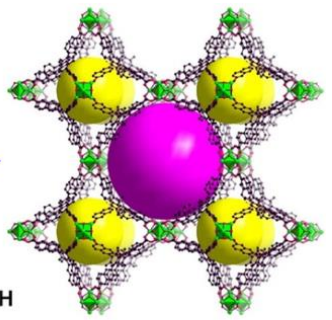

BUT-13
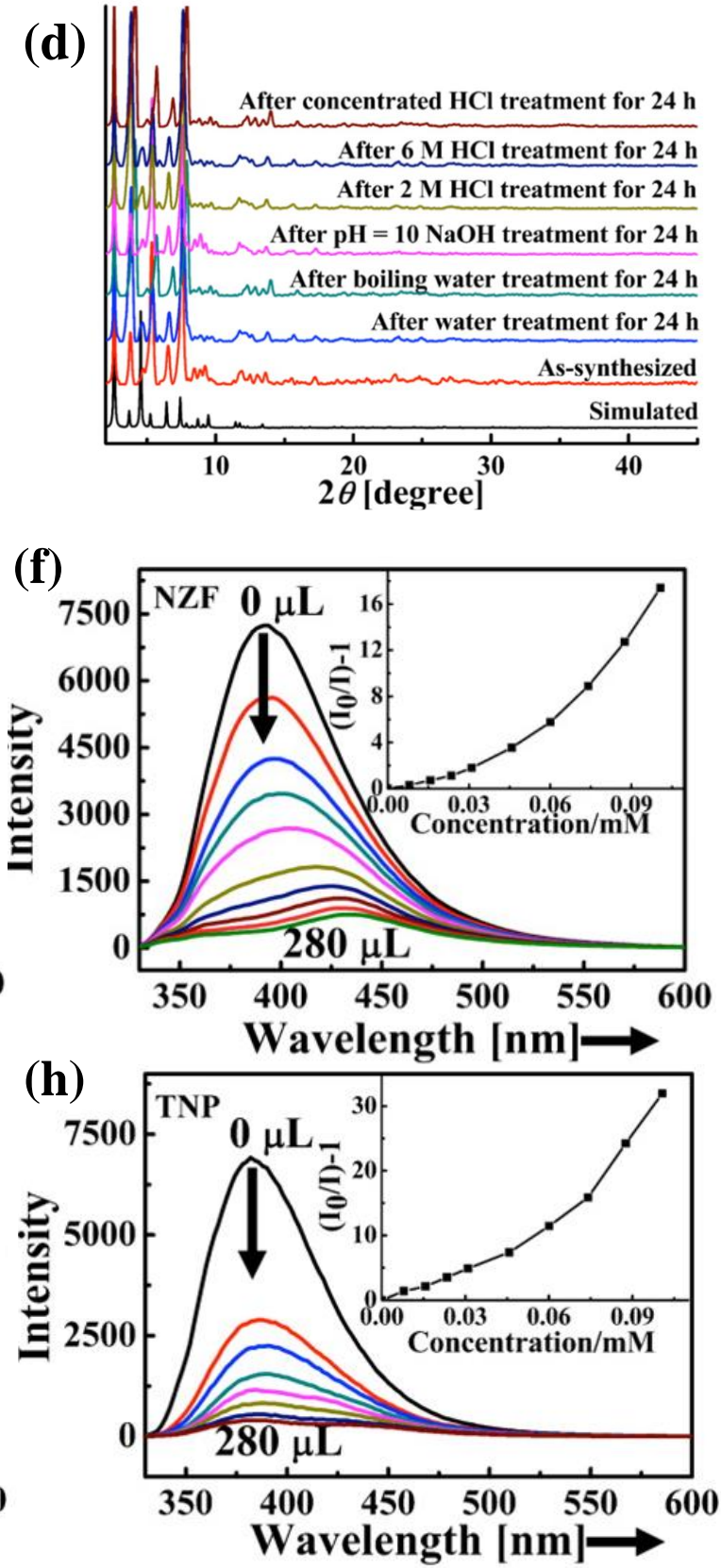

Fig. 12 (a) The $\mathrm{H}_{3}$ CTTA and BUT-12 structures. (b) The H3TTNA and BUT-13 structures (color code: C, black; O, red; and Zr, green; H atoms on ligands are omitted for clarity; the pink and yellow spheres represent cage void regions inside the frameworks). The X-ray powder diffraction patterns of BUT-12 (c) and BUT-13 (d) upon the treatment with water, boiling water, $\mathrm{pH}=10 \mathrm{NaOH}$ solution, $2 \mathrm{~mol} / \mathrm{L} \mathrm{HCl}, 6 \mathrm{~mol} / \mathrm{L} \mathrm{HCl}$, and concentrated $\mathrm{HCl}$. Effect on the emission spectra of BUT-12 (e) and BUT-13 (f) dispersed in water upon incremental addition of nitrofurazone (NZF) (g) and 2,4,6-trinitrophenol (TNP) (h) $\left(1 \mathrm{mM}, 20 \mu \mathrm{L}\right.$ addition each time, from 0 to $280 \mu \mathrm{L}$; inset: Stern-Volmer plots of NZF and TNP). ${ }^{[83]}$ Adapted and reprinted with permission from reference of 83, copyright 2016 American Chemical Society. 
ZIF-67 through the electrostatic (anionic), hydrogen bonding (cationic/neutral), coordination, and $\pi$ - $\pi$ stacking interactions. ${ }^{[193]}$ An interesting phenomenon showed that although the organic dyes have obviously larger molecular sizes (e.g., $1.57 \mathrm{~nm} \times 0.73 \mathrm{~nm} \times 0.68 \mathrm{~nm}$ of neutral SD-III) ${ }^{[193]}$ than ZIF-67 pore aperture of $0.34 \mathrm{~nm}$, a high absorption capacity of these organic dyes by ZIF-67 was determined. ${ }^{[59,75]}$ The mechanism demonstrated by using a quartz crystal microbalance (QCM) illustrated that the gate-opening sorption behavior of ZIF-67 was the primary factor to absorb larger guest mole clues than its pore aperture, and thus absorbing these larger molecule weight dyes with $\pi$ electron structure and revisable charges. ${ }^{[59]}$ Recently, Yang and co-workers fabricated a magnetic $\mathrm{Fe}_{3} \mathrm{O}_{4}$-PSS@ZIF-67 (PSS is donated as polystyrene sulfonate) composite with a core-shell structure to absorb organic dyes from waste water, showing an absorption capacity of 738 mg MO per one gram of this $\mathrm{Fe}_{3} \mathrm{O}_{4}$-PSS@ZIF67. ${ }^{[194]}$ All these MOFs above ${ }^{[75,190,193,195-197]}$ demonstrated effective organic dye remove scavenging capacity.

\subsection{Removal of antibiotics}

Antibiotics are one of the main organic pollutants in agricultural wastewater, and have been detected in drinking water, which is an essential issue that affects food safety and needs a solution as soon as possible. The antibiotic molecules always take furan group (e.g., nitrofurazone, nitrofurantoin, and furazolidone) and benzene group (e.g., thiamphenicol and chloramphenicol), which can be seen as electron donors and acceptors through dipole interaction, and therefore provide binding sites for MOFs. ${ }^{\left[{ }^{[3]}\right]}$ Recently, the porous MOFs with super stable structures in aqueous are considered as promising materials for the removal of antibiotics primarily via $\pi$ structural absorption, e.g., imidazole and benzene groups of antibiotics can form cation- $\pi$ and $\pi-\pi$ stacking interactions with $\pi$-structural MOF ligands. Wang et al. developed two novel $\mathrm{Zr}$-MOFs (i.e., BUT-12, $\mathrm{Zr}_{6} \mathrm{O}_{4}(\mathrm{OH})_{8}\left(\mathrm{H}_{2} \mathrm{O}\right)_{4}(\mathrm{CTTA})_{8 / 3}$, $\mathrm{H}_{3}$ CTTA is 5'-(4-carboxyphenyl)-2',4',6'-trimethyl-[1,1':3',1"terphenyl]-4,4"-dicarboxylic acid and BUT-13, $\mathrm{Zr}_{6} \mathrm{O}_{4}(\mathrm{OH})_{8}\left(\mathrm{H}_{2} \mathrm{O}\right)_{4}(\mathrm{TTNA})_{8 / 3}, \quad \mathrm{H}_{3}$ TTNA is $6,6^{\prime}, 6^{\prime \prime}-(2,4,6-$ trimethylbenzene-1,3,5-triyl)tris(2-naphthoic acid)) (Fig. 12ab) guided by a topological design approach with the BET specific surface area of 3387 and $3948 \mathrm{~m}^{2} / \mathrm{g}$ and total pore volumes of 1.52 and $2.20 \mathrm{~cm}^{3} / \mathrm{g}$. ${ }^{[83]}$ Such two $\mathrm{Zr}-\mathrm{MOFs}$ represented good stability in boiling water as well as in $\mathrm{NaOH}$ $(\mathrm{pH}=10)$ or hydrochloric acid $(\mathrm{HCl})(2,6$, and $12 \mathrm{~mol} / \mathrm{L})$ aqueous solutions without change of crystallinity (Fig. 12c-d). These two Zr-MOFs also represented excellent fluorescent properties, which can be quenched by antibiotics such as nitrofurazone and nitrofurantoin (Fig. 12e-h). Based on the Stern-Volmer equation 1 (eq. 1), ${ }^{[198]}$ it was found that all the antibiotics absorbed by BUT-12 and BUT-13 represented a very high $K_{s v}$, which is significantly higher than the critical static quenching constant, i.e., $2.0 \times 10^{2} \mathrm{M}^{-1}$. That means that stable complexes of antibiotics with BUT-12 or BUT-13 were formed rather than dynamic collision with short-lived sorption behaviors.

$$
\frac{F_{\mathrm{o}}}{F}=1+k_{q} \tau_{\mathrm{o}}[Q]
$$

where $F_{\mathrm{o}}$ and $F$ are the fluorescence intensities without and with a quencher (here is antibiotics), respectively, $[Q]$ is the concentration of the quencher $(\mathrm{mol} / \mathrm{L}), k_{q}$ is the bio-molecular quenching constant, and constant $\tau_{\mathrm{o}}\left(=10^{-8} \mathrm{~s}\right)$ is the average lifetime of the fluorophore in the absence of a quencher. The $k_{q} \tau_{\mathrm{o}}$ can be replaced by the quenching constant of $K_{s v}(\mathrm{~L} / \mathrm{mol})$.

Following up the above excellent contribution, another exciting research reported that a large specific surface area and thermally stable Cu-MOF (i.e., HKUST-1) was employed to remove a model sulfonamide antibiotic, sulfachloropyridazine (SCP), which was fit with the pseudo second order kinetic adsorption model expressed as eq. 2 :

$$
\frac{t}{q_{t}}=\frac{1}{k_{2} q_{e}^{2}}+\frac{t}{q_{e}}
$$

where $q_{e}$ is the amount of SCP adsorbed at equilibrium $(\mathrm{mg} / \mathrm{g}), q_{t}$ is the amount adsorbed at time $\mathrm{t}(\mathrm{mg} / \mathrm{g}), t$ is the adsorption time in minutes, $k_{2}$ is the first-order or secondorder rate constant. ${ }^{[199]}$

The sorption reached equilibrium for $\sim 30$ min with the maximum SCP adsorption capacity of $384 \mathrm{mg} / \mathrm{g}$ at $298 \mathrm{~K}$ and $526 \mathrm{mg} / \mathrm{g}$ at $318 \mathrm{~K}$, mainly caused by the $\pi-\pi$ stacking, hydrogen bonding, and electrostatic interactions. ${ }^{[199]}$ Another study reported a chemically modified MIL-101 through grafting urea or melamine to introduce $-\mathrm{NH}_{2}$ group at the interface of MIL-101 by a post-synthesis means to provide hydrogen donors. These $-\mathrm{NH}_{2}$ group conjugated with nitro group (as the hydrogen acceptor) of nitroimidazole antibiotics via hydrogen binding for nitroimidazole antibiotics absorption and removal. ${ }^{[200]}$ Recently, a core-shell magnetic ZIF-8 (i.e., $\mathrm{Fe}_{3} \mathrm{O}_{4} @$ ZIF-8) was developed to absorb the tetracycline antibiotics such as tetracycline, oxytetracycline, and chlortetracycline from environmental water samples. ${ }^{[201]}$ After a desorption by using methanol with $1 \%$ of acetic acid, the tetracycline antibiotics could be quantized by ultra-high performance liquid chromatography combined with mass spectrometry at the detection limits of $0.125,0.122$, and 0.143 $\mathrm{ng} / \mathrm{L}$ for tetracycline, chlortetracycline, and oxytetracycline, respectively. He et al. synthesized a magnetic MIL$101(\mathrm{Fe}) / \mathrm{TiO}_{2}$ composite for the degradation of tetracycline with a degradation rate of $92.76 \%$ at $\mathrm{pH}$ of 7.9 under solar light irradiation for only $10 \mathrm{~min}$ to generate a large amount of $\cdot \mathrm{O}^{2-}$ and $\cdot \mathrm{OH}$ free radicals. ${ }^{[202]}$ The photocatalytic degradation rates of tetracycline within 5 min were $65.03 \%$, $90.99 \%$, and $95.07 \%$ under visible light, sunlight, and ultraviolet light irradiations respectively, which suggested a perfect tetracycline degradation repetition in quintuple. All these methods for antibiotics removal by functionalized MOFs discussed here represented a great potential in practical application for food safety. 


\subsection{Removal of heavy metals}

The heavy metal ion pollution in environment especially drinking water, fruits, vegetables, and sea foods is a serious issue harming human health, which is concerned for its high carcinogenic risk after a long-term intake. ${ }^{[203]}$ Therefore, removal of heavy metal ions is significant in food safety.

In the last decade, a dramatic increase of developing MOFs to remove heavy metal ions for the improvement of food safety was reported because of a great number of advantages of MOFs as porous heavy ion sorbents, ${ }^{[204-206]}$ which were reported in an overview by Feng and co-workers. ${ }^{[188]} \mathrm{Lv}$ et al. employed MIL-101- $\mathrm{NH}_{2}$ as a sorbent to study the dynamic absorption of $\mathrm{Fe}^{3+}, \mathrm{Cu}^{2+}$, and $\mathrm{Pb}^{2+}$ based on the fluorescence quenching determination of $\mathrm{NH}_{2}-\mathrm{BDC}$ ligand. ${ }^{[207]}$ The MIL101- $\mathrm{NH}_{2}$ nanocrystals kept an unchanged crystal morphology after the introduction of $-\mathrm{NH}_{2}$ compared to MIL-101 but a slightly decreased BET specific surface area from 587.4 to $454.6 \mathrm{~m}^{2} / \mathrm{g}$. Employing these MIL-101-NH $\mathrm{NH}_{2}$ nanocrystals to detect $\mathrm{Fe}^{3+}, \mathrm{Cu}^{2+}$, and $\mathrm{Pb}^{2+}$ showed well linear relationship $b$ e $t$ w (a)

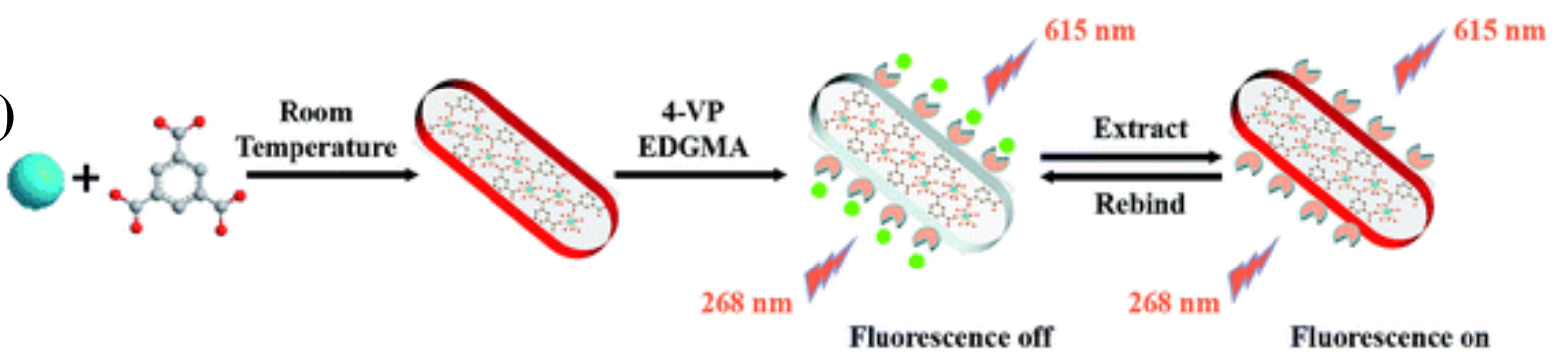

\section{$\mathrm{Eu}^{3+} \mathrm{H}_{3} \mathrm{BTC} \mathrm{Eu}(\mathrm{BTC}) \rightarrow \mathrm{MIP} \cdot$ Lincomycin}
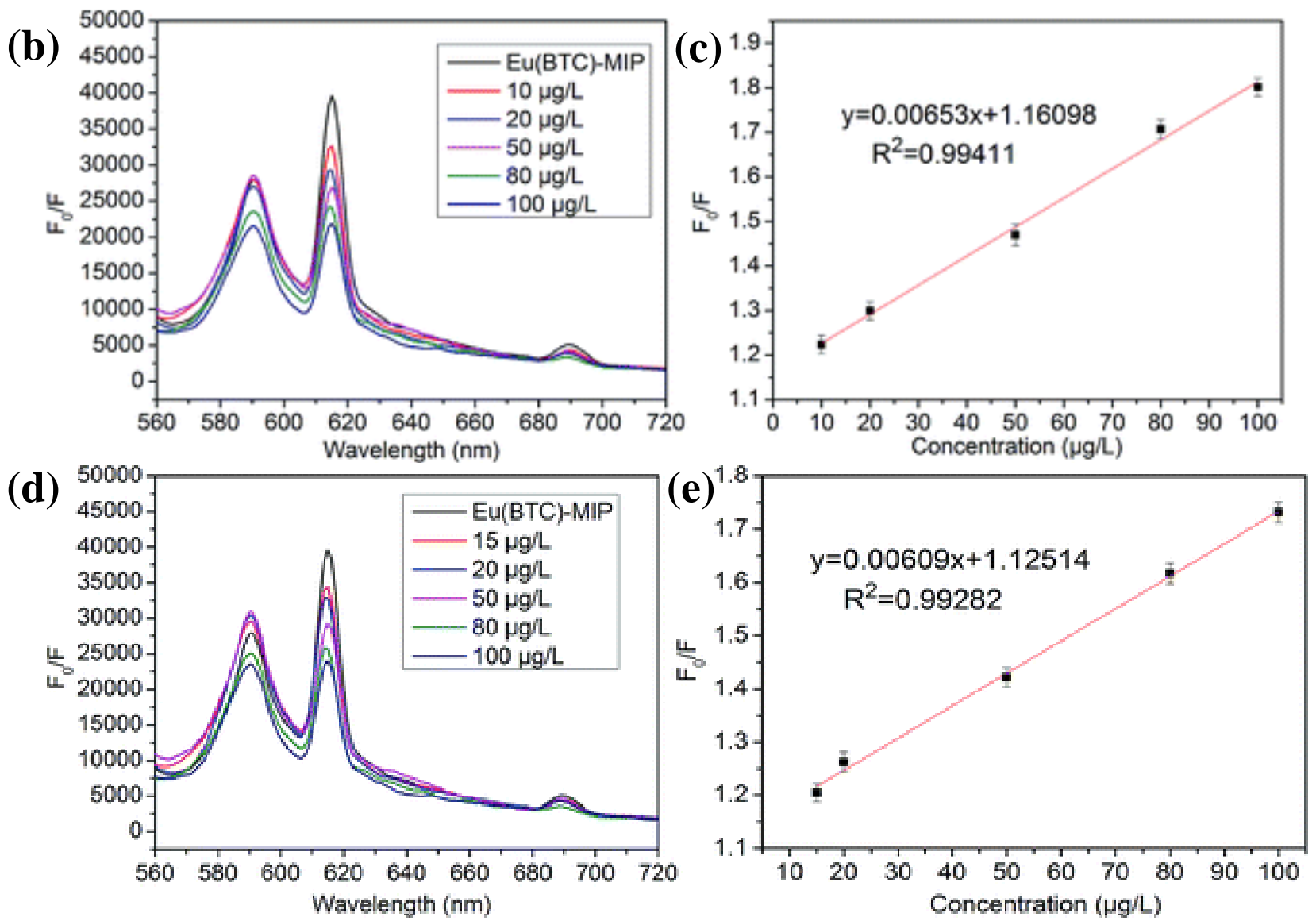

Fig. 13 (a) Schematic of Eu(BTC)-MIP synthesis. (b) Fluorescence spectra of Eu(BTC)-MIP with different lincomycin concentrations from 0 to $100 \mu \mathrm{g} / \mathrm{L}$, and (c) the corresponding calibration curve. (d) Fluorescence spectra of Eu(BTC)-MIP at different lincomycin concentrations in egg samples from 0 to $100 \mu \mathrm{g} / \mathrm{L}$, and (e) the corresponding calibration curve. ${ }^{[209]}$ Adapted and reprinted with permission from reference 209, copyright 2019 Royal Society of Chemistry. 
fluorescence intensities of activated MIL-101- $\mathrm{NH}_{2}$ nanocrystals to that with metal ion absorption and metal ion concentrations at 0 to $10 \mathrm{mmol} / \mathrm{L}$ for $\mathrm{Fe}^{3+}, 0.01$ to $10 \mathrm{mmol} / \mathrm{L}$ for $\mathrm{Cu}^{2+}$, and 0.01 to $1 \mathrm{mmol} / \mathrm{L}$ for $\mathrm{Pb}^{2+}$. The absorption mechanism between metal ions and MIL-101- $\mathrm{NH}_{2}$ nanocrystals was primarily through electro- static interactions, fitting the Langmuir and Freundlich adsorption isotherm models at $\mathrm{pH} 3$ and 5 within $180 \mathrm{~min}$.

Zhu et al. developed a magnetic core-double-shell structured polydopamine@ZIF-8 spherical composite with average diameter of approximately $503 \mathrm{~nm}$ for heavy metal ion absorption, which showed a $\mathrm{Cr}^{4+}(\sim 7.5 \AA)$ absorption capacity of $136.56 \mathrm{mg} / \mathrm{g}$ primarily through the larger gappore $(3.4 \AA) .{ }^{[208]}$ The absorbed $\mathrm{Cr}^{4+}$ was capable of penetrating into the interior and achieving onto polydopamine, which was further converted to low toxicity $\mathrm{Cr}^{3+}$ by the phenolic hydroxyl groups of polydopamine. Recently, Mon et al. reported a novel multivariate (MTV) MOF prepared by combining two different oxamide-based metals ligands derived from the natural amino acids of $\left[\mathrm{Ca}^{\mathrm{II}} \mathrm{Cu}_{6}^{\mathrm{II}}{ }_{6}[(S, S) \text {-methox }]_{1.43-1.46}(S, S)\right.$ $\mathrm{s}$ e ri mox ] $\left.1.57-1.54(\mathrm{OH})_{2}\left(\mathrm{H}_{2} \mathrm{O}\right)\right] \cdot 30 \mathrm{H}_{2} \mathrm{O}$ with a BET specific surface area of $659 \mathrm{~m}^{2} / \mathrm{g} .{ }^{[205]}$ This synthesized MTV-MOF, at a dose of only $50 \mathrm{mg}$, suggested a remarkable heavy metal ion capture capacity via sulfur-heavy metal ions affinity, such as forming sulfur- $\mathrm{Hg}^{2+}$ bond, with complete removal of $\mathrm{Hg}^{2+}, \mathrm{Pb}^{2+}$, and $\mathrm{Tl}^{+}$within $210 \mathrm{~min}$ from $20 \mathrm{~mL}$ aqueous solution at initial metal ion concentration of 1 ppm at $\mathrm{pH}$ 7.0. These efficient sorbents employing functionalized MOFs provided feasible strategies for heavy metal ion removal to improve food safety especially the water quality.

\subsection{Detection and analyses of pollutants in food}

Developing chemical sensors to detect and analyze pollutants in food by MOFs has been reported based mainly on two fundamental principles, i.e., (i) quenching luminous groups of MOFs such as the fluorescence (e.g., luminescence) and ultraviolet caused by the conjugated $\pi$ groups of ligands and lanthanide (or denoted as rare earth elements) ion clusters, ${ }^{[209,210]}$ and (ii) capturing guest molecules by activated groups of MOFs or encapsulated constituents such as enzymes, antibody, etc. with further reactions e.g., chromogenic reaction and redox reaction. ${ }^{[211]}$ Yao and co-authors summarized the rapid determination of contaminants in food by employing luminescent MOFs. ${ }^{[212]}$ Recently, Wu et al. developed a highly luminescent europium Eu-MOF, i.e.,
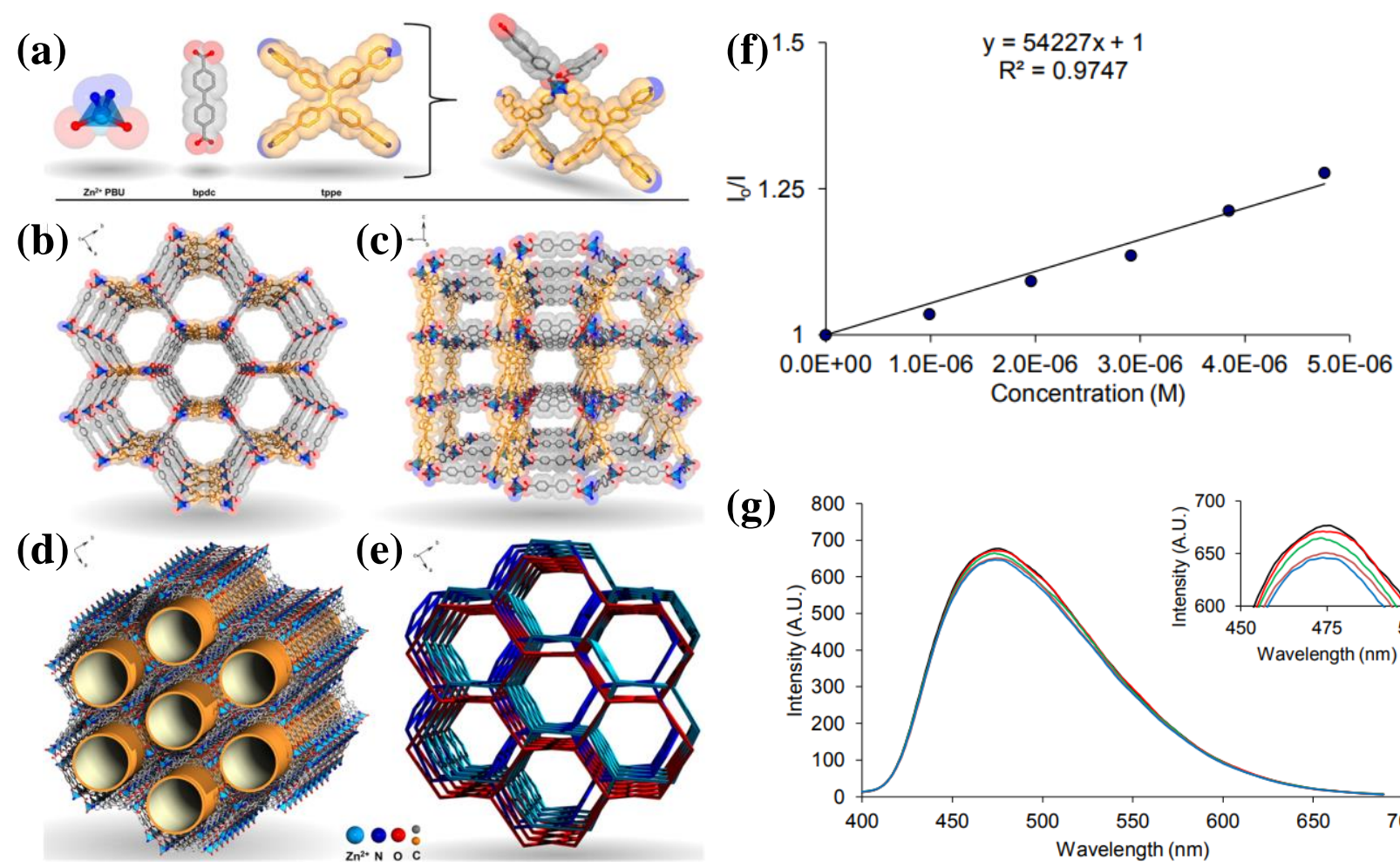

(g)

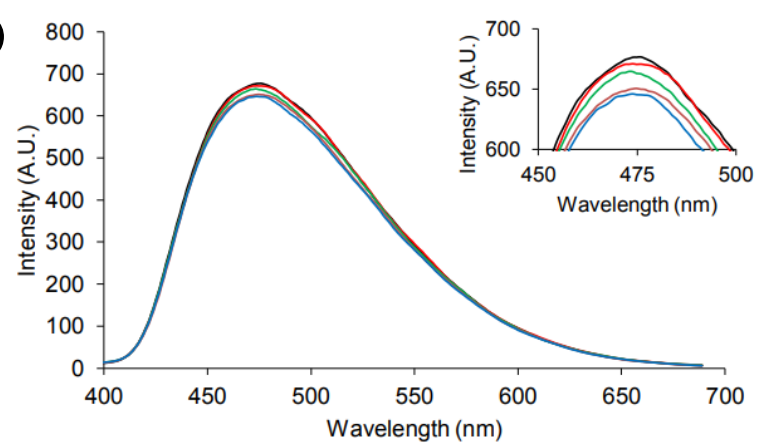

Fig. 14 (a) The primary building unit of LMOF-241, representing a tetrahedrally coordinated $\mathrm{Zn}^{2+}$ center bound with two TPPE ligand molecules and two BPDC ligand molecules. (b) The LMOF-241 single net viewed along the $c$ axis, composed of edge-sharing hexagonal channels. (c) The LMOF-241 single net viewed along the $b$ axis, showing pores that are closed upon the interpenetration. (d) Overall crystal structure suggesting a three-fold interpenetration and 1D pore channel along the $c$ axis. (e) LMOF-241 drawn as 2-nodal (4,4)-c net (mog-type), with TPPE and BPDC simplified as a 4-c node and 2-c node, respectively. The different colors (red, blue, and aqua) indicate the three distinct interpenetrated networks that build the complete structure of LMOF-241. The H atoms are omitted for clarity. (f) The Stern-Volmer curve for Aflatoxins B1 detection. (g) 
LMOF-241 emission spectra from the LMOF-241 at Aflatoxin B1 concentrations of 0 ppb (black), 46 ppb (red), 91 ppb (green), 134 ppb (orange), and $177 \mathrm{ppb}$ (blue). ${ }^{[210]}$ Adapted and reprinted with permission from reference of 210, copyright 2015 American Chemical Society.

Eu(BTC)-molecularly imprinted polymers (MIP) composites to detect the antibiotic of lincomycin in eggs. ${ }^{[209]}$ The highly luminescent $\mathrm{Eu}(\mathrm{BTC})$ was first synthesized and subsequently covered by the MIP with lincomycin as template molecules to obtain Eu(BTC)-MIP. During the detection, the MIP played a role to capture lincomycin, and the $\mathrm{Eu}(\mathrm{BTC})$ acted as a support of MIP and worked as a fluorescence probe to detect the captured lincomycin (Fig. 13a). Because of the chemical structural properties, lincomycin has a low ultraviolet absorption and therefore is difficult to be detected by using conventional high-performance liquid chromatography- diode array detector (HPLC-DAD) or ultraviolet spectro-photometer. However, employing the Eu(BTC)- MIP probe could achieve the specific detection of lincomycin at concentrations of 10 to $100 \mu \mathrm{g} / \mathrm{L}$ with a detection limit of $7.18 \mu \mathrm{g} / \mathrm{L}$ based on the $\mathrm{Eu}$ (BTC) fluorescence quenching by lincomycin (Fig. 13b-c). This Eu(BTC)-MIP probe was successfully utilized to detect lincomycin in eggs (Fig. 13d-e), with a recovery of $88.02 \%$ to $97.29 \%$ and a relative standard deviation of less than $3.46 \%$. He et al. developed an electrode with electro -chemically reduced graphene oxide (ERGO) function, which was synthesized through coordinate bonding between $\mathrm{Cu}$ ion clusters and 2,4,6-tris(3,5-dicarboxylphenyl -amino)-1,3,5triazine(TDP-AT)ligands (i.e., $\mathrm{Cu}$-TDPAT), and further conjugated with $\mathrm{Au}$ nanoparticles to form $\mathrm{Au} / \mathrm{ERGO} / \mathrm{Cu}-$ TDPAT composite. ${ }^{[211]}$ This Au/ERGO/Cu- TDPAT electrode represented a superior response to the oxidation process of nitrite, which enabled to detect nitrite with a wide linear concentrations of 0.001 to $1,000 \mu \mathrm{mol} / \mathrm{L}$ with the detection limit of $0.006 \mu \mathrm{mol} / \mathrm{L}$, and was successfully applied on nitrite detection in tap water, milk, sausage, and pickled vegetable. $\mathrm{Hu}$ et al. synthesized a novel luminescent MOF (LMOF), denoted as LMOF-241, with the ligands of 1,1,2,2-tetrakis(4(pyridin-4-yl)phenyl) ethane (TPPE) and biphenyl-4,4'dicarboxylic acid (BPDC) coordinated bonding zinc ion cultures (Fig. 14a-e).[210] This LMOF-241 was extremely sensitive to Aflatoxin B1, resulting in a fast fluorescence quenching of LMOF-241. The linear curve for Aflatoxin B1 detection based on the Stern-Volmer equation was $\frac{F_{0}}{F}=1+$ 54227[Q] at the Aflatoxin B1 concentration of lower than 5 $\mu \mathrm{mol} / \mathrm{L}$ (Fig. 14f) with the detection limit of $46 \mathrm{ppb}$ (Fig. 14g), much more sensitive than the tolerant level of $300 \mathrm{ppb}$ for beef cattle set by the Food and Drug Administration for corn and peanut feeds. A possible fluorescence quenching mechanism supporting the Aflatoxin B1 detection by using LMOF-241 was suggested via electron transfer processes rather than energy transfer. The stronger orbital overlap of Aflatoxin B1 and LMOF-241 was likely due to the more complete $\pi$-type overlap between conjugate $\pi$-orbitals of Aflatoxin B1 and LMOF-241, and therefore facilitated a more efficient electron transfer with extremely sensitive fluorescence quenching. A very detailed and forward- looking summary of the MOF application on sensors has been overviewed by Wang et al., including the detection of toxins, bacterial contamination, veterinary residues, pesticide residues, environmental pollutants, heavy metals, harmful additive, etc. ${ }^{[213]}$ This demonstrated that the MOFs are very promising to provide contributions in analysis and detection of pollutants in food.

\section{Applications in food preservation}

\subsection{Regulation of ethylene}

The MOFs have been successfully applied in gas storage, separation, and release. ${ }^{[23,39,41,42,214]}$ In general, gaseous guest molecules, such as hydrogen, ${ }^{[215]}$ oxygen, ${ }^{[216]}$ carbon dioxide, ${ }^{[39]}$ and methane ${ }^{[23]}$ can easily pass through the surface pores of MOFs and enter into interior because of their small molecular size that is smaller than pore cavity of MOFs, ${ }^{[59]}$ which can be further captured by organic ligands and/or unsaturated coordination sites from metal ion cultures. Current researches have demonstrated that the MOFs are ideal porous materials with compatible pore cavities and binding sites, and therefore are promising to be applied for gas storage. In the present overview, we primarily discuss current contributions of ethylene regulation by MOFs with potential applications in food preservation

Ethylene is a growth regulation gas in fruit and vegetable postharvest, ${ }^{[217]}$ which has been applied to accelerate fruit and vegetable ripening. However, the flammable and explosive properties of ethylene prevent broad applications at a large dose. Therefore, synthesizing nano- or micron- sized ethylene storage and release agents is a potential strategy for the development of household ripening agents. Zhang et al. synthesized a copper terephthalate (Cu-TPA) MOF using a solvothermal method for ethylene storage and release (Fig. 15a). ${ }^{[218]}$ This $\mathrm{Cu}$-TPA MOF was highly porous with a total pore volume of $0.39 \mathrm{~cm}^{3} / \mathrm{g}$ and ethylene loading capacity of $13.1 \mathrm{~cm}^{3} / \mathrm{g}$, allowing $50 \mathrm{mg}$ of Cu-TPA to absorb and release $2.6 \mathrm{~mL}$ of ethylene in a $4 \mathrm{~L}$ closed container (i.e., $654 \mu \mathrm{L} / \mathrm{L}$ ) after 180-min release, which can significantly regulate the ripening of bananas and avocados blowing a critical ethylene safe level of $27 \mathrm{~mL} / \mathrm{L}$. Chopra et al. employed the Basolite C300 (i.e., HKUST-1) to investigate the adsorption and release of ethylene as food packaging materials, and obtained an interesting result that little ethylene was released after exposing ethylene-loaded Basolite C300 in dry air but a majority of ethylene desorption in the presence of water. ${ }^{[219]}$ Guan et al. synthesized an Al-MOF to entrap ethylene with the loading capability of $41.0 \mathrm{~cm}^{3}$ per gram of Al-MOF, and further encapsulated the Al-MOF-ethylene complex into an egg-box structural alginate- $\mathrm{Fe}^{3+}$ composite for ethylene storage and controlled release (Fig. 15b-f). ${ }^{[13]}$ This Al-MOFethylene in alginate- $\mathrm{Fe}^{3+}$ composite encapsulated $46.7 \% \mathrm{Al}-$ MOF could be completely released by exposing into 200 $\mathrm{mmol} / \mathrm{L}$ sodium citrate aqueous solution within $150 \mathrm{~min}$, and 
followed by a quick release of stored ethylene to saturated interaction between carbon-carbon double bond and concentration of 9.4-10.4 mL/L (i.e., 8.2-9.1 mg/L) in a $4 \mathrm{~L}$ unsaturated metal ion sites, $\mathrm{CH}-\pi$ interactions between closed vial within $180 \mathrm{~min}$. The intermolecular dipolecation

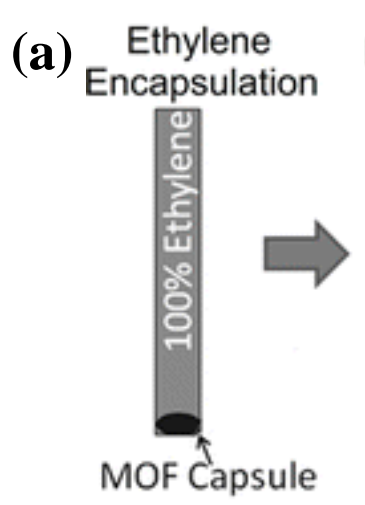

(b)

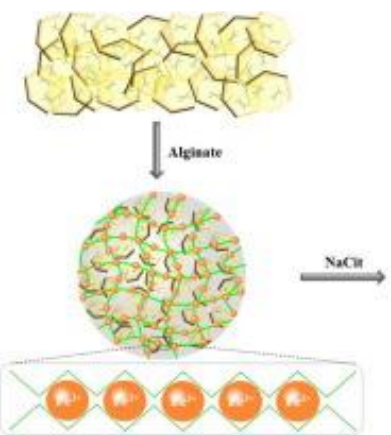

(d)

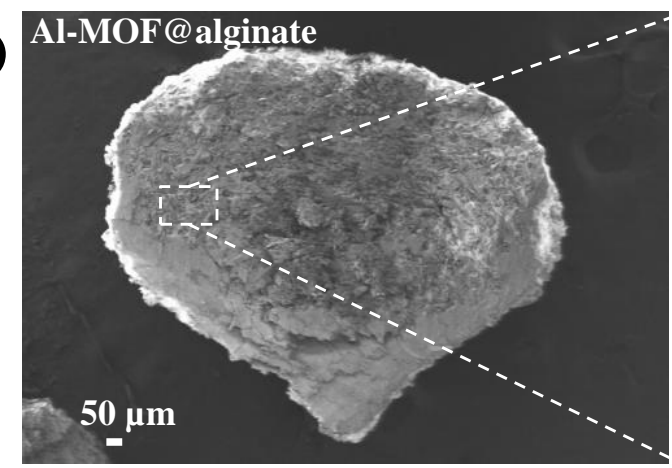

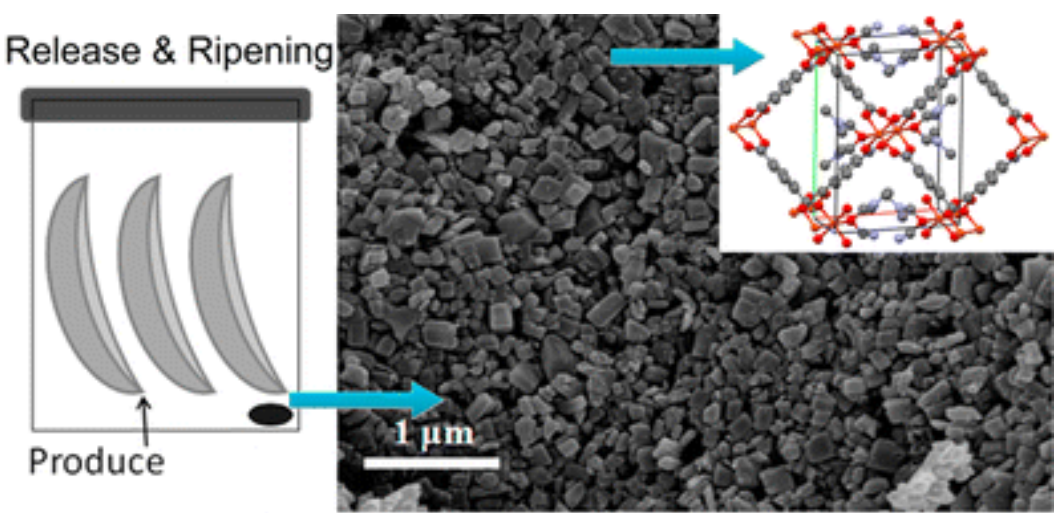

(c)
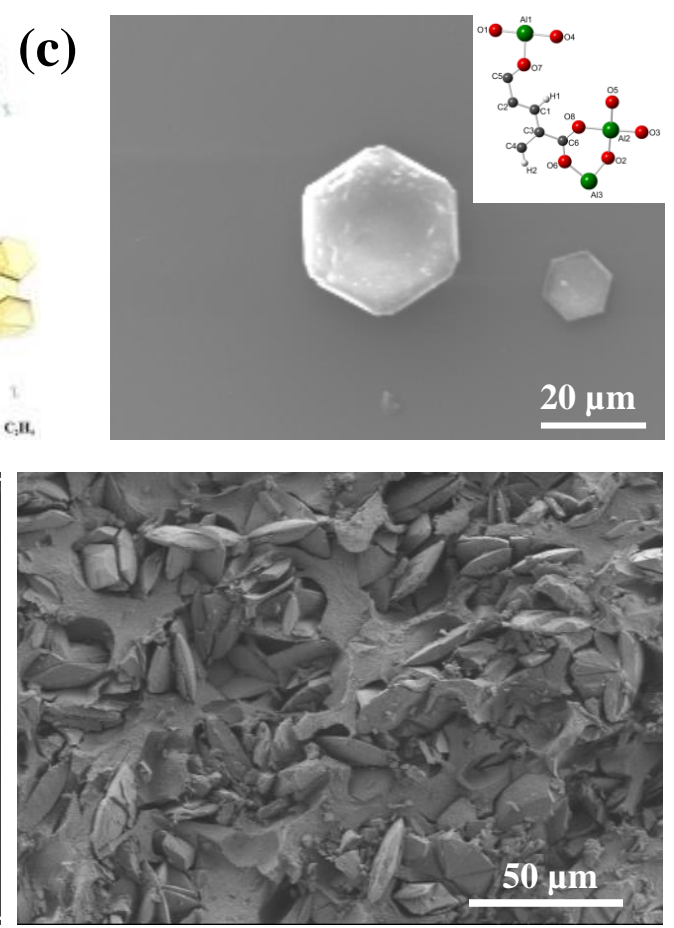

(e)

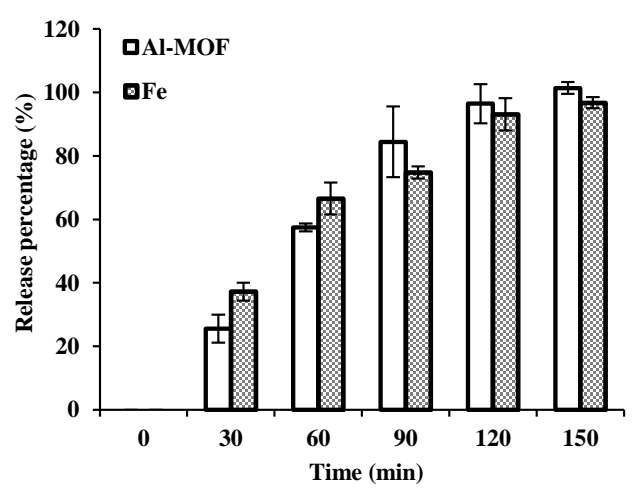

(f) 15$]$ - Al-MOF-alginate-Fe(III) in $200 \mathrm{mM} \mathrm{NaCit}$

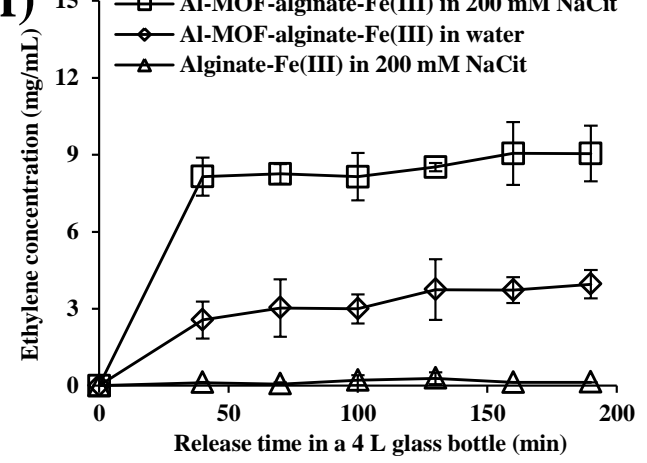

Fig. 15 (a) The schematic of ripening strategy by ethylene loaded Cu-TPA (left) and morphology of Cu-TPA crystals observed by SEM (right). The simulated unit cell structure of $\mathrm{Cu}$-TPA was shown on the top right corner. ${ }^{[218]}$ (b) The schematic of ripening strategy by sodium citrate triggered release of ethylene from egg-box structural alginate-Fe ${ }^{3+}$ coated ethylene-Al-MOF. (c) The morphology of Al-MOF crystal observed by SEM with a simulated molecular structure shown on the top right corner. (d)The cross section morphology of dried Al-MOF in alginate-Fe ${ }^{3+}$ composites observed by using a SEM. (e) The dynamic release of Al-MOF and $\mathrm{Fe}^{3+}$ from Al-MOF in alginate-Fe ${ }^{3+}$ composites in $200 \mathrm{mM}$ sodium citrate 
aqueous solution without $\mathrm{pH}$ adjustment. (f) The kinetics of ethylene release from $43 \mathrm{mg}$ of dried ethylene loaded $\mathrm{Al}-\mathrm{MOF}$-alginate-Fe ${ }^{3+}$ composites in $10 \mathrm{~mL}$ of $200 \mathrm{mM}$ sodium citrate aqueous solution and water in a $4 \mathrm{~L}$ container. The same mass dried alginate- $\mathrm{Fe}^{3+}$ composites were dispersed in $10 \mathrm{~mL}$ of $200 \mathrm{mM}$ sodium citrate aqueous solution as control. ${ }^{[13]}$ The (a) is adapted and reprinted with permission from reference of 218 Copyright 2016 American Chemical Society; (b)-(f) adapted and reprinted with permission from reference of 13, copyright 2019 Elsevier.

ethylene and benzene group in ligands, and van der Waals interaction force were considered to maintain ethylene in MOF pore cavity to a thermal dynamic stability, ${ }_{,}^{[220]}$ which was a potential in practical application for flexibly regulating the ripening of fruits and vegetables.

Additionally, removing ethylene is a strategy to control the fruit and vegetable ripening and to attain the aim of shelflife extension. Huang et al. developed a palladium-platinum in ZIF-8 (PtPd@ZIF-8) nano-sized photo-catalyst that was capable of capturing ethylene and subsequently oxidizing toCO $\mathrm{CO}_{2}$ at room temperature. ${ }^{[221]}$ All these studies suggested MOFs are promising to regulate fruit and vegetable ripening.

\subsection{Removal of moisture and oxygen}

The moisture and oxygen contents seriously affect the quality of food, generating higher water activity for pathogen contamination and lipid oxidation, and therefore result in safety and quality concerns to human health. ${ }^{[222,223]}$ Removal of moisture and oxygen is necessary to improve food quality in food postharvest and preservation.

Wang et al. firstly reported the moisture adsorption by HKUST-1 (Cu-BTU) in 2002. ${ }^{[224]}$ The HKUST-1 presented advantages including its large specific surface area (normally in a range of $\left.600-1600 \mathrm{~m}^{2} / \mathrm{g}\right)$, large pore volume $\left(\sim 0.70 \mathrm{~cm}^{3} / \mathrm{g}\right)$, and good thermal stability (thermally stable up to $\left.350{ }^{\circ} \mathrm{C}\right) .{ }^{[225,226]}$ The moisture adsorption capacity of HKUST-1 (Cu-BTC) at $25^{\circ} \mathrm{C}$ and ambient pressure was measured to be $33.3 \mathrm{mmol} / \mathrm{g}$ (i.e. $0.6 \mathrm{~g} / \mathrm{g}$ ). ${ }^{[226]} \mathrm{Kim}$ et al. designed a device based on a porous MOF- $801\left[\mathrm{Zr}_{6} \mathrm{O}_{4}(\mathrm{OH})_{4}(\text { fumarate })_{6}\right]$ and demonstrated that this MOF-801 device could effectively capture moisture from the atmosphere in ambient conditions by using low-grade heat from natural sunlight at less than 1 solar flux (1 kilowatt per square meter). The fabricated MOF801 crystals showed an average diameter of $\sim 0.6 \mu \mathrm{m}$, which could absorb 2.8 liters of water by 1 kilogram of MOF-801 (i.e. $2.8 \mathrm{~g} / \mathrm{g}$ ) at a relative lower humidity level of $20 \%$ without extra energy. ${ }^{[22]}$ This research provided a valuable strategy to develop novel moisture capturer agents in food storage. Yan et al. developed a MIL-101(Cr)-graphite oxide (GO) composite (MIL-101@GO-6) with 6\% GO homogeneously distributed in MIL-101, which showed ultrahigh Langmuir specific surface area $\left(5188 \mathrm{~m}^{2} / \mathrm{g}\right)$ and pore volume $\left(1.78 \mathrm{~cm}^{3} / \mathrm{g}\right)$, and therefore super-high moisture capture efficiency up to $1.58 \mathrm{~g} / \mathrm{g}$, about 6 times greater than that of conventional silica gel adsorbent. ${ }^{[227]}$

Zhang et al. presented an interesting strategy to improve the selective adsorption of oxygen at room temperature using a synthetic ferrocene in MIL-101 composites. ${ }^{[228]}$ The ferrocene was loaded in heated MIL-101 by a vapordeposition method at $120^{\circ} \mathrm{C}$, reaching a maximum theoretical loading value of $1.2 \mathrm{~g}$ of ferrocene per gram of MIL-101 (i.e., 4.5 ferrocene per formula unit) within $\sim 72 \mathrm{~h}$. This synthetic ferrocene in MIL-101 composite showed a remarkable absorption capacity of oxygen compared to MIL-101 only after activated at temperatures of 200 to $350{ }^{\circ} \mathrm{C}$, which suggested a significant oxygen separation and removal capacity against nitrogen, carbon dioxide, and argon, and provided a potential to prevent the autoxidation of food components in storage.

\subsection{Control-release of antimicrobials}

Volatile natural antimicrobial essential oils such as eugenol, thymol, and carvacrol showed a high-effective antimicrobial activity. ${ }^{[229]}$ The phenolic hydroxyl group of these essential oil molecules can destroy the bio-membrane of bacteria, and further enter into the bacterial cell to disturb the ion equilibrium and $\mathrm{pH}$ homeostasis of cytoplasm. ${ }^{[230]}$ Moreover, these essential oil molecules are capable of binding with membrane proteins and intracellular targets, and therefore break the citrate metabolic pathway and adenosine triphosphate synthesis. ${ }^{[230]}$ It is important that these antimicrobial essential oils are edible safe, ${ }^{[231]}$ and are promising to be utilized as food preservatives. Instability and uncontrollable release of essential oils severely restricts their practical application in food storage and preservation.

Conventional methods for encapsulating antimicrobial essential oils into micro- or nano-sized soft matters are oil-inwater dispersions such as micelles and emulsions built by small molecular surfactants, biopolymers, and Pickering-type particles with thermodynamic stability in aqueous. ${ }^{[232,233]}$ Recently, a concept of employing MOFs as carriers for antimicrobial essential oil encapsulation and flexible release was reported by $\mathrm{Wu}$ et al. and was considered as a rudiment to develop novel solid antimicrobial agents in food sterilization. ${ }^{[234]}$ These authors developed a Zn-MOF (i.e., IRMOF-3) with hexahedron structure to load thymol through self-absorption. The BET specific surface area and average pore size of the fabricated IRMOF-3 were $617.53 \mathrm{~m}^{2} / \mathrm{g}$ and 3.0 $\mathrm{nm}$, respectively, and therefore with a thymol loading capacity of $3.96 \%$. The $\pi-\pi$ stacking interaction between ligands and thymol and cation- $\pi$ interaction between unsaturated metal clusters and benzene group of thymol were considered as the primary conjugating sites maintaining thymol in IRMOF-3. In addition, the zeta-potential of IRMOF-3 is positive in neutral, resulting in a robust conjugation with negatively changed Gram-negative or Gram-positive bacteria through electrostatic attraction, suggesting a high-efficiency delivery pathway of thymol molecules from IRMOF-3 to bacterial cells. Both the electrostatic interaction and thymol bioactivity endowed thymol in IRMOF-3 complexes a significant antimicrobial activity against Escherichia coli (E. coli) $\mathrm{O} 157: \mathrm{H} 7$ by achieving $4.4 \mathrm{Log}$ reduction in $24 \mathrm{~h}$. 


\section{Perspectives}

The MOFs have been developed and applied as adsorbents, carriers, and sensors in food safety and preservation with potential scale-up to industrial level attributed to the abovementioned advantages. The MOF synthesis methods, crystallization mechanisms, structure and surface properties, as well as successful applications in organic and inorganic pollutant detection and removal in food samples, sterilization, and fruit and vegetable postharvest preservation have been discussed in this review. Two perspectives focusing on the applications of MOFs, i.e., development of food-grade safe MOFs and functionalized MOF composites are suggested for further contributing to food safety and quality based on our understanding.

\subsection{Food-grade MOFs}

In most cases, MOFs are generally non-recyclable caused by the potential safety uncertain and confirmed toxins of metal ions and organic linkers, which limit the practical application as food-grade agents. Therefore, developing biocompatible and food-grade MOFs with biologically acceptable metal ions like $\mathrm{Ca}, \mathrm{K}, \mathrm{Ti}$, and $\mathrm{Zn}$, and nontoxic linkers such as amino acids, peptides, cyclodextrin (CD), and carboxylic acids can provide a solution to overcome such issues. ${ }^{[80,81,235]}$

In 2010, Smald one and co-workers reported an edible MOF via green synthesis of biocompatible metal ions of potassium and sodium linking $\gamma$-cyclodextrin $(\gamma-C D)$ unit with a body-centered cubic structure in aqueous media at ambient temperature and pressure, denoted as the CD-MOF-1 with an empirical formula of $\left[\left(\mathrm{C}_{48} \mathrm{H}_{80} \mathrm{O}_{40}\right)(\mathrm{KOH})_{2}\right]_{\mathrm{n}}{ }^{\left[{ }^{[81]}\right.} \mathrm{The} \gamma-\mathrm{CD}$ is a symmetrical cyclic oligosaccharide comprising of eight asymmetric $\alpha$-1,4-linked D-glucopyranosyl residues, which is primarily prepared by the enzyme hydrolysis of starch in food industry. ${ }^{\left[{ }^{[1]}\right.}$ The central metal ions like potassium ion from potassium chloride or potassium benzoate (food additive $\mathrm{E}_{212}$ ) are biologically acceptable, and have been approved as food additives. ${ }^{[236]}$ That means that the CD-MOF-1 can be entirely synthesized from edible ingredients without toxicity. The synthesis route of CD-MOF-1 was through a simple mixing of $\gamma$-CD $(1.30 \mathrm{~g}, 1 \mathrm{mmol})$ and potassium hydroxide $(\mathrm{KOH}, 0.45$ $\mathrm{g}, 8 \mathrm{mmol})$ in water $(20 \mathrm{~mL})$ with subsequent methanol vapor diffusion into the $\gamma-\mathrm{CD} /$ potassium hydroxide solution to lower CD-MOF-1 solubility and to precipitate the supersaturated CD-MOF-1 from solution during a period of one week Further investigation of the CD-MOF-1 structural properties found that there were two coordination types of potassium ion with D-glucopyranosyl residue. That is, one potassium ion linked two contiguous $\gamma$-CD sides through coordination bond with the oxygen atom of $\mathrm{C} 6$ linked hydrogen bond group $(\mathrm{K}$ $\mathrm{O}$ bond, $2.843 \AA$ ) and glycosidic oxygen atom (K-O bond, $2.824 \AA$ ) of a D-glucopyranosyl residue on the primary face to build the first coordination type. Also, one potassium ion linked two contiguous pairs through coordination bond with oxygen atoms of carbon 2 (K-O bond, $2.787 \AA$ ) and carbon 3
(K-O bond, $2.954 \AA$ ) linked hydrogen bond groups of another independent D-glucopyranosyl residue on the secondary face to build second coordination type. Both these two coordination types of potassium ion with D-glucopyranosyl residue alternatively linked together to form a $\gamma$-CD unit with totally eight D-glucopyranosyl residues. Overall, such six coordinatelinked $\gamma-C D$ units assembled through four potassium ions associating with the carbon 6 hydrogen bond groups and the glycosidic ring oxygen atoms of four sites of Dglucopyranosyl residues on the primary faces of the $\gamma$-CD tori. Further, the 3D cubes with six $\gamma$-CD units occupied the faces defined as the $(\gamma-\mathrm{CD})_{6}$ were built by the coordination linked four potassium ions to the $\mathrm{C} 2$ and $\mathrm{C} 3$ hydrogen bond groups of the other sites of D-glucopyranosyl residues on the secondary faces of the $\gamma$-CD tori. This CD-MOF-1 showed a BET specific surface area of $1220 \mathrm{~m}^{2} / \mathrm{g}$ and pore density of $0.47 \mathrm{~g} / \mathrm{cm}^{3}{ }^{3}{ }^{[8]}$ Referring the above method, Moussa and coworker successfully utilized the CD-MOF-1 to encapsulate curcumin and fabricated stable complexes via the hydrogen bond interaction between the hydrogen bond group of Dglucopyranosyl residues of CD-MOF-1 and the phenolic hydroxyl group of the curcumin, which showed a more than 3fold enhancement of stability of curcumin at $\mathrm{pH} 11.5$ in aqueous compared to free curcumin or curcumin in $\gamma$ cyclodextrin. ${ }^{[235]}$ Further study employed $\gamma$-CD-MOFs to encapsulate vitamin A palmitate (VAP) with a loading capability of $9.77 \%$, and found that the loaded VAP in $\gamma$-CDMOFs without addition of any antioxidants showed a better stability with 1.6-fold extended half-life compared to that of a best available reference product. ${ }^{[237]}$ Recently, various CDMOFs through the coordination linking of $\alpha-\mathrm{CD}$ $\left[\mathrm{K}_{3}\left(\mathrm{C}_{36} \mathrm{H}_{60} \mathrm{O}_{30}\right)_{2} \cdot 7 \mathrm{H}_{2} \mathrm{O}\right]$ and $\beta-\mathrm{CD} \quad\left[\left(\mathrm{C}_{42} \mathrm{O}_{35} \mathrm{H}_{70}\right)_{2}\right.$ $(\mathrm{NaOH})_{4} \cdot \mathrm{H}_{2} \mathrm{O}$ ] with metal ions were synthesized and revealed similar geometrical structures, which have been applied not only in food packaging, but also in drug delivery, sensor, $\mathrm{CO}_{2}$ capture, insecticide, and separation fields. ${ }^{[80]}$

Lactate is another ligand resource for synthesizing foodgrade MOF, which has been applied in developing safe pesticide formulas. Yang et al. fabricated two chiral MOFs constructed from biocompatible $\mathrm{Ca}^{2+}$ ions binding with the carboxylate and hydroxyl groups of lactate and the carboxylate group of acetate with formulae of $\mathrm{Ca}_{14}(\mathrm{~L}-$ lactate $)_{20}$ (acetate $)_{8}\left(\mathrm{C}_{2} \mathrm{H}_{5} \mathrm{OH}\right)\left(\mathrm{H}_{2} \mathrm{O}\right)(\mathrm{MOF}-1201)$ and $\mathrm{Ca}_{6}(\mathrm{~L}-$ lactate $)_{3}(\text { acetate })_{9}\left(\mathrm{H}_{2} \mathrm{O}\right)(\mathrm{MOF}-1203) .{ }^{[74]}$ The MOF-1201 was synthesized by mixing calcium acetate monohydrate, $(0.071 \mathrm{~g}$, $0.4 \mathrm{mmol})$ and L-(+)-lactic acid $(0.072 \mathrm{~g}, 0.8 \mathrm{mmol})$ in $6 \mathrm{~mL}$ anhydrous ethanol in a $23 \mathrm{~mL}$ Teflon autoclave. The autoclave was then sealed and heated in $120^{\circ} \mathrm{C}$ isothermal oven for 4 days. The MOF-1203 was synthesized in a same manner except that the $\mathrm{L}-(+)$-lactic acid dosage was $0.036 \mathrm{~g}(0.4$ mmol), reaction temperature was $100{ }^{\circ} \mathrm{C}$, and reaction time was 3 days. These two Ca-MOFs had permanent aperture and internal diameter of 7.8 and $9.6 \AA$ (MOF-1201) and 4.6 and $5.6 \AA$ (MOF-1203), respectively, and therefore permanent 
porosities of 430 and $160 \mathrm{~m}^{2} / \mathrm{g}$. Utilizing the MOF-1201 to slowly release the agricultural fumigant of cis-1,3dichloropropene suggested 100 times lower release rate compared to liquid cis-1,3-dichloropropene under the same test condition, which provided a promising strategy to develop a safe carrier for controlled release of pesticides.

Amino acids and peptides are another promising foodgrade MOF ligands because of their free carboxyl and amino groups, ${ }^{[238]}$ comparing to hydroxyl coordination sites from $\mathrm{CD}$ ligands. ${ }^{[239]}$ Anderson et al. overviewed MOF synthesis utilizing amino acids and peptides as biological ligands, ${ }^{[238]}$ and suggested that amino acid-type ligands were flexible in structure attributing to the hydrophilic and hydrophobic as well as polar and non-polar side chains, and therefore provided affluent functions for MOFs. Anokhina et al. synthesized a one-dimensional (1D) Ni-MOF with ligand of aspartate and denoted a chemical formula of $\left[\mathrm{Ni}_{2} \mathrm{O}(\mathrm{l}-\mathrm{Asp})\left(\mathrm{H}_{2} \mathrm{O}\right)_{2}\right] \cdot 4 \mathrm{H}_{2} \mathrm{O}$. ${ }^{[82]}$ $\mathrm{The} \mathrm{Ni}$ ion culture and aspartate ligand linked together to form a helical chain with extended Ni-O-Ni bond. Increasing the reaction $\mathrm{pH}$, a 3D homochiral microporous Ni-aspartate MOF was synthesized, and denoted a chemical formula of $\left[\mathrm{Ni}_{2.5}(\mathrm{OH})(\mathrm{l}-\mathrm{Asp})_{2}\right]_{6.55} \cdot 5 \mathrm{H}_{2} \mathrm{O}$, which built an extended $3 \mathrm{D}$ network with a helical channel diameter of $8 \times 5 \AA .{ }^{[82]}$ This $\left[\mathrm{Ni}_{2.5}(\mathrm{OH})(\mathrm{l}-\mathrm{Asp})_{2}\right] \cdot 6.55 \mathrm{H}_{2} \mathrm{O} \mathrm{Ni}-\mathrm{MOF}$ was synthesized by an achievable operation via mixing $\mathrm{NiCl}_{2}, 1$-aspartic acid, and triethylamine at molar ratio of $1.25: 1: 2.5$, and heated at $150{ }^{\circ} \mathrm{C}$ for 4 days with a final $\mathrm{pH}$ of 7.3. Peptide synthesized by the condensation of amino acids through peptide bonds can be seen as an amino acid-type ligand providing chemical coordination sites with metal ion cultures in MOF synthesis. Recently, dipeptides have been successfully employed as ligands in biological MOF development. Ueda and co-workers synthesized a Zn-dipeptide complex with glycine-thronine as ligand with outstanding $\mathrm{CO}_{2}$ and methane sorption selectivity, and denoted a chemical formula of $\left[\mathrm{Zn}(\mathrm{GlyThr})_{2}\right] \mathrm{H}_{2} \mathrm{O}$. ${ }^{[142]}$ Rabone and co-workers synthesized a Zn-dipeptide MOF with glycine-alanine ligand (denoted as [Zn(GlyAla $\left.)_{2}\right] \cdot$ (solvent)) in $90 \%$ methanol $/ 10 \%$ aqueous $\mathrm{NaOH} .{ }^{[143]}$ From a structural point of view, a zinc ion binds to two carboxylate and amine groups as the four peptide torsions, and forms the maximumsolvent accessible pore area of $29.2 \AA^{2}$ with maximum and minimum dimensions of 6.2 and $3.7 \AA$ respectively, as well as the minimum-solvent accessible pore area of $15.6 \AA^{2}$ with maximum and minimum dimensions of 5.2 and $2.0 \AA$ respectively.

\subsection{MOF composites}

MOF composites are defined as the MOFs are polymerized with other materials, such as organic biopolymers or small molecules, inorganic constituents, etc. to form a series of complexes through covalent or non-covalent bonds. Assembly of metal ions and molecules provides dimensional framework, whilst building composites with other functionalized groups or materials based on the concepts of mechanical unit assembly and optimal alloy design is capable of endowing

(C) Engineered Science Publisher LLC 2020
MOFs more intelligences and functions. Although simple selfassembly of MOFs through coordination link between metal ion cultures and organic ligands has generated potential applications, synthesizing MOF composites is promising to provide wider applications. Based on our knowledge, development of MOF-other functionalized material composites is expected to provide more contributions for future food safety and quality.

The MOF composites have been developed to detect and remove inorganic heavy metals for drink water. Bagheri et al. synthesized a $\mathrm{Fe}_{3} \mathrm{O}_{4}$-pyridine/MOF and successfully applied it for absorbing $\mathrm{Pd}^{2+}$ from water and subsequent determination by flame atomic absorption spectrometry (FAAS) with the relative standard deviation and detection limit of $2.1 \%$ and $0.37 \mathrm{ng} / \mathrm{mL}$, respectively. ${ }^{[240]}$ Sohrabi and co-workers reported an interesting strategy via covalently synthesizing $\mathrm{Fe}_{3} \mathrm{O}_{4-}$ pyridine and further encapsulated into $\mathrm{Cu}-\mathrm{BTC} \mathrm{MOF}$ to fabricate a magnetic MOF composite. ${ }^{[241]}$ The presence of pyridine group in the magnetic MOF compositse enabled to concentrate $\mathrm{Cd}^{2+}$ and $\mathrm{Pb}^{2+}$ ions from water for further quantitative analysis by the FAAS. The enrichment capacity of this MOF composite was $190 \mathrm{mg} / \mathrm{g}$ for both $\mathrm{Cd}^{2+}$ and $\mathrm{Pb}^{2+}$ ions and therefore completed the quantitative analysis with the detection limit of 0.2 and $1.1 \mu \mathrm{g} / \mathrm{L}$ and the relative standard deviations of less than $4.5 \%$. Other functionalized groups and layers such as 4-(thiazolylazo) resorcinol, ${ }^{[22]}$ ethylenediamine, ${ }^{[243]}$ thiol, ${ }^{[244]}$ thiadiazole, ${ }^{[245]}$ benzoyl isothiocyanate, ${ }^{[246]}$ L-cysteine, ${ }^{[247]}$ dipyridylamine, ${ }^{[248]}$ bisquinoline Mannich, ${ }^{[249]} \quad$ 1,5-diph-enylcarbazide, ${ }^{[250]}$ carboxymethylcellulose, ${ }^{[251]}$ cellulose na-nocrystal, ${ }^{252]}$ polydopamine, ${ }^{[253]}$ urea, ${ }^{[254]}$ chitosan, ${ }^{[255]}$ mon-tmorillonite, ${ }^{[256]}$ and even eggshell membrane ${ }^{[257]}$ were also employed to conjugate with MOFs to develop functionalized MOF composites for heavy metal ion determination and removal in water, baby food, vegetable, sea food, etc.

Employing MOF composites to determine and remove organic pollutants such as dyes and antibiotics has also been evaluated. Pei and co-workers fabricated a calcium alginate and gelatin coated $\mathrm{Cu}-\mathrm{BTC}$ MOF composite by using 3D printing, and suggested a MB adsorption efficiency of $99.8 \%$ within 20 min by $0.5 \mathrm{~g}$ of this 3D-printed Cu-BTC MOF composite from $50 \mathrm{~mL}$ of $\mathrm{MB}$ solution at an initial concentration of $20 \mathrm{ppm}$, which was significantly higher than the MB adsorption efficiency of only $43.6 \%$ by alginategelatin scaffolds without MOF. ${ }^{[258]}$ Doping functionalized materials for MOF composite development such as celerium, ${ }^{[259,260]}$ titanium, ${ }^{[261]}$ fumarate, ${ }^{[262]} \mathrm{TiO}_{2},{ }^{[263,264]}$ cellulose nanofibrous, ${ }^{[265]}$ and peroxidase, ${ }^{[266,267]}$ as well as magnetic basic materials ${ }^{[268-270]}$ were also demonstrated to successfully improve dye absorption and removal efficiency. The MOF composites were also applied in determination and removal of antibiotics. Sun and co-workers synthesized a calcium solidified alginate-UiO-66 composite to absorb and remove levofloxacin from water. ${ }^{[271]}$ This calcium solidified alginateUiO-66 composite showed a stable absorption on levofloxacin 
with a removal efficiency higher than $70 \%$ after five cycles. $\mathrm{Du}$ and co-workers synthesized a magnetic $\mathrm{Fe}_{3} \mathrm{O}_{4} @ \mathrm{Cu}_{3}(\mathrm{BTC})_{2}$-embedded polymerized high internal phase emulsion ( $\mathrm{Fe}_{3} \mathrm{O}_{4} @$ $@$ HKUST-1-polyHIPE) monolithic cake, which was employed to concentrate tetracycline antibiotics from food samples and used for HPLCfluorescence detector (HPLC-FLD) in a linear range from 20 to $800 \mathrm{ng} / \mathrm{mL}$ for milk and egg samples, and 20 to $800 \mathrm{ng} / \mathrm{g}$ for chicken muscle and kidney samples with corresponding detection limits in the range of $1.9-4.6$ and $5.5-13.9 \mathrm{ng} / \mathrm{mL}$, and $1.8-3.7$ and $5.3-13.0 \mathrm{ng} / \mathrm{g}$, respectively. ${ }^{[272]}$

The application of MOF composites with functionalized materials in food preservation such as sterilization, fruit and vegetable growth regulation as well as oxygen and water control is relatively scarce with great opportunities and challenges. Based on our understanding and viewpoint, functionalized MOF composites are very promising to contribute to smart material development for food preservation. Finally, we sincerely expect that the trivial contribution of this overview may become a small stepping stone to further promote the scientific research and practical application of MOFs in food.

\section{Abbreviation}

1D: one-dimensional

3D: three-dimensional

AF: acriflavine

Asa: alanine

Asp: aspartate

ATC: 1,3,5,7-adamantanetetracarboxylate

BDC: terephthalate

BET: Brun Auer-Emmett-Teller

bIM: benzimidazole BTN, 6,6',6"-benzene-1,3,5-triyl2,2',2"trinaphthalate

BPDC: 4,4'-biphenyl dicarboxylate

BPTC: 3,3',5,5'-biphenyltetracarboxylate

BTB: 1,3,5-benzenetribenzoate

BTC: benzene-1,3,5-tricarboxylate

BTEC: 1,2,4,5-benzenetetracarboxylate

BTT: 1,3,5-benzenetristetrazolate

BUT-n: Beijing University of Technology

$\mathrm{CaCl}_{2}$ : calcium chloride

CAU-n: Christian Albrechts University

CB: cotton blue

$\mathrm{CD}$ : cyclodextrin

CNT: classic nucleation theory

$\mathrm{CO}_{2}$ : carbon dioxide

CPO-n: Coordination Polymer of Oslo

CTSA: $\quad 3,3^{\prime}, 3^{\prime \prime}, 3^{\prime \prime}$--((9H-carbazole-1,3,6,8-tetrayl)

kis(benzene-4,1-diyl))-tetra acrylate

CTTA: 5'-(4-carboxyphenyl)-2',4',6'-trimethyl-[1,1':3', 1"terphenyl]-4,4"-dicarboxylate

DAD: diode array detector

DHBDC: 2,5-dihydroxybenzenedicarboxylate
DMF: N,N-dimethylformamide

DOT: dioxidoterephthalate

DPV: differential pulse voltammetry

DUT-n: Dresden University of Technology

E. coli: Escherichia coli

ERGO: electrochemically reduced graphene oxide

FA: fuchsin acid

FAAS: flame atomic absorption spectrometry

$\mathrm{Fe}_{3} \mathrm{O}_{4}$ : ferro ferric oxide

FLD: fluorescence detector

Gly: glycine

GO: graphite oxide

$\mathrm{H}_{2} \mathrm{O}$ : water

$\mathrm{H}_{2} \mathrm{Q}$ : hydroquinone

$\mathrm{HCl}$ : hydrochloric acid

HIPE: high internal phase emulsion

HKUST-n: Hong Kong University of Science and Technology

Hmim: 2-methylimidazole

HPDC: 2,7-tetrahydropyrenedicarboxylate

HPLC: high-performance liquid chromatography

HSAB: hard/soft acid/base

HT: high throughput

ICA: imidazolate-2-carboxyaldehyde

IRMOF: is reticular MOF

$\mathrm{KOH}$ : potassium hydroxide

LMOF: luminescent MOF

Ln: lanthanide

MB: methylene blue

Mg: magnesium

MIL-n: Materials of Institute Lavoisier

mIM: 2-methyimidazole

MIP: molecularly imprinted polymers

MO: methyl orange

MOFs: metal-organic frameworks

MTV: multivariate

MTZ: 3-methyl1,2,4-triazole

$\mathrm{NaOH}$ : sodium hydroxide

NBU: nucleation building unit

NDC: 2,6-naphthalenedicarboxylate

$\mathrm{NH}_{2}$ : amino group

nIM: 2-nitroimidazole

NOTT-n: University of Nottingham

NU-n: Northwestern University

NZF: nitrofurazone

OG-II: orange II

PBA: 4-(4-pyridyl) benzoate

PDC: 2,7-pyrenedicarboxylate or 3,5-pyridine-dicarbo -xylate

PNBUs: pre-nucleation building units

tetra- POST-n: Pohang University of Science and Technology

PSS: polystyrene sulfonate

- PTSA: pyrene-1,3,6,8-tetrayltetrakis(benzene-4,1-diyl))

tetraacrylate

QCM: quartz crystal microbalance

SBUs: secondary building units 
SCP: sulfachloropyridazine

SD-III: sudan III

SEM: scanning electron microscope

SOM: stands for single-crystal ordered macropore

TATB: 4,4',4"-s-triazine-2,4,6-triyl-tribenzoate

TCPP: tetrakis(4-carboxyphenyl)porphyrin

TDC: 2,5-thiophenedicarboxylate

TDPAT: $\quad$ 2,4,6-tris(3,5-dicarboxylphenyl-amino)-1,3,5

triazine

TEM: transmission electron microscope

THF: tetrahydrofuran

Thr: thronine

$\mathrm{TiO}_{2}$ : titanium dioxide

TNP: 2,4,6-trinitrophenolTPA: terephthalate

TPPE: 1,1,2,2-tetrakis(4-(pyridin-4-yl) phenyl) ethane

TTNA: $6,6^{\prime}, 6^{\prime \prime}-(2,4,6$-trimethylbenzene-1,3,5-triyl) tris (2naphthoyloxy))

UiO-n: University of Oslo

UMCM-n: University of Michigan Crystalline Material

UTSA-n: University of Texas at San Antonio

VAP: vitamin A palmitate

XRD: X-Ray Diffraction

ZIFs: zeolitic imidazolate frameworks

\section{Acknowledgements}

The authors acknowledge financial support from the National Natural Science Foundation of China, award number 31871845.

\section{Supporting Information}

Not applicable

\section{Conflict of interest}

There are no conflicts to declare.

\section{References}

[1] T. Duncan, J. Colloid Interf. Sci., 2011, 363, 1-24, doi: 10.1016/j.jcis.2011.07.017.

[2] F. Stintzing and R. Carle, Trends Food Sci. Tech., 2004, 15, 19-38, doi: 10.1016/j.tifs.2003.07.004

[3] E. Shimoni, J. Food Sci., 2013, 69, R160-R166, doi: 10. 1111/j.1365-2621.2004.tb11005.x.

[4] A. Schieber, F. Stintzing and R. Carle, Trends Food Sci. Tech., 2001, 12, 401-413, doi: 10.1016/S0924-2244(02)00012-2.

[5] A. Rossmann, Food Rev. Int., 2001, 17, 347-381, doi: 10. 1081/FRI-100104704.

[6] H. Almasi, S. Azizi and S. Amjadi, Food Hydrocolloid., 2020, 99, 105338, doi: 10.1016/j.foodhyd.2019.105338.

[7] Y. Luo, Y. Zhang, K. Pan, F. Critzer, P. M. Davidson and Q. Zhong, J. Agr. Food Chem., 2014, 62, 4417-4424, doi: 10.1021/jf500698k.

[8] Y. Zhang, K. Pan and Q. Zhong, Food Biophys., 2018, 13, 37-48, doi: 10.1007/s11483-017-9509-0.

[9] J. Xue, P. M. Davidson and Q. Zhong, J. Agr. Food Chem., 2013, 61, 12720-12726, doi: 10.1021/jf4043437.
[10] S. Saadat, G. Pandey, M. Tharmavaram, V. Braganza and D. Rawtani, Adv. Colloid Interfac., 2020, 275, 102063, doi: 10. 1016/j.cis.2019.102063.

[11] M. Kashiri, J. Cerisuelo, I. Domínguez, G. López-Carballo, V. Muriel-Gallet, R. Gavara and P. Hernández-Muñoz, Food Hydrocolloid., 2017, 70, 260-268, doi: 10.1016/j.foodhyd.2017. 02.021 .

[12] H. Chi, S. Song, M. Luo, C. Zhang, W. Li, L. Li and Y. Qin, Sci. Horticulturae, 2019, 249, 192-198, doi: 10.1016/j.scienta.2019.01.059.

[13] Y. Guan, Z. Teng, L. Mei, J. Zhang, Q. Wang and Y. Luo, J. Colloid Interf. Sci., 2019, 533, 207-215, doi: 10.1016/j.jcis.2018.08.057.

[14] W. Zhang, C. Liu, F. Liu, X. Zou, Y. Xu and X. Xu, Food Chem., 2020, 303, 125378, doi: 10.1016/j.foodchem.2019.125378.

[15] J. Hu, X. Yang, Q. Peng, F. Wang, Y. Zhu, X. Hu, B. Zheng, J. Du and D. Xiao, Food Control, 2020, 108, 106832, doi: 10.1016/j.foodcont.2019.106832.

[16] Y. Fang, J. Fu, P. Liu and B. Cu, Ind. Crop. Prod., 2020, 143, 111939, doi: 10.1016/j.indcrop.2019.111939.

[17] C. Fontes-Candia, E. Erboz, A. Martínez-Abad, A. López-Rubio and M. Martínez-Sanz, Food Hydrocolloid., 2019, 96, 151-160, doi: 10.1016/j.foodhyd.2019.05.011.

[18] B. F. Hoskins and R. Robson, J. Am. Chem. Soc., 1989, 111, 59625964, doi: 10.1021/ja00197a079.

[19] O. M. Yaghi, G. Li and H. Li, Nature, 1995, 378, 703-706, doi: 10.1038/378703a0.

[20] N. L. Rosi, J. Kim, M. Eddaoudi, B. Chen, M. O'Keeffe and O. M. Yaghi, J. Am. Chem. Soc., 2005, 127, 1504-1518, doi: 10.1021/ja045123o.

[21] F. Bigdeli, C. T. Lollar, A. Morsali and H. C. Zhou, Angew. Chem. Int. Edit., 2020, 59, 4652-4669, doi: 10.1002/anie.201900666.

[22] H. Kim, S. Yang, S. R. Rao, S. Narayanan, E. A. Kapustin, H. Furukawa, A. S. Umans, O. M. Yaghi and E. N. Wang, Science, 2017, 356, 430-432, doi: 10.1126/science.aam8743.

[23] J. A. Mason, J. Oktawiec, M. Taylor, M. Hudson, J. Rodriguez, J. Bachman, M. Gonzalez, A. Cervellino, A. Guagliardi, C. Brown, P. Llewellyn, N. Masciocchi and J. Long, Nature, 2015, 527, $357-$ 361, doi: 10.1038/nature15732.

[24] H. Deng, S. Grunder, K. Cordova, C. Valente, H. Furukawa, M. Hmadeh, F. Gandara, A. Whalley, Z. Liu, S. Asahina, H. Kazumori, M. O'Keeffe, O. Terasaki, J. Stoddart and O. Yaghi, Science, 2012, 336, 1018-1023, doi: 10.1126/science.1220131.

[25] K. Shen, L. Zhang, X. Chen, L. Liu, D. Zhang, Y. Han, J. Chen, J. Long, R. Luque, Y. Li and B. Chen, Science, 2018, 359, 206-210, doi: 10.1126/science.aao3403.

[26] S. Wang, J. Lee, M. Wahiduzzaman, J. Park, M. Muschi, C. Martineau-Corcos, A. Tissot, K. Cho, J. Marrot, W. Shepard, G. Maurin, J. Chang and C. Serre, Nat. Energy 2018, 3, 985-993, doi: 10.1038/s41560-018-0261-6.

[27] C. Sun, C. Qin, C. Wang, Z. Su, S. Wang, X. Wang, G. Yang, K. Shao, Y. Lan and E. Wang, Adv. Mater., 2011, 23, 5629-5632, doi: 10.1002/adma.201102538.

[28] H. Wen, B. Li, L. Li, R. Lin, W. Zhou, G. Qian and B. Chen, $A d v$. Mater, 2018, 30, 1704792, doi: 10.1002/adma.201704792. 
[29] T. Devic, C. Serre, N. Audebrand, J. Marrot and G. Ferey, J. Am. Chem. Soc., 2005, 127, 12788-12789, doi: 10.1021/ja053992n.

[30] O. Farha, I. Eryazici, N. Jeong, B. Hauser, C. Wilmer, A. Sarjeant, R. Snurr, S. Nguyen, A. Yazaydin and J. Hupp, J. Am. Chem. Soc., 2012, 134, 15016-15021, doi: 10.1021/ja3055639.

[31] A. Lanza, L. S. Germann, M. Fisch, N. Casati and P. Macchi, J. Am. Chem. Soc., 2015, 137, 13072-13078, doi: 10.1021/jacs.5b09231.

[32] S. Henke, M. T. Wharmby, G. Kieslich, I. Hante, A. Schneemann, Y. Wu, D. Daisenberger and A. K. Cheetham, Chem. Sci., 2018, 9, 1654-1660, doi: 10.1039/c7sc04952h.

[33] G. Smith, J. Eyley, X. Han, X. Zhang, J. Li, N. Jacques, H. Godfrey, S. Argent, L. McPherson, S. Teat, Y. Cheng, M. Frogley, G. Cinque, S. Day, C. Tang, T. Easun, S. Rudić, A. Ramirez-Cuesta, S. Yang and M. Schröder, Nat. Mater., 2019, 18, 1358-1365, doi: 10.1038/s41563-019-0495-0.

[34] M. Chen, Y. Feng, S. Wang, Y. Cheng and Z. Zhou, ACS Appl. Mater. Inter., 2020, 12, 1412-1418, doi: 10.1021/acsami.9b20184.

[35] L. Li, R. Lin, R. Krishna, H. Li, S. Xiang, H. Wu, J. Li, W. Zhou and B. Chen, Science, 2018, 362, 443-446, doi: 10.1126/ science.aat 0586 .

[36] H. Furukawa, K. E. Cordova, M. O'Keeffe and O. M. Yaghi, Science, 2013, 341, 1230444, doi: 10.1126/science.1230444.

[37] X. Cui, K. Chen, H. Xing, Q. Yang, R. Krishna, Z. Bao, H. Wu, W. Zhou, X. Dong, Y. Han, B. Li, Q. Ren, M. Zaworotko and B. Chen, Science, 2016, 353, 141-144, doi: 10.1126/science. aaf2458.

[38] A. Cadiau, K. Adil, P. M. Bhatt, Y. Belmabkhout and M. Eddaoudi, Science, 2016, 353, 137-140, doi: 10.1126/science. aaf6323.

[39] P. Nugent, E. G. Giannopoulou, S. Burd, O. Elemento, E. Giannopoulou, K. Forrest, T. Pham, S. Ma, B. Space, L. Wojtas, M. Eddaoudi and M. Zaworotko, Nature, 2013, 495, 80-84, doi: 10.1038/nature11893.

[40] S. Kitagawa, R. Kitaura and S. Noro, Angew. Chem. Int. Edit., 2004, 43, 2334-2375, doi: 10.1002/anie.200300610.

[41] J. Li, R. Kuppler and H. Zhou, Chem. Soc. Rev., 2009, 38, $1477-$ 1504, doi: 10.1039/b802426j.

[42] H. Li, M. Eddaoudi, M. O'Keeffe and O. M. Yaghi, Nature, 1999, 402, 276-279, doi: 10.1038/46248.

[43] J. Li, J. Sculley and H. Zhou, Chem. Rev., 2012, 112, 869-932, doi: $10.1021 / \mathrm{cr} 200190 \mathrm{~s}$.

[44] J. Seo, D. Whang, H. Lee, S. Jun, J. Oh, Y. Jeon and K. Kim, Nature, 2000, 404, 982-986, doi: 10.1038/35010088.

[45] J. Lee, O. K. Farha, J. Roberts, K. A. Scheidt, S. T. Nguyen and J. T. Hupp, Chem. Soc. Rev., 2009, 38, 1450-1459, doi: 10.1039/b807080f.

[46] P. Horcajada, R. Gref, T. Baati, P. Allan, G. Maurin, P. Couvreur, G. Ferey, R. Morris and C. Serre, Chem. Rev., 2012, 112, 12321268, doi: $10.1021 / \mathrm{cr} 200256 \mathrm{v}$.

[47] J. Rocca, D. Liu and W. Lin, Acc. Chem. Res., 2011, 44, 957-968, doi: 10.1021/ar200028a.

[48] P. Horcajada, C. Serre, M. Vallet-Regi, M. Sebban, F. Taulelle and G. Ferey, Angew. Chem. Int. Edit., 2006, 45, 5974-5978, doi: 10.1002/anie.200601878.
[49] P. Horcajada, C. Serre, G. Maurin, N. A. Ramsahye, F. Balas, M. Vallet-Regi, M. Sebban, F. Taulelle and G. Ferey, J. Am. Chem. Soc., 2008, 130, 6774-6780, doi: 10.1021/ja710973k.

[50] K. M. L. Taylor-Pashow, J. D. Rocca, Z. Xie, S. Tran and W. Lin, J. Am. Chem. Soc., 2009, 131, 14261-14263, doi: 10.1021/ ja906198y.

[51] J. An, S. Geib and N. Rosi, J. Am. Chem. Soc., 2009, 131, 83768377, doi: 10.1021/ja902972w.

[52] L. E. Kreno, K. Leong, O. K. Farha, M. Allendorf, R. P. V. Duyne and J. T. Hupp, Chem. Rev., 2012, 112, 1105-1125, doi: $10.1021 / \mathrm{cr} 200324 \mathrm{t}$.

[53] G. Lu and J. T.Hupp, J. Am. Chem. Soc., 2010, 132, 7832-7833, doi: $10.1021 /$ ja101415b.

[54] X. Z. Song, S. Y. Song, S. N. Zhao, Z. M. Hao, M. Zhu, X. Meng, L. L. Wu and H. J. Zhang, Adv. Funct. Mater, 2014, 24, 4034-4041, doi: 10.1002/adfm.201303986.

[55] L. Jiao, J. Y. R. Seow, W. S. Skinner, Z. U. Wang and H. L. Jiang, Mater. Today, 2019, 27, 43-68, doi: 10.1016/j.mattod. 2018.10.038.

[56] C. Serre, F. Millange, C. Thouvenot, M. Noguès, G. Marsolier, D. Louër and G. Férey, J. Am. Chem. Soc., 2002, 124, 13519-13526, doi: $10.1021 /$ ja0276974.

[57] S. Devautour-Vinot, G. Maurin, F. Henn, C. Serre and G. Férey, Phys. Chem. Chem. Phys., 2010, 12, 12478-12485, doi: 10.1039/ c0cp00142b.

[58] N. Burtch, H. Jasuja and K. Walton, Chem. Rev., 2014, 114, 1057510612, doi: 10.1021/cr5002589.

[59] M. Tu, S. Wannapaiboon, K. Khaletskaya and R. A. Fischer, $A d v$. Funct. Mater, 2015, 25, 4470-4479, doi: 10.1002/adfm.2015 00760 .

[60] I. Cabria, M. J. Lopez and J. A. Alonso, Phys. Rev. B, 2008, 78, 205432, doi: 10.1103/PhysRevB.78.205432.

[61] Y. Ban, Y. Li, X. Liu, Y. Peng and W. Yang, Micropor. Mesopor. Mat., 2013, 173, 29-36, doi: 10.1016/j.micromeso.2013.01.031.

[62] M. Vleet, T. Weng, X. Li and J. Schmidt, Chem. Rev., 2018, 118, 3681-3721, doi: 10.1021/acs.chemrev.7b00582.

[63] A. Aerts, C. E. A. Kirschhock and J. A. Martens, Chem. Soc. Rev., 2010, 39, 4626-4642, doi: 10.1039/b919704b.

[64] P. W. Voorhees, J. Stat. Phys., 1985, 38, 231-252, doi: 10.1007/ BF01017860.

[65] J. Cravillon, C. A. Schroder, H. Bux, A. Rothkirch, J. Caro and M. Wiebcke, CrystEngComm, 2012, 14, 492-498, doi: 10.1039/c1ce06002c.

[66] S. R. Venna, J. B. Jasinski and M. A.Carreon, J. Am. Chem. Soc., 2010, 132, 18030-18033, doi: 10.1021/ja109268m.

[67] X. Chen, M. Qiao, S. Xie, K. Fan, W. Zhou and Y. He, J. Am. Chem. Soc., 2007, 129, 13305-13312, doi: 10.1021/ja074834u.

[68] K. Self, M. Telfer, H. Greer and W. Zhou, Chem-Eur. J., 2015, 21, 19090-19095, doi: 10.1002/chem.201503437.

[69] Y. Wang, L. Li, H. Liang, Y. Xing, L. Yan, P. Dai, X. Gu, G. Zhao and X. Zhao, ACS Nano, 2019, 13, 2901-2912, doi: 10.1021/acsnano.8b06706.

[70] F. A. A. Paz, J. Klinowski, S. M. F. Vilela, J. P. C. Tome, J. A. S. Cavaleiro and J. Rocha, Chem. Soc. Rev., 2012, 41, 1088-1110, doi: $10.1039 / \mathrm{c} 1 \mathrm{cs} 15055 \mathrm{c}$. 
[71] H. C. J. Zhou and S. Kitagawa, Chem. Soc. Rev., 2014, 43, 54155418, doi: 10.1039/c4cs90059f.

[72] X. Lin, I. Telepeni, A. J. Blake, A. Dailly, C. M. Brown, J. M. Simmons, M. Zoppi, G. S. Walker, K. M. Thomas, T. J. Mays, P. Hubberstey, N. R. Champness and M. Schröder, J. Am. Chem. Soc., 2009, 131, 2159-2171, doi: 10.1021/ja806624j.

[73] N. Stock and S. Biswas, Chem. Rev., 2012, 112, 933-969, doi: $10.1021 / \mathrm{cr} 200304 \mathrm{e}$.

[74] J. Yang, C. A. Trickett, S. B. Alahmadi, A. S. Alshammari and O. M. Yaghi, J. Am. Chem. Soc., 2017, 139, 8118-8121, doi: 10.1021/jacs.7b04542.

[75] R. Banerjee, A. Phan, B. Wang, C. Knobler, H. Furukawa, M. O'Keeffe and O. M. Yaghi, Science, 2008, 319, 939-943, doi: $10.1126 /$ science. 1152516 .

[76] W. Liang, H. Xu, F. Carraro, N. K. Maddigan, Q. Li, S. G. Bell, D. M. Huang, A. Tarzia, M. B. Solomon, H. Amenitsch, L. Vaccari, C. J. Sumby, P. Falcaro and C. J. Doonan, J. Am. Chem. Soc., 2019, 141, 2348-2355, doi: 10.1021/jacs.8b10302.

[77] K. Sumida, S. Horike, S. Kaye, Z. Herm, W. Queen, C. Brown, F. Grandjean, G. Long, A. Dailly and J. Long, Chem. Sci., 2010, 1, 184-191, doi: 10.1039/c0sc00179a.

[78] H. M. Wen, C. Liao, L. Li, A. Alsalme, Z. Alothman, R. Krishna, H. Wu, W. Zhou, J. Hu and B. Chen, J. Mater. Chem. A, 2019, 7, 3128-3134, doi: 10.1039/c8ta11596f.

[79] H. Li, L. Li, R. Lin, G. Ramirez, W. Zhou, R. Krishna, Z. Zhang, S. Xiang and B. Chen, ACS Sustain. Chem. Eng., 2019, 7, 48974902, doi: 10.1021/acssuschemeng.8b05480.

[80] T. Rajkumar, D. Kukkar, K. H. Kim, J. R. Sohn and A. Deep, J. Ind. Eng. Chem., 2019, 72, 50-66, doi: 10.1016/j.jiec.2018.12.048.

[81] R. Smaldone, R. Forgan, H. Furukawa, J. Gassensmith, A. Slawin, O. Yaghi and J. Stoddart, Angew. Chem. Int. Edit., 2010, 49, 86308634, doi: 10.1002/anie.201002343.

[82] E. Anokhina, Y. Go, Y. Lee, T. Vogt and A. Jacobson, J. Am. Chem. Soc., 2006, 128, 9957-9962, doi: 10.1021/ja062743b.

[83] B. Wang, X. L. Lv, D. Feng, L. H. Xie, J. Zhang, M. Li, Y. Xie, J. R. Li and H. C. Zhou, J. Am. Chem. Soc., 2016, 138, 6204-6216, doi: $10.1021 /$ jacs.6b01663.

[84] H. Reinsch, M. Krüger, J. Wack, J. Senker, F. Salles, G. Maurin and N. Stock, Micropor. Mesopor. Mat., 2012, 157, 50-55, doi: 10.1016/j.micromeso.2011.05.029.

[85] K. Kongshaug and H. Fjellvåg, Inorg. Chem., 2006, 45, 2424-2429, doi: $10.1021 / \mathrm{ic} 050662 \mathrm{v}$.

[86] F. Bonino, S. Chavan, J. Vitillo, E. Groppo, G. Agostini, C. Lamberti, P. Dietzel, C. Prestipino and S. Bordiga, Chem. Mater, 2008, 20, 4957-4968, doi: 10.1021/cm800686k.

[87] P. Dietzel, P. Georgiev, J. Eckert, R. Blom, T. Strässle and T. Unruh, Chem. Commun., 2010, 46, 4962-4964, doi: 10.1039/ c0cc00091d.

[88] S. M. Chavan, G. C. Shearer, E. Bloch and S. Bordiga, ChemPhysChem, 2012, 13, 445-448, doi: 10.1002/cphc.2011 00950.

[89] M. J. Katz, A. J. Howarth, P. Z. Moghadam, J. B. DeCoste, R. Q. Snurr, J. T. Hupp, O. K. Farha, Dalton T., 2016, 45, 4150-4153, doi: $10.1039 / \mathrm{c} 5 \mathrm{dt} 03436 \mathrm{a}$.

[90] J. Xu, R. Sinelnikov and Y. Huang, Langmuir, 2016, 32, 5468-5479, doi: 10.1021/acs.langmuir.6b00851.
[91] V. Bon, I. Senkovska, I. Baburin and S. Kaskel, Cryst. Growth Des., 2013, 13, 1231-1237, doi: 10.1021/cg301691d.

[92] S. Chui, S. Lo, J. Charmant, A. Orpen and I. Williams, Science, 1999, 283, 1148-1150, doi: 10.1126/science.283.5405.1148.

[93] M. Eddaoudi, J. Kim, N. Rosi, D. Vodak, J. Wachter, M. O'Keeffe and O. M. Yaghi, Science, 2002, 295, 469-472, doi: 10.1126/science.1067208.

[94] W. Kaveevivitchai, X. Wang, L. Liu and A. Jacobson, Inorg. Chem., 2015, 54, 1822-1828, doi: 10.1021/ic502730y.

[95] M. Meilikhov, K. Yusenko and R. Fischer, Dalton T., 2010, 39, 10990-10999, doi: 10.1039/c0dt00856g.

[96] L. Hamon, C. Serre, T. Devic, T. Loiseau, F. Millange, G. Férey and G. D. Weireld, J. Am. Chem. Soc., 2009, 131, 8775-8777, doi: 10.1021/ja901587t.

[97] P. Llewellyn, P. Horcajada, G. Maurin, T. Devic, N. Rosenbach, S. Bourrelly, C. Serre, D. Vincent, S. Loera-Serna, Y. Filinchuk and G. Férey, J. Am. Chem. Soc., 2009, 131, 13002-13008, doi: 10.1021/ja902740r.

[98] S. Surblé, C. Serre, C. Mellot-Draznieks, F. Millange and G. Férey, Chem. Commun., 2006, 3, 284-286, doi: 10.1039/b512169h.

[99] C. Serre, F. Millange, S. Surblé and G. Férey, Angew. Chem. Int. Edit., 2004, 43, 6286-6289, doi: 10.1002/anie.200454250.

[100] B. V. D. Voorde, M. Boulhout, F. Vermoortele, P. Horcajada, D. Cunha, J. S. Lee, J. S. Chang, E. Gibson, M. Daturi, J. C. Lavalley, A. Vimont, I. Beurroies and D. E. D. Vos, J. Am. Chem. Soc., 2013, 135, 9849-9856, doi: 10.1021/ja403571z.

[101] G. Férey, C. Serre, C. Mellot-Draznieks, F. Millange, S. Surblé, J. Dutour and I. Margiolaki, Angew. Chem. Int. Edit., 2004, 43, 62966301, doi: 10.1002/anie.200460592.

[102] P. Horcajada, S. Surblé, C. Serre, D. Y. Hong, Y. K. Seo, J. S. Chang, J. M. Grenèche, I. Margiolakid and G. Férey, Chem. Commun., 2007, 27, 2820-2822, doi: 10.1039/b704325b.

[103] R. Grall, T. Hidalgo, J. Delic, A. Garcia-Marquez, S. Chevillard and P. Horcajada, J. Mater. Chem. B, 2015, 3, 8279-8292, doi: $10.1039 / \mathrm{c} 5 \mathrm{tb} 01223 \mathrm{f}$.

[104] G. Férey, C. Mellot-Draznieks, C. Serre, F. Millange, J. Dutour, S. Surblé and I. Margiolaki, Science, 2005, 309, 2040-2042, doi: 10.1126/science.1116275.

[105] Z. Q. Bai, L. Y. Yuan, L. Zhu, Z. R. Liu, S. Q. Chu, L. R. Zheng, J. Zhang, Z. F. Chai and W. Q. Shi, J. Mater. Chem. A, 2015, 3, 525534, doi: 10.1039/c4ta04878d.

[106] C. Volkringer, T. Loiseau, N. Guillou, G. Férey, M. Haouas, F. Taulelle, E. Elkaim and N. Stock, Inorg. Chem., 2010, 49, 98529862, doi: 10.1021/ic101128w.

[107] M. Dan-Hardi, C. Serre, T. Frot, L. Rozes, G. Maurin, C. Sanchez and G. Férey, J. Am. Chem. Soc., 2009, 131, 10857-10859, doi: $10.1021 / \mathrm{ja} 903726 \mathrm{~m}$.

[108] H. Li, M. Eddaoudi, T. L. Groy and O. M. Yaghi, J. Am. Chem. Soc., 1998, 120, 8571-8572, doi: 10.1021/ja981669x.

[109] N. Rosi, J. Eckert, M. Eddaoudi, D. Vodak, J. Kim, M. O'Keeffe and O. Yaghi, Science, 2003, 300, 1127-1129, doi: 10.1126/science. 1083440.

[110] H. Chae, D. Siberio-Pe'rez, J. Kim, Y. Go, M. Eddaoudi, A. Matzger, M. O'Keeffe and O. M. Yaghi, Nature, 2004, 247, 523527, doi: $10.1038 /$ nature 02311 . 
[111] B. Chen, N. Ockwig, A. Millward, D. Contreras and O. Yaghi, Angew. Chem. Int. Edit., 2005, 44, 4745-4749, doi: 10.1002/ anie. 200462787.

[112] H. Mautschke, F. Drache, I. Senkovska, S. Kaskel and F. Xamena, Catal. Sci. Technol., 2018, 8, 3610-3616, doi: 10.1039/c8cy 00742j.

[113] S. Yang, J. Sun, A. Ramirez-Cuesta, S. Callear, W. David, D. Anderson, R. Newby, A. Blake, J. Parker, C. Tang and M. Schröder, Nat. Chem., 2012, 4, 887-894, doi: 10.1038/nchem. 1457.

[114] S. Ma, J. Eckert, P. Forster, W. Ji, K. Young, J. Chang, C. Collier, J. Parise and H. Zhou, J. Am. Chem. Soc., 2008, 130, 15896-15902, doi: $10.1021 /$ ja803492q.

[115] D. Feng, Z. Gu, J. Li, H. Jiang, Z. Wei and H. Zhou, Angew. Chem. Int. Edit., 2012, 51, 10307-10310, doi: 10.1002/anie.201204475.

[116] L. Valenzano, B. Civalleri, S. Chavan, S. Bordiga, M. Nilsen, S. Jakobsen, K. Lillerud and C. Lamberti, Chem. Mater., 2011, 23, 1700-1718, doi: 10.1021/cm1022882.

[117] J. Cavka, S. Jakobsen, U. Olsbye, N. Guillou, C. Lamberti, S. Bordiga and K. Lillerud, J. Am. Chem. Soc., 2008, 130, 1385013851, doi: 10.1021/ja8057953.

[118] K. Koh, A. Wong-Foy and A. Matzger, Angew. Chem. Int. Edit., 2008, 47, 677-680, doi: 10.1002/anie.200705020.

[119] A. Wong-Foy, O. Lebel and A. Matzger, J. Am. Chem. Soc., 2007, 129, 15740-15741, doi: 10.1021/ja0753952.

[120] J. Ma, L. Tran and A. Matzger, Cryst. Growth Des., 2016, 16, 41484153, doi: 10.1021/acs.cgd.6b00698.

[121] Z. Chen, S. Xiang, H. Arman, J. Mondal, P. Li, D. Zhao and B. Chen, Inorg. Chem., 2011, 50, 3442-3446, doi: 10.1021/ ic102347b.

[122] S. Xiang, X. Wu, J. Zhang, R. Fu, S. Hu and X. Zhang, J. Am. Chem. Soc., 2005, 127, 16352-16353, doi: 10.1021/ja0546065.

[123] S. Xiang, Y. He, Z. Zhang, H. Wu, W. Zhou, R. Krishna and B. Chen, Nat. Commun., 2012, 3, 954, doi: 10.1038/ncomms 1956.

[124] Z. Chen, S. Xiang, H. D. Arman, P. Li, D. Zhao and B. Chen, Eur. J. Inorg. Chem., 2011, 14, 2227-2231, doi: 10.1002/ejic. 201100034.

[125] Y. He, Z. Guo, S. Xiang, Z. Zhang, W. Zhou, F. R. Fronczek, S. Parkin, S. T. Hyde, M. O'Keeffe and B. Chen, Inorg. Chem., 2013, 52, 11580-11584, doi: 10.1021/ic401870e.

[126] Y. He, Z. Zhang, S. Xiang, F. R. Fronczek, R. Krishna and B. Chen, Chem.- Eur. J., 2012, 18, 613-619, doi: 10.1002/ chem.201102734.

[127] M. C. Das, H. Xu, S. Xiang, Z. Zhang, H. D. Arman, G. Qian and B. Chen, Chem.- Eur. J., 2011, 17, 7817-7822, doi: 10.1002/ chem.201100350.

[128] H. Xu, Y. He, Z. Zhang, S. Xiang, J. Cai, Y. Cui, Y. Yang, G. Qian and B. Chen, J. Mater. Chem. A, 2013, 1, 77-81, doi: 10.1039/ c2ta00155a.

[129] H. Alawisi, B. Li, Y. He, H. D. Arman, A. M. Asiri, H. Wang and B. Chen, Cryst. Growth Des., 2014, 14, 2522-2526, doi: $10.1021 / \operatorname{cg} 500235 \mathrm{j}$.

[130] F. Luo, C. Yan, L. Dang, R. Krishna, W. Zhou, H. Wu, X. Dong, Y. Han, T. Hu, M. O'Keeffe, L. Wang, M. Luo, R. Lin and B. Chen, J. Am. Chem. Soc., 2016, 138, 5678-5684, doi: 10.1021/jacs.6b02030.
[131] B. Li, H. M. Wen, H. Wang, H. Wu, M. Tyagi, T. Yildirim, W. Zhou and B. Chen, J. Am. Chem. Soc., 2014, 136, 6207-6210, doi: 10.1021/ja501810r.

[132] H. M. Wen, B. Li, D. Yuan, H. Wang, T. Yildirim, W. Zhou and B. Chen, J. Mater. Chem. A, 2014, 2, 11516-11522, doi: 10.1039/c4ta01860e.

[133] W. Yang, G. Chang, H. Wang, T. L. Hu, Z. Yao, K. Alfooty, S. Xiang and B. Chen, Eur. J. Inorg. Chem., 2016, 2016, 4470-4475, doi: 10.1002/ejic.201600201.

[134] H. M. Wen, G. Chang, B. Li, R. B. Lin, T. L. Hu, W. Zhou and B. Chen, Cryst. Growth Des., 2017, 17, 2172-2177, doi: 10.1021/acs.cgd.7b00111.

[135] L. Li, H. M. Wen, C. He, R. B. Lin, R. Krishna, H. Wu, W. Zhou, J. Li, B. Li and B. Chen, Angew. Chem. Int. Edit., 2018, 57, 1518315188, doi: 10.1002/anie.201809869.

[136] Y. Sun, Y. Li and J. C. Tan, ACS Appl. Mater. Inter., 2018, 10, 41831-41838, doi: 10.1021/acsami.8b16527.

[137] M. Gomar and S. Yeganegi, Micropor. Mesopor. Mat., 2017, 252, 167-172, doi: 10.1016/j.micromeso.2017.06.010.

[138] K. Liang, R. Ricco, C. Doherty, M. Styles, S. Bell, N. Kirby, S. Mudie, D. Haylock, A. Hill, C. Doonan and P. Falcaro, Nat. Commun., 2015, 6, 7240, doi: 10.1038/ncomms8240.

[139] K. Park, Z. Ni, A. Cote, J. Choi, R. Huang, F. Uribe-Romo, H. Chae, M. O'Keeffe and O. Yaghi, P. Natl. Acad. Sci. USA, 2006, 103, 10186-10191, doi: 10.1073/pnas.0602439103.

[140] J. Groves, P. Wright and P. Lightfoot, Inorg. Chem., 2005, 44, 1736-1739, doi: 10.1021/ic048456v.

[141] M. Plabst and T. Bein, Inorg. Chem., 2009, 48, 4331-4341, doi: 10.1021/ic802294e.

[142] E. Ueda, Y. Yoshikawa, N. Kishimoto, M. Tadokoro, H. Sakurai, N. Kajiwara and Y. Kojima, B. Chem. Soc. Jpn., 2004, 77, 981-986, doi: 10.1246/bcsj.77.981.

[143] J. Rabone, Y. Yue, S. Chong, K. Stylianou, J. Bacsa, D. Bradshaw, G. Darling, N. Berry, Y. Khimyak, A. Ganin, P. Wiper, J. Claridge and M. Rosseinsky, Science, 2010, 329, 1053-1057, doi: 10.1126/science. 1190672 .

[144] D. Akporiaye, I. Dahl, A. Karlsson and R. Wendelbo, Angew. Chem. Int. Edit., 1998, 37, 609-611, doi: 10.1002/(SICI)15213773(19980316)37:5<609::AID-ANIE609>3.0.CO;2-X.

[145] H. Daglar and S. Keskin, Adv. Theo. Simulations, 2019, 2, 1900109 , doi: 10.1002/adts.201900109.

[146] S. Wu, Z. Xin, S. Zhao and S. Sun, Nano Res., 2019, 12, 27362742, doi: 10.1007/s12274-019-2507-4.

[147] A. N. V. Azar, S. Velioglu and S. Keskin, ACS Sustain. Chem. Eng., 2019, 7, 9525-9536, doi: 10.1021/acssuschemeng.9b01020.

[148] W. Li, X. Xia, M. Cao and S. Li, J. Mater. Chem. A, 2019, 7, 74707479, doi: 10.1039/C8TA07909A.

[149] S. Bauer, C. Serre, T. Devic, P. Horcajada, J. Marrot, G. Férey and N. Stock, Inorg. Chem., 2008, 47, 7568-7576, doi: 10.1021/ic800538r.

[150] A. Tarzia, M. Takahashi, P. Falcaro, A. W. Thornton, C. J. Doonan and D. M. Huang, ACS Appl. Mater. Inter., 2018, 10, 40938-40950, doi: 10.1021 /acsami.8b14756. 
[151] A. Rabenau, Angew. Chem. Int. Edit., 1985, 24, 1026-1040, doi: 10.1002/anie. 198510261.

[152] M. J. Platers, R. A. Howie and A. J. Roberts, Chem. Commun., 1997, (9), 893-894, doi: 10.1039/A700675F.

[153] D. M. Young, U. Geiser, A. J. Schultz and H. H. Wang, J. Am. Chem. Soc., 1998, 120, 1331-1332, doi: 10.1021/ja973483o.

[154] P. M. Forster, P. M. Thomas and A. K. Cheetham, Chem. Mater., 2002, 14, 17-20, doi: 10.1021/cm010820q.

[155] U. Mueller, M. Schubert, F. Teich, H. Puetter, K. Schierle-Arndt and J. Pastré, J. Mater. Chem., 2006, 16, 626-636, doi: 10.1039/b511962f.

[156] J. H. Bang and K. S. Suslick, Adv. Mater., 2010, 22, 1039-1059, doi: 10.1002/adma.200904093.

[157] H. Embrechts, M. Kriesten, K. Hoffmann, W. Peukert, M. Hartmann and M. Distaso, J. Phys. Chem. C, 2018, 122, $12267-$ 12278, doi: 10.1021/acs.jpcc.8b02484.

[158] B. Tan, Y. Luo, X. Liang, S. Wang, X. Gao, Z. Zhang and Y. Fang, Ind. Eng. Chem. Res., 2019, 58, 2983-2990, doi: 10.1021/acs.iecr.8b05243.

[159] T. W. Murinzi, E. Hosten and G. M. Watkins, Polyhedron, 2017, 137, 188-196, doi: 10.1016/j.poly.2017.08.030.

[160] T. Cao, C. Shi, N. Zhao, C. He, J. Li and E. Liu, J. Phys. Chem. C, 2015, 119, 28749-28756, doi: 10.1021/acs.jpcc.5b09948.

[161] S. Jabarian, A. Ghaffarinejad and H. Kazemi, Ana. Bioanaly. Electrochem., 2018, 10, 1611-1619.

[162] S. Jabarian and A. Ghaffarinejad, J. Inorg. Organomet. P., 2019, 29, 1565-1574, doi: 10.1007/s10904-019-01120-4.

[163] T. Vo, V. Le, K. Yoo, M. Song, D. Kim and J. Kim, Cryst. Growth Des., 2019, 19, 4949-4956, doi: 10.1021/acs.cgd.9b00170.

[164] C. Chen, X. Feng, Q. Zhu, R. Dong, R. Yang, Y. Cheng and C. He, Inorg. Chem., 2019, 58, 2717-2728, doi: 10.1021/acs.inorgchem.8b03271.

[165] F. Hillman, J. M. Zimmerman, S. M. Paek, M. R. A. Hamid, W. T. Lim and H. K. Jeong, J. Mater. Chem. A, 2017, 5, 6090-6099, doi: 10.1039/c6ta11170j.

[166] P. Zhang, Y. Xiao, H. Sun, X. Dai, X. Zhang, H. Su, Y. Qin, D. Gao, A. Jin, H. Wang, X. Wang and S. Sun, Cryst. Growth Des., 2018, 18, 3841-3850, doi: 10.1021/acs.cgd.8b00045.

[167] M. R. Armstrong, S. Senthilnathan, C. J. Balzer, B. Shan, L. Chen and B. Mu, Ultrason. Sonochem., 2017, 34, 365-370, doi: 10.1016/j.ultsonch.2016.06.011.

[168] S. Tunsrichon, J. Boonmak and S. Youngme, Cryst. Growth Des., 2019, 19, 2139-2148, doi: 10.1021/acs.cgd.8b01724.

[169] V. V. Boldyrev and K. Tkacova, J. Mater. Synth. Proces., 2000, 8, 121-132, doi: 10.1023/A:1011347706721.

[170] A. Pichon, A. Lazuen-Garay and S. L. James, CrystEngComm, 2006, 8, 211-214, doi: 10.1039/b513750k.

[171] A. D. Katsenis, A. Puskaric, V. S. Strukil, C. Mottillo, P. A. Julien, K. Uzarevic, M. H. Pham, T. O. Do, S. A. J. Kimber, P. Lazic, O. Magdysyuk, R. E. Dinnebier, I. Halasz and T. Friscic, Nat. Commun., 2015, 6, 6662, doi: 10.1038/ncomms7662.

[172] Y. H. Huang, W. S. Lo, Y. W. Kuo, W. J. Chen, C. H. Lin and F. K. Shieh, Chem. Commun., 2017, 53, 5818-5821, doi: $10.1039 / \mathrm{c} 7 \mathrm{cc} 03105 \mathrm{j}$.
[173] T. H. Wei, S. H. Wu, Y. D. Huang, W. S. Lo, B. P. Williams, S. Y. Chen, H. C. Yang, Y. S. Hsu, Z. Y. Lin, X. H. Chen, P. E. Kuo, L. Y. Chou, C. K. Tsung and F. K. Shieh, Nat. Commun., 2019, 10, 5002, doi: 10.1038/s41467-019-12966-0.

[174] X. Li, C. Li, C. Wu and K. Wu, Anal. Chem., 2019, 91, 6043-6050, doi: 10.1021/acs.analchem.9b00556.

[175] Y. Luo, D. Chen, F. Wei and Z. Liang, ChemistrySelect, 2018, 3, 11435-11440, doi: 10.1002/slct.201802067.

[176] S. Mahdian, M. R. Naimi-Jamal and L. Panahi, ChemistrySelect, 2018, 3, 11223-11229, doi: 10.1002/slct.201801585.

[177] W. Yuan, T. Friscic, D. Apperley and S. L. James, Angew. Chem. Int. Edit., 2010, 49, 3916-3919, doi: 10.1002/anie.200906965.

[178] T. Friscic, D. G. Reid, I. Halasz, R. S. Stein, R. E. Dinnebier and M. J. Duer, Angew. Chem. Int. Edit., 2010, 49, 712-715, doi: 10.1002/anie.200906583.

[179] W. Yuan, J. O'Connorb and S. L. James, ChemistrySelect, 2010, 12, 3515-3517, doi: 10.1039/c0ce00216j.

[180] C. Dong, J. Bai, X. L. Lv, W. Wu, J. Lv and J. R. Li, Inorg. Chem., 2019, 58, 15909-15916, doi: 10.1021/acs.inorgchem.9b02397.

[181] A. J. Howarth, Y. Liu, P. Li, Z. Li, T. C. Wang, J. Hupp and O. K. Farha, Nat. Rev. Mater., 2016, 1, 15018, doi: 10.1038/natrevmats.2015.18.

[182] D. Song, J. Bae, H. Ji, M. B. Kim, Y. S. Bae, K. S. Park, D. Moon and N. C. Jeong, J. Am. Chem. Soc., 2019, 141, 7853-7864, doi: 10.1021/jacs.9b02114.

[183] P. Li, S. Y. Moon, M. A. Guelta, S. P. Harvey, J. T. Hupp and O. K. Farha, J. Am. Chem. Soc., 2016, 138, 8052-8055, doi: 10.1021/jacs.6b03673.

[184] X. Qian, Q. Ren, X. Wu, J. Sun, H. Wu and J. Lei, ChemistrySelect, 2018, 3, 657-661, doi: 10.1002/slct.201702114.

[185] S. M. Moosavi, P. G. Boyd, L. Sarkisov and B. Smit, ACS Central Sci., 2019, 4, 832-839, doi: 10.1021/acscentsci.8b00157.

[186] Y. Fu, D. Sun, Y. Chen, R. Huang, Z. Ding, X. Fu and Z. Li, Angew. Chem. Int. Edit., 2012, 51, 3364-3367, doi: 10.1002/anie.201108357.

[187] W. Li, A. Thirumurugan, P. T. Barton, Z. Lin, S. Henke, H. H. M. Yeung, M. T. Wharmby, E. G. Bithell, C. J. Howard and A. K. Cheetham, J. Am. Chem. Soc., 2014, 136, 7801-7804.

[188] M. Feng, P. Zhang, H. C. Zhou and V. K. Sharma, Chemosphere, 2018, 209, 783-800, doi: 10.1016/j.chemosphere.2018.06.114.

[189] Ü. Kökçam-Demir, A. Goldman, L. Esrafili, M. Gharib, A. Morsali, O. Weingart and C. Janiak, Chem. Soc. Rev., 2020, 49, 2751-2798, doi: $10.1039 / \mathrm{c} 9 \mathrm{cs} 00609 \mathrm{e}$

[190] A. Sudik, A. Cote and O. Yaghi, Inorg. Chem., 2005, 44, 29983000, doi: $10.1021 / \mathrm{ic} 050064 \mathrm{~g}$.

[191] E. Haque, J. W. Jun and S. H. Jhung, J. Hazard. Mater., 2011, 185(1), 507-511, doi: 10.1016/j.jhazmat.2010.09.035.

[192] X. Zhao, S. Liu, Z. Tang, H. Niu, Y. Cai, W. Meng, F. Wu and J. P. Giesy, Sci. Rep-UK, 2015, 5, 11849, doi: 10.1038/srep11849.

[193] X. D. Du, C. C. Wang, J. G. Liu, X. D. Zhao, J. Zhong, Y. X. Li, J. Li and P. Wang, J. Colloid Interf. Sci., 2017, 506, 437-441, doi: 10.1016/j.jcis.2017.07.073.

[194] Q. Yang, S. Ren, Q. Zhao, R. Lu, C. Hang, Z. Chen and H. Zheng, Chem. Eng. J., 2018, 333, 49-57, doi: 10.1016/j.cej.2017.09.099. 
[195] N. Tran, D. Kim, K. Yoo and J. Kim, B. Kor. Chem. Soc., 2019, 40, 112-117, doi: 10.1002/bkcs.11650.

[196] J. Tang, R. R. Salunkhe, J. Liu, N. L. Torad, M. Imura, S. Furukawa and Y. Yamauchi, J. Am. Chem. Soc., 2015, 137, 1572-1580, doi: 10.1021/ja511539a.

[197] J. Qian, F. Sun and L. Qin, Mater. Lett., 2012, 82, 220-223, doi: 10.1016/j.matlet.2012.05.077.

[198] S. Lehrer, Biochemistry, 1971, 10, 3254-3263, doi: 10.1021/bi00793a015.

[199] M. R. Azhar, H. R. Abid, H. Sun, V. Periasamy, M. O. Tade and S. Wang, J. Colloid Interf. Sci., 2016, 478, 344-352, doi: 10.1016/j.jcis.2016.06.032.

[200] P. W. Seo, N. A. Khan and S. H. Jhung, Chem. Eng. J., 2017, 315, 92-100, doi: 10.1016/j.cej.2017.01.021.

[201] H. Liu, L. Chen and J. Ding, Microchim. Acta, 2017, 184, 40914098, doi: 10.1007/s00604-017-2442-6.

[202] L. He, Y. Dong, Y. Zheng, Q. Jia, S. Shan and Y. Zhang, J. Hazard. Mater., 2019, 361, 85-94, doi: 10.1016/j.jhazmat.2018.08.079.

[203] X. Wang, L. Zhang, Z. Zhao and Y. Cai, Sci. Total Environ., 2018, 634, 158-169, doi: 10.1016/j.scitotenv.2018.03.340.

[204] Y. Y. Deng, X. F. Xiao, D. Wang, B. Han, Y. Gao and J. L. Xue, J. Nanosci. Nanotechno., 2020, 20, 1660-1669, doi: 10.1166/jnn.2020.17157.

[205] M. Mon, R. Bruno, E. Tiburcio, M. Viciano-Chumillas, L. H. G. Kalinke, J. Ferrando-Soria, D. Armentano and E. Pardo, J. Am. Chem. Soc., 2019, 141, 13601-13609, doi: 10.1021/jacs.9b06250.

[206] A. Hakimifar and A. Morsali, Inorg. Chem., 2019, 58, 180-187, doi: 10.1021/acs.inorgchem.8b02133.

[207] S. W. Lv, J. M. Liu, C. Y. Li, N. Zhao, Z. H. Wang and S. Wang, Chem. Eng. J., 2019, 375, 122111, doi: 10.1016/j.cej.2019. 122111.

[208] K. Zhu, C. Chen, H. Xu, Y. Gao, X. Tan, A. Alsaedi and T. Hayat, ACS Sustain. Chem. Eng., 2017, 5, 6795-6802, doi: 10.1021/acssuschemeng.7b01036.

[209] P. Wu, Q. Du, Y. Sun, Z. Li and H. He, Anal. Methods, 2019, 11, 4501-4510, doi: 10.1039/c9ay01448a.

[210] Z. Hu, W. P. Lustig, J. Zhang, C. Zheng, H. Wang, S. J. Teat, Q. Gong, N. D. Rudd and J. Li, J. Am. Chem. Soc., 2015, 137, 1620916215, doi: 10.1021/jacs.5b10308.

[211]B. He and D. Yan, Food Control, 2019, 103, 70-77, doi: 10.1016/j.foodcont.2019.04.001.

[212] C. X. Yao, N. Zhao, J. C. Liu, L. J. Chen, J. M. Liu, G. Z. Fang and S. Wang, Polymers, 2020, 12, 691, doi: 10.3390/polym12030691.

[213] P. L. Wang, L. H. Xie, E. A. Joseph, J. R. Li, X. O. Su and H. C. Zhou, Chem. Rev., 2019, 119, 10638-10690, doi: 10.1021/acs.chemrev.9b00257.

[214] Y. P. Li, Y. Wang, Y. Y. Xue, H. P. Li, Q. G. Zhai, S. N. Li, Y. C. Jiang, M. C. Hu and X. Bu, Angew. Chem. Int. Edit., 2019, 58, 13590-13595, doi: 10.1002/anie.201908378.

[215] N. Balahmar and R. Mokaya, J. Mater. Chem. A, 2019, 7, 1746617479, doi: 10.1039/c9ta06308k.

[216] W. Xia, J. Tang, J. Li, S. Zhang, K. C. W. Wu, J. He and Y. Yamauchi, Angew. Chem. Int. Edit., 2019, 58, 13354-13359, doi: 10.1002/anie.201906870.
[217] J. Zhang, D. Cheng, B. Wang, I. Khan and Y. Ni, J. Agr. Food Chem., 2017, 65, 7308-7319, doi: 10.1021/acs.jafc.7b02616.

[218] B. Zhang, Y. Luo, K. Kanyuck, G. Bauchan, J. Mowery and P. Zavalij, J. Agr. Food Chem., 2016, 64, 5164-5170, doi: 10.1021/acs.jafc.6b02072.

[219] S. Chopra, S. Dhumal, P. Abeli, R. Beaudry and E. Almenar, Postharvest Biol. Tec., 2017, 130, 48-55, doi: 10.1016/j.postharvbio.2017.04.001.

[220] K. Shibasaki, A. Fujii, N. Mikami and S. Tsuzuki, J. Phys. Chem. A, 2007, 111, 753-758, doi: 10.1021/jp065076h.

[221] Y. Huang, Y. Zhang, X. Chen, D. Wu, Z. Yi and R. Cao, Chem. Commun., 2014, 50, 10115-10117, doi: 10.1039/c4cc04479g.

[222] J. W. Park, J. Y. Kim, M. J. Kim and J. Lee, J. Am. Oil Chem. Soc., 2014, 91, 439-444, doi: 10.1007/s11746-013-2385-y.

[223] X. Wen and J. S. Dickson, J. Food Protect., 2013, 76, 595-600, doi: 10.4315/0362-028X.JFP-12-287.

[224] Q. M. Wang, D. Shen, M. Bülow, M. L. Lau, S. Deng, F. R. Fitch, N. O. Lemcoff and J. Semanscin, Micropor. Mesopor. Mat., 2002, 55, 217-230, doi: 10.1016/S1387-1811(02)00405-5.

[225] M. Schlesinger, S. Schulze, M. Hietschold and M. Mehring, Micropor. Mesopor. Mat., 2010, 132, 121-127, doi: 10.1016/j.micromeso.2010.02.008.

[226] N. Al-Janabi, P. Hill, L. Torrente-Murciano, A. Garforth, P. Gorgojo, F. Siperstein and X. Fan, Chem. Eng. J., 2015, 281, 669677, doi: 10.1016/j.cej.2015.07.020.

[227] P. Bareschino, G. Diglio, F. Pepe, G. Angrisani, C. Roselli and M. Sasso, Appl. Therm. Eng., 2017, 124, 641-651, doi: 10.1016/j.applthermaleng.2017.06.024.

[228] W. Zhang, D. Banerjee, J. Liu, H. T. Schaef, J. V. Crum, C. A. Fernandez, R. K. Kukkadapu, Z. Nie, S. K. Nune, R. K. Motkuri, K. W. Chapman, M. H. Engelhard, J. C. Hayes, K. L. Silvers, R. Krishna, B. P. McGrail, J. Liu and P. K. Thallapally, Adv. Mater., 2016, 28, 3572-3577, doi: 10.1002/adma.201600259.

[229] H. J. D. Dorman and S. G. Deans, J. Appl. Microbiol., 2000, 88, 308-316, doi: 10.1046/j.1365-2672.2000.00969.x.

[230] S. Burt, Int. J. Food Microbiol., 2004, 94, 223-253, doi: 10.1016/j.ijfoodmicro.2004.03.022.

[231] L. Sánchez-González, M. Vargas, C. González-Martínez, A. Chiralt and M. Cháfer, Food Eng. Rev., 2011, 3, 1-16, doi: 10.1007/s12393-010-9031-3.

[232] H. M. C. Marques, Flavour Frag. J., 2010, 25, 313-326, doi: 10.1002/ffj.2019.

[233] R. Ribeiro-Santos, M. Andrade and A. Sanches-Silva, Curr. Opin. Food Sci., 2017, 14, 78-84, doi: 10.1016/j.cofs.2017.01.012.

[234] Y. Wu, Y. Luo, B. Zhou, L. Mei, Q. Wang and B. Zhang, Food Control, 2019, 98, 174-178, doi: 10.1016/j.foodcont.2018.11.011.

[235] Z. Moussa, M. Hmadeh, M. G. Abiad, O. H. Dib and D. Patra, Food Chem., 2016, 212, 485-494, doi: 10.1016/ j.foodchem.2016.06.013.

[236] M. Torres-Gonzalez, C. Cifelli, S. Agarwal and I. Victor Fulgoni, Current Developments Nutrition, 2019, 3, 1590, doi: 10.1093/ cdn/nzz039.P18-045-19.

[237] G. Zhang, F. Meng, Z. Guo, T. Guo, H. Peng, J. Xiao, B. Liu, V. Singh, S. Gui, P. York, W. Qian, L. Wu and J. Zhang, J. 
Microencapsul., 2018, 35, 249-258, doi: 10.1080/ 02652048.2018 .1462417$.

[238] S. L. Anderson and K. C. Stylianou, Coordin. Chem. Rev., 2017, 349, 102-128, doi: 10.1016/j.ccr.2017.07.012.

[239] G. Crini, Chem. Rev., 2014, 114, 10940-10975, doi: 10.1021/cr500081p.

[240] A. Bagheri, M. Taghizadeh, M. Behbahani, A. A. Asgharinezhad, M. Salarian, A. Dehghani, H. Ebrahimzadeh and M. M. Amini, Talanta, 2012, 99, 132-139, doi: 10.1016/j.talanta.2012.05.030.

[241] M. R. Sohrabi, Z. Matbouie, A. A. Asgharinezhad and A. Dehghani, Microchim. Acta, 2013, 180, 589-597, doi: 10.1007/ s00604-0130952-4.

[242] E. Ghorbani-Kalhor, Microchim. Acta, 2016, 183, 2639-2647, doi: 10.1007/s00604-016-1896-2.

[243] M. Babazadeh, R. Hosseinzadeh-Khanmiri, J. Abolhasani, E. Ghorbani-Kalhor and A. Hassanpour, RSC Adv., 2015, 5, 1988419892, doi: 10.1039/c4ra15532g.

[244] F. Ke, J. Jiang, Y. Li, J. Liang, X. Wan and S. Ko, Appl. Surf. Sci., 2017, 413, 266-274, doi: 10.1016/j.apsusc.2017.03.303.

[245] E. Ghorbani-Kalhor, R. Hosseinzadeh-Khanmiri, M. Babazadeh, J. Abolhasani and A. Hassanpour, Can. J. Chem., 2015, 93, 518-525, doi: 10.1139/cjc-2014-0474.

[246] A. Hassanpour, R. Hosseinzadeh-Khanmiri, M. Babazadeh, J. Abolhasani and E. Ghorbani-Kalhor, Food Addit. Contam. A, 2015, 32, 725-736, doi: 10.1080/19440049.2015.1007397.

[247] L. Fan, M. Deng, C. Lin, C. Xu, Y. Liu, Z. Shi, Y. Wang, Z. Xu, L. $\mathrm{Li}$ and M. He, RSC Adv., 2018, 8, 10561-10572, doi: $10.1039 / \mathrm{c} 8 \mathrm{ra00070k}$.

[248] M. Babazadeh, R. H. Khanmiri, J. Abolhasani, E. Ghorbani-Kalhor and A. Hassanpour, B. Chem. Soc. Jpn., 2015, 88, 871-879, doi: 10.1246/bcsj.20140380.

[249] R. M. Abdelhameed, R. A. Ismail, M. El-Naggar, E. S. Zarie, R. Abdelaziz, M. T. E. Sayed, Micropor. Mesopor. Mat., 2019, 279, 26-36, doi: 10.1016/j.micromeso.2018.12.018.

[250] M. Esmaeilzadeh, Microchem. J., 2019, 145, 367-372, doi: 10.1016/j.microc.2018.10.058.

[251] H. X. Jin, H. P. Xu, N. Wang, L. Y. Yang, Y. G. Wang, D. Yu and X. K. Ouyang, Materials, 2019, 12, 942, doi: 10.3390/ma12060942.

[252] N. Wang, X. K. Ouyang, L. Y. Yang and A. M. Omer, ACS Sustain. Chem. Eng., 2017, 5, 10447-10458, doi: 10.1021/acssuschemeng. $7 \mathrm{~b} 02472$.

[253] E. Yavuz, S. Tokalioglu and S. Patat, Food Chem., 2018, 263, 232239, doi: 10.1016/j.foodchem.2018.04.134.

[254] L. Huang, M. He, B. Chen and B. Hu, Chemosphere, 2018, 199, 435-444, doi: 10.1016/j.chemosphere.2018.02.019.

[255] K. Wang, X. Tao, J. Xu and N. Yin, Chem. Lett., 2016, 45, 13651368, doi: 10.1246/cl.160718.

[256] J. Shen, N. Wang, Y. G. Wang, D. Yu and X. K. Ouyang, Polymers, 2018, 10, 1383, doi: 10.3390/polym10121383.

[257] N. M. Mahmoodi, M. Taghizadeh, A. Taghizadeh, J. Abdi, B. Hayati and A. A. Shekarchi, Appl. Surf. Sci., 2019, 480, 288-299, doi: 10.1016/j.apsusc.2019.02.211.
[258] R. Pei, L. Fan, F. Zhao, J. Xiao, Y. Yang, A. Lai, S. F. Zhou and G. Zhan, J. Hazard. Mater., 2020, 384, 121418, doi: 10.1016/j.jhazmat.2019.121418.

[259] J. M. Yang, B. C. Yang, Y. Zhang, R. N. Yang, S. S. Ji, Q. Wang, S. Quan and R. Z. Zhang, Micropor. Mesopor. Mat., 2020, 292, 109764, doi: 10.1016/j.micromeso.2019.109764.

[260] J. M. Yang, R. J. Ying, C. X. Han, Q. T. Hu, H. M. Xu, J. H. Li, Q. Wang and W. Zhang, Dalton T., 2018, 47, 3913-3920, doi: $10.1039 / \mathrm{c} 8 \mathrm{dt} 00217 \mathrm{~g}$.

[261] Y. Han, M. Liu, K. Li, Q. Sun, W. Zhang, C. Song, G. Zhang, Z. C. Zhang and X. Guo, Inorg. Chem. Front., 2017, 4, 1870-1880, doi: 10.1039/c7qi00437k.

[262] R. Azhdari, S. M. Mousavi, S. A. Hashemi, S. Bahrani and S. Ramakrishna, J. Environ. Chem. Eng., 2019, 7, 103437, doi: 10.1016/j.jece.2019.103437.

[263] F. H. Jawdat, J. Lin, S. X. Dou, M. S. Park, A. Nattestad and J. H. Kim, B. Chem. Soc. Jpn., 2019, 92(12), 2012-2018, doi: 10.1246/bcsj.20190238.

[264] S. Y. Zhu and B. Yan, New J. Chem., 2018, 42, 4394-4401, doi: 10.1039/c7nj04786j.

[265] Y. Song, J. Y. Seo, H. Kim and K. Y. Beak, Carbohyd. Polym., 2019, 222, 115018, doi: 10.1016/j.carbpol.2019.115018.

[266] M. Salgaonkar, S. S. Nadar and V. K. Rathod, J. Environ. Chem. Eng., 2019, 7, 102969, doi: 10.1016/j.jece.2019.102969.

[267] E. Gkaniatsou, C. Sicard, R. Ricoux, L. Benahmed, F. Bourdreux, Q. Zhang, C. Serre, J. P. Mahy and N. Steunou, Angew. Chem. Int. Edit., 2018, 57(49), 16141-16146, doi: 10.1002/anie. 201811327.

[268] J. Ye, L. Jin, X. Zhao, X. Qian and M. Dong, J. Colloid Interf. Sci., 2019, 536, 483-492, doi: 10.1016/j.jcis.2018.10.073.

[269] K. Zhang, D. Sun, C. Ma, G. Wang, X. Dong and X. Zhang, Chemosphere, 2020, 241, 125021, doi: 10.1016/j.chemosphere. 2019.125021.

[270] H. Sun, H. Zhang, H. Mao, B. Yu, J. Han and G. Bhat, Environ. Chem. Lett., 2019, 17, 1091-1096, doi: 10.1007/s10311-01800833-1.

[271] X. Sun, D. Hu, L. Y. Yang, N. Wang, Y. G. Wang and X. K. Ouyang, J. Sol-Gel Sci. Techn., 2019, 91, 353-363, doi: 10.1007/ s10971019-05001-7.

[272] F. Du, L. Sun, W. Tan, Z. Wei, H. Nie, Z. Huang, G. Ruan and J. Li, Anal. Bioanal. Chem., 2019, 411, 2239-2248, doi: 10.1007/ s00216-019-01660-1. 


\section{Author information}

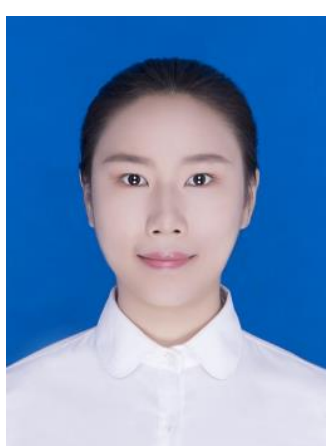

\section{Wenqian Nong}

Wenqian Nong started her PhD study under the supervision of Professor Jun $W u$ in the Department of Chemistry at Zhejiang University in 2018. She received her BSc. degree (2015) in College of Light Industry and Food Engineering, and MSc (2018) degree in College of Chemistry and Chemical Engineering, Guangxi University, China. Her research focuses on the design and synthesis of multifunctional antimicrobial essential oil delivery systems for public health protection.

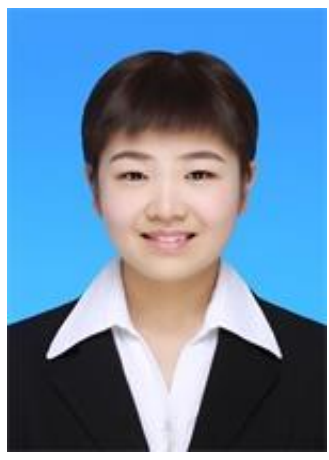

\section{Xiaoyue Liu}

Xiaoyue Liu is a master student since 2018 under the supervision of A.P. Yongguang Guan in Department of Food Science and Engineering, Shanghai Jiao Tong University. She received her BSc degree in College of Food Science \& Technology, Huazhong Agricultural University, China in 2018. Her current research focuses on investigating the enzymatic synthesis by employing biomimetic mineralized lipase in metal-organic frameworks.

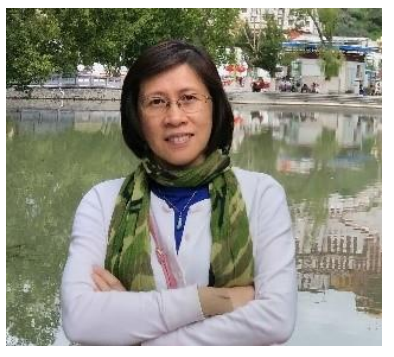

\section{Qin Wang}

Dr. Qin Wang is an Associate Professor in the Department of Nutrition and Food Science at the University of Maryland (UMD). Dr. Wang joined the UMD in year 2008 after she has done a 3-year post-doctoral study at the University of Illinois at Urbana-Champaign, where she got her Ph.D. degree in Food Science in 2004. Her key research efforts have been applied in three directions: food nanotechnology, food protein modification, and safety and quality improvement of food products. She has published more than 100 peer-reviewed journal papers.

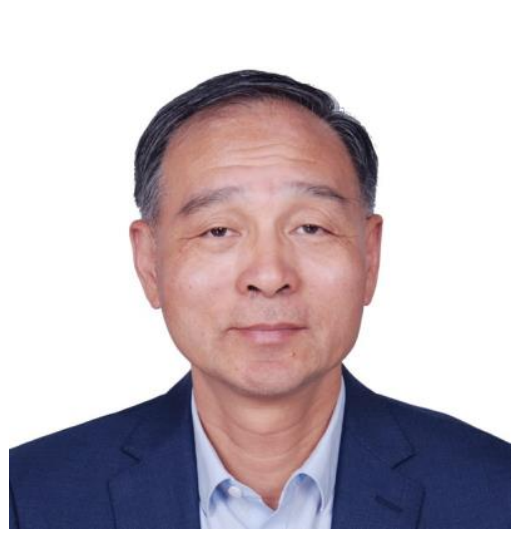

Jun $\boldsymbol{W u}$

Jun Wu obtained his BSc from Hangzhou University (Now: Zhejiang University) in 1985, his MSc degree from Shanghai Institute of Organic Chemistry, Chinese Academy of Sciences in 1988, and his PhD degree from Zhejiang University in 2005. He received one-year training as a visiting research scholar at University of North London (Now: London Metropolitan University), United Kingdom. He worked in Department of Chemistry, Zhejiang University since 2000, and became a professor in 2006. His current research focuses on general organic chemistry, green chemistry and crop protection chemistry.

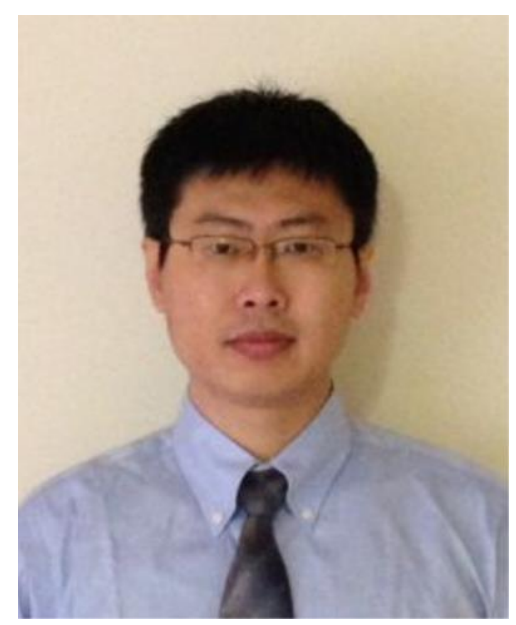

Yongguang Guan

Yongguang Guan obtained his PhD from South China University of Technology in 2012, and received fiveyear postdoctoral training at University of Tennessee Knoxville, University of Maryland College Park, and United States Department of Agriculture. After postdoctoral research, he started his independent academic career as a tenure-track Associate Professor in Department of Food Science and Technology, Shanghai Jiao Tong University in 2018. His current research focuses on development of intelligent porous nanocomposites for the applications on improving food safety and quality.

Publisher's Note: Engineered Science Publisher remains neutral with regard to jurisdictional claims in published maps and institutional affiliations. 